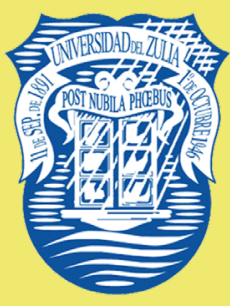

UNIVERSIDAD DEL ZULIA

REVISTA CIENTÍFICA

FACULTAD DE CIENCIAS VETERINARIAS DIVISIÓN DE INVESTIGACIÓN

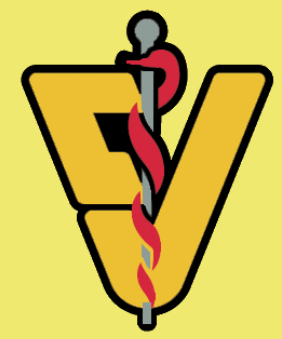

MARACAIBO, ESTADO ZULIA, VENEZUELA

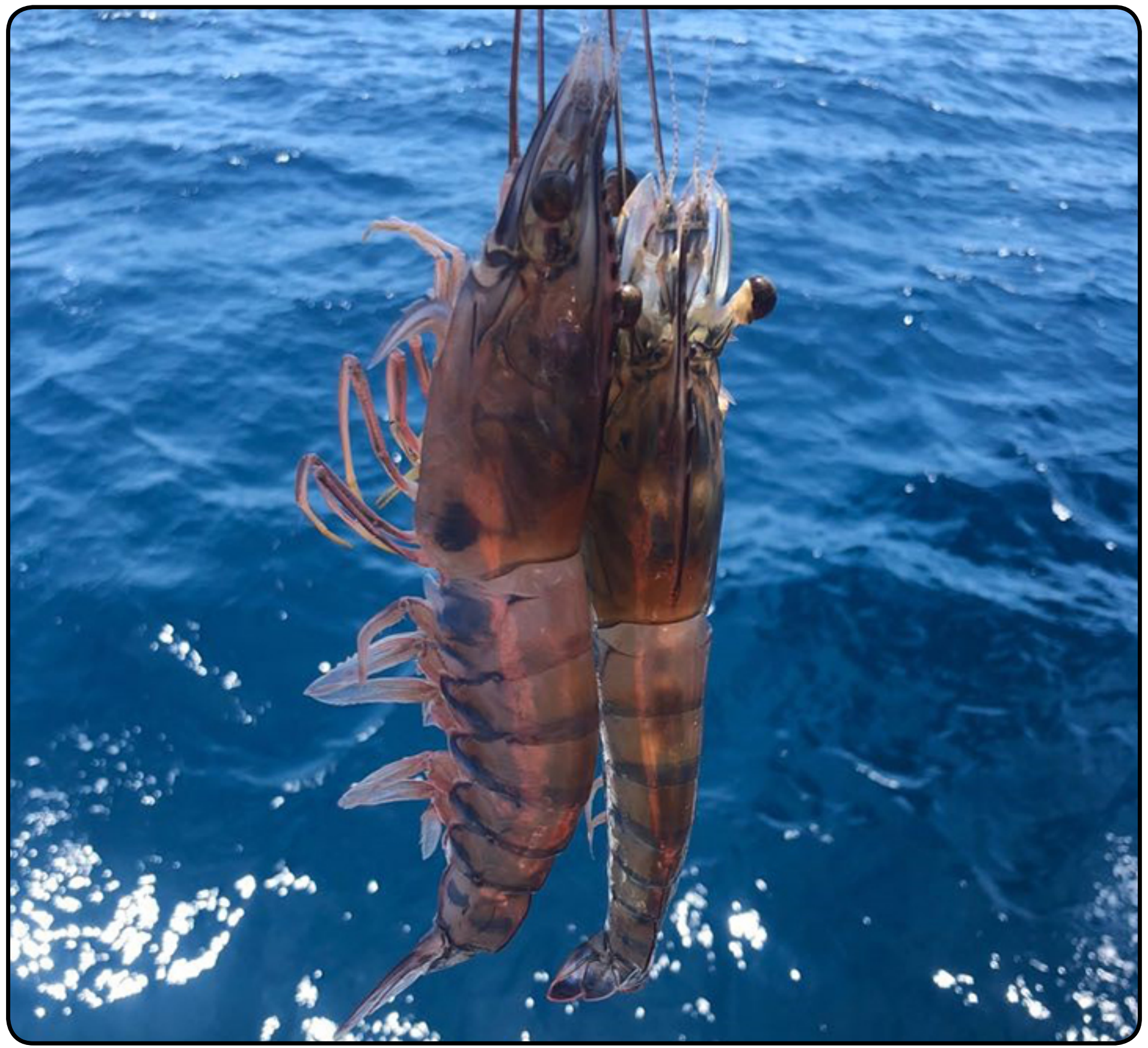

Vol. XXXI (1) 2021 


\section{REVISTA CIENTÍFICA}

\author{
Fundada en 1990 \\ Universidad del Zulia \\ Facultad de Ciencias Veterinarias \\ Maracaibo, Estado Zulia, Venezuela \\ Vol.XXXI (1) 2021 \\ MIEMBROS FUNDADORES \\ José Faría R. $(\dagger)$ \\ Mario Pérez $\mathrm{B}$. \\ Manuel Alvarado M. \\ DIRECTOR FUNDADOR \\ Rafael César Reátegui Cárdenas $(\dagger)$ \\ EDITOR JEFE \\ Mario Pérez Barrientos \\ EDITOR ASOCIADO \\ Edison Pascal-Bello \\ Portada:
}

Biometría y longitud de migración de Penaeus stylirostris (Crustacea: Penaeidae) en tres zonas de captura en la costa de Sinaloa, México

(Págs. 17 - 24)

SECRETARIA EJECUTIVA

Marilyn Del V. Añez Davila

DISEÑO GRÁFICO

Alonso Eleazar Flores Rondón

La edición de esta revista ha sido auspiciada por el Vicerrectorado Académico LUZ, el Sistema de Servicios Bibliotecarios y de Información

(Serbiluz) y Consejo de Desarrollo Científico

y Humanístico de LUZ (CONDES)

SE AGRADECE CANJE

EXCHANGE DESIRED

DIRECCIÓN:

Revista Científica

Universidad del Zulia,

Facultad de Ciencias Veterinarias

Núcleo Agropecuario Ciudad Universitaria

Apdo.15252, Maracaibo 4005-A

Estado Zulia-Venezuela

Telf.-Fax:58-261-4126158

E-mail:revistafcv@gmail.com

http://www.fcv.luz.edu.ve

http://produccioncientificaluz.org/index.php/cientifica

El índice acumulado anual aparecerá en el último número de cada volumen.

Esta revista fue editada en formato digital y publicada en Diciembre de 2020, por

La Facultad de Ciencias Veterinarias de La Universidad del Zulia

Maracaibo - Venezuela.
UNIVERSIDAD DEL ZULIA

\section{EDITORES ASOCIADOS}

Dr. Dionel García Bracho. Universidad del Zulia, Maracaibo, Venezuela

Dr. Willian Mejía Silva. Universidad del Zulia, Maracaibo, Venezuela

Dr. Armando Quintero Moreno. Universidad del Zulia, Maracaibo, Venezuela

Dr. José Atilio Aranguren Méndez. Universidad del Zulia, Maracaibo, Venezuela

Dra. María Elena Peña. Universidad del Zulia, Maracaibo, Venezuela

Dra. Julia Velasco Fuenmayor. Universidad del Zulia, Maracaibo, Venezuela

Dr. Wilfido Briñez Zambrano. Universidad del Zulia, Maracaibo, Venezuela

Dr. José Manuel Rodríguez. Universidad del Zulia, Maracaibo, Venezuela

Dr. Francisco Angulo Cubillán. UTE. Quito. Ecuador

Dra. Libia Guzmán. Universidad del Tolima, Colombia

Dr. Hugo Hernández Fonseca. St. George's University, Granada

Dr. Aureliano Hernández. Universidad Nacional de Colombia, Colombia

Dr. José María Alunda. Universidad Complutense de Madrid, España

Dr. Andrés Ortega Ojeda. UTE. Quito, Ecuador

\section{COMITÉ DE ASESORES}

Pedro M. Aso. Universidad Simón Bolívar, Caracas, Venezuela

Alfredo Coronado. Universidad Centro-Occidental Lisandro Alvarado, Barquisimeto, Venezuela

Roy D. Meléndez. Universidad Centro-Occidental Lisandro Alvarado, Barquisimeto, Venezuela

Héctor Soto Castellanos. Universidad Nacional Experimental Simón Rodríguez, Caracas, Venezuela Antonio Bretaña. Universidad Nacional Experimental Simón Rodríguez, Caracas, Venezuela

Marc Desquesnes. CIRAD-EMVT, Burkina Faso, West Africa

Edmundo Grisard. Universidade Federal de Santa Catarina, Brasil

Alexis Rodríguez Acosta. Universidad Central de Venezuela, Caracas, Venezuela

Elías Sogbe Martinís. Universidad Central de Venezuela, Maracay, Venezuela

Andrés Soyano. Instituto Venezolano de Investigaciones Científicas (IVIC), Los Teques, Venezuela

Rafael Román Bravo. Universidad del Zulia, Maracaibo, Venezuela

Enrique Márquez Salas. Universidad del Zulia, Maracaibo, Venezuela

Nelson Huerta Leidenz. Universidad del Zulia, Maracaibo, Venezuela

Eleazar Soto Belloso. Universidad del Zulia, Maracaibo, Venezuela

José Luis Ramírez. Universidad de Oriente, Maturín, Venezuela

La revista no se hace responsable de los conceptos emitidos por sus autores Prohibida la reproducción total o parcial del contenido de esta Revista (C) REVISTA CIENTÍFICA, 2018

(C) FCV, Universidad del Zulia

Revista impresa ISSN 0798-2259 Depósito Legal: pp $199102 Z U 46$

Revista electrónica ISSN electrónico: 2477-944X Depósito Legal: ppi $201502 Z U 4665$ 


\author{
UNIVERSIDAD \\ DEL ZULIA \\ FACULTAD DE CIENCIAS VETERINARIAS \\ DIVISIÓN DE INVESTIGACIÓN \\ REVISTA CIENTÍFICA \\ REVISTA INTERNACIONAL ARBITRADA DEDICADA A LA DIVULGACIÓN \\ DE INVESTIGACIONES ORIGINALES EN EL ÁREA AGROPECUARIA \\ Vol. XXXI (1) 2021 \\ MARACAIBO, ESTADO ZULIA, VENEZUELA
}

Indizada y registrada en:

Institute for Scientific Information (ISI): Research Alert $B_{\text {y }}$ Focus on: Veterinary Science \& MedicineTM

Science Citation Index (SCIExpanded)

RevicyhLUZ. Revistas Científicas y Humanísticas de LUZ (URL: http://produccioncientificaluz.org/revicyhluz/)

SWETS Blackwell Database

ELSEVIER Extended Science Direct Navigator Database

Ulrich's Periodicals International Directory

Veterinary Bulletin

Index Veterinarius

CAB Abstracts Database - UK

Base de Datos Wildlife \& Ecology Studies Worldwide (EBSCO Publishing Inc.)

Base de Datos de Revistas Venezolanas de Ciencia y Tecnología (REVENCYT)

Registro de Publicaciones Científicas y Tecnológicas Venezolanas del FONACIT - MCT

Asociación de Editores de Revistas Biomédicas Venezolanas (ASEREME)

Asociación Venezolana de Editores de Publicaciones de las Ciencias del Agro (AVEPAGRO)

LATINDEX

Base de Datos "Informe Académico" (Thomson-Gale) USA

Base de Datos LILACS (Literatura Latinoamericana de Ciencias de la Salud)

Base de Datos LIVECS (Literatura Venezolana en Ciencias de la Salud)

Scielo Venezuela (www.scielo.org.ve)

Red de Revistas Científicas de América Latina y el Caribe, España y Portugal (Redalyc): http://redalyc.uaemex.mx/ Sociedad Iberoamericana de Información Científica (SIIC Data Bases), siicsalud. www.siicsalud.com

Citefactor Journals Citefactor.org. Director Indexing of International Research Journals 


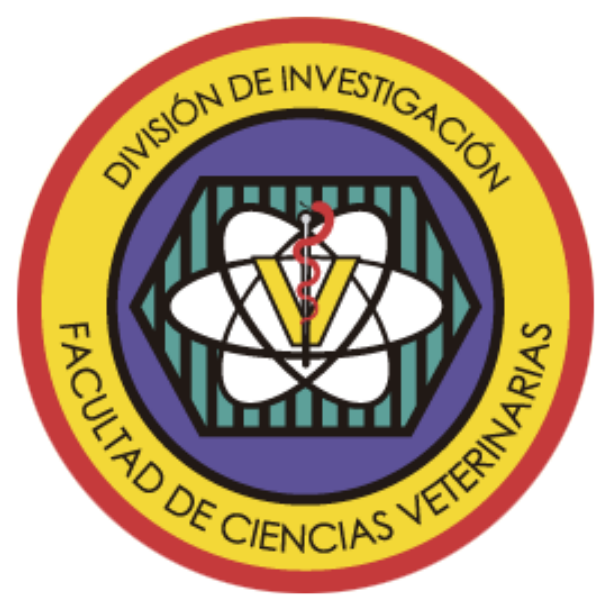

REVISTA CIENTÍFICA, es una revista internacional que representa el órgano científico de la Facultad de Ciencias Veterinarias de la Universidad de Zulia, Maracaibo, Estado Zulia, Venezuela. La misión es publicar la mejor literatura científica tropical y subtropical relacionada a las áreas de las ciencias veterinarias, producción animal, salud pública y tecnología de alimentos de origen animal, así como, literatura científica generada en zonas templadas, pero con aplicabilidad tropical. Todos los trabajos recibidos deben seguir el formato que se presenta en las instrucciones para autores y pasar por un proceso de arbitraje anónimo.

La revista publica cuatro números al año.

Toda correspondencia debe ser enviada a: Editor Jefe REVISTA CIENTÍFICA Facultad de Ciencias Veterinarias Universidad del Zulia. Apartado 15252. Maracaibo 4005-A, Estado Zulia, Venezuela Teléfono-Fax: (58-0261) 4126158. http://produccioncientifica.luz.edu.ve http: //www.fcv.luz.edu.ve
REVISTA CIENTÍFICA, is an international journal representing the scientific organ of the Faculty of Veterinary Sciences at the University of Zulia, Maracaibo, Zulia State, Venezuela. The aim is publishing the best tropical and subtropical scientific literature related to the fields of veterinary clinical sciences, animal production, public health, food sciences and technology of animal products as well as scientific literature generated in temperate zones but with tropical applicability. All the submitted manuscripts must follow the established editorial guidelines and go through an anonymous peer review process.

The journal publishes four issues a year.

All mail must be sent to: Editor in Chief REVISTA CIENTÍFICA Facultad de Ciencias Veterinarias Universidad del Zulia. Apartado 15252. Maracaibo 4005-A, Estado Zulia, Venezuela Teléfono-Fax: (58-0261) 4126158. http://produccioncientifica.luz.edu.ve http: //www.fcv.luz.edu.ve 
ciepuffica Bzolivariana de Esentezuela Dlliversiond del Bufia Consejo Ð̇tniversitario

$$
r \rightarrow \infty
$$

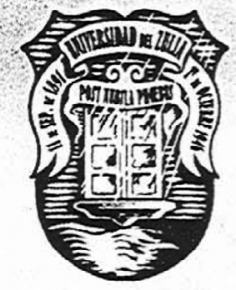

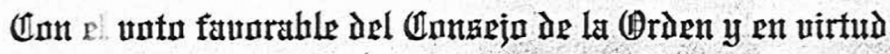

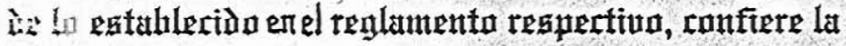

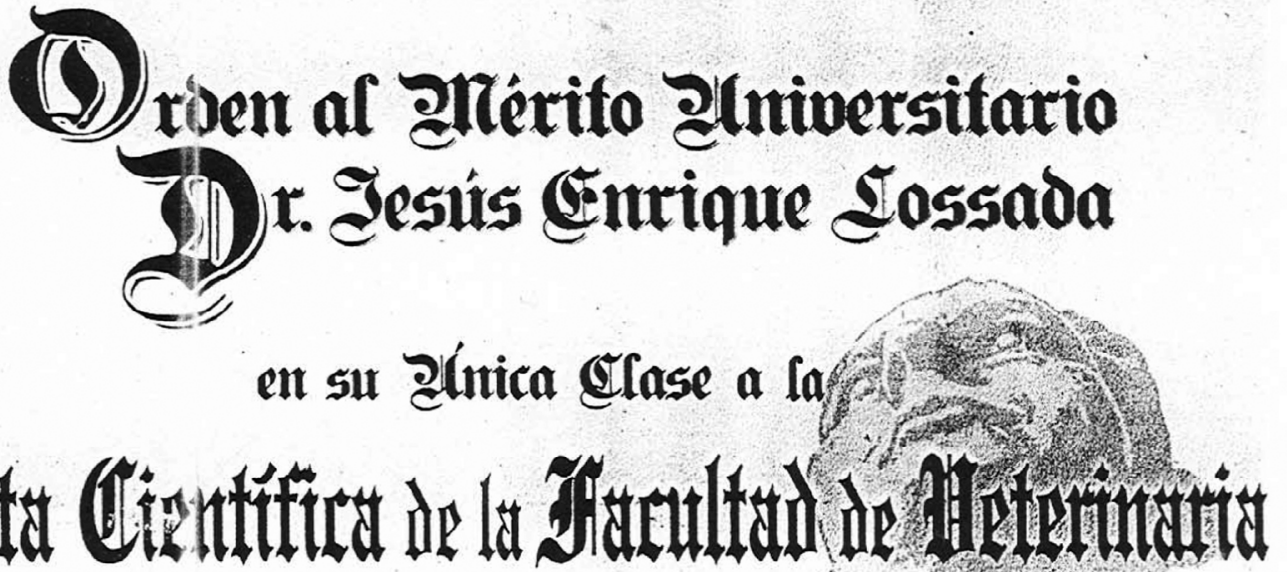

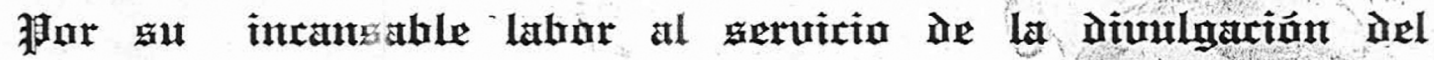

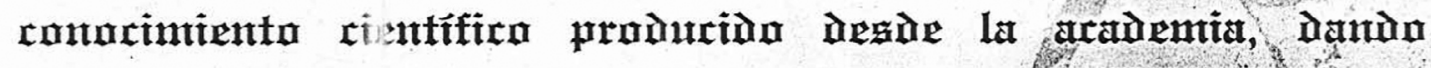

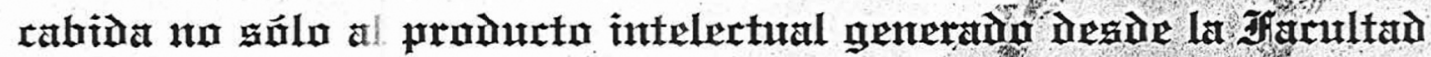

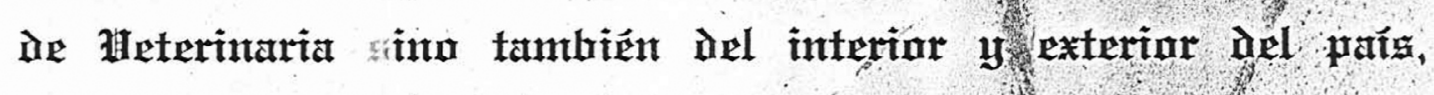

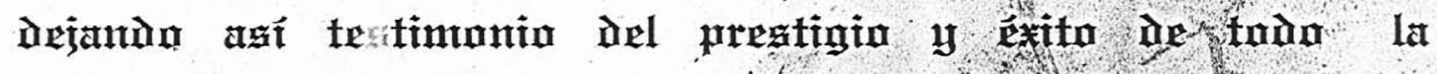

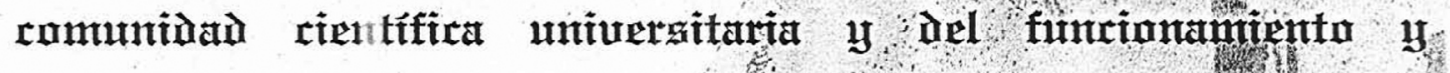

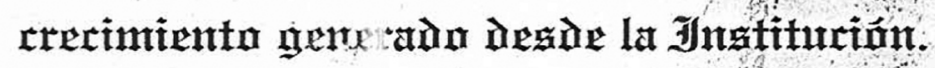

ßrefrentào,

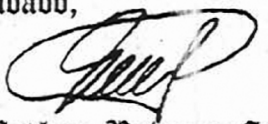

政ra. Atarlene 3 rimera balué Serretari

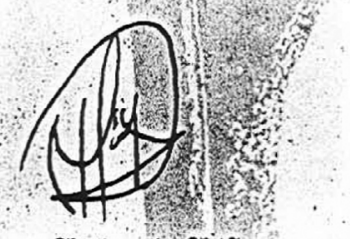

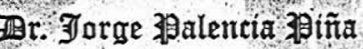

Zhector- 相resididente 


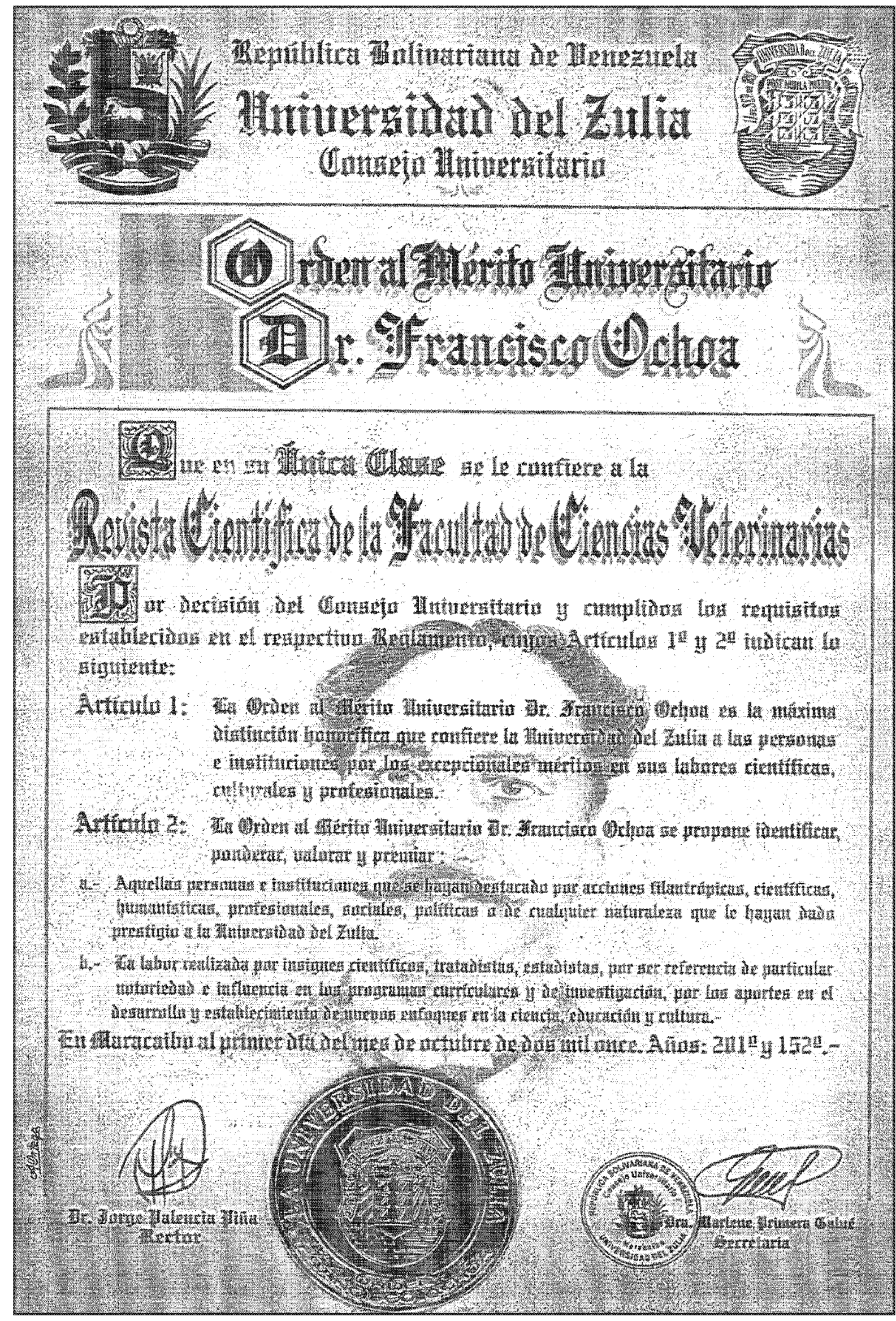




\section{REVISTA CIENTÍFICA}

\section{REVISTA INTERNACIONAL ARBITRADA DEDICADA A LA DIVULGACIÓN \\ DE INVESTIGACIONES ORIGINALES EN EL ÁREA AGROPECUARIA}

Vol. XXXI (1)

EDITORIAL

Salud Pública Veterinaria / Veterinary Public Health

Modelo de distribución espacial de Panstrongylus geniculatus Latreille 1811 (Hemiptera: Reduviidae: Triatominae) vector del agente de la Enfermedad de Chagas en Venezuela

Spatial distribution model of Panstrongylus geniculatus Latreille 1811 (Hemiptera: Reduviidae: Triatominae) vector of Chagas Disease agent in Venezuela

Evelyn Tineo-González, Yasmín Contreras-Peña, Matías Reyes-Lugo, Antonio Morocoima y Leidi Herrera

Vida Silvestre / Wild Life

Biometría y longitud de migración de Penaeus stylirostris (Crustacea: Penaeidae) en tres zonas de captura en la costa de Sinaloa, México

Biometric and at migration of Penaeus stylirostris (Crustacea: Penaeidae) in three catch zones on the coast of Sinaloa, Mexico

Yanira Leyva-Vázquez, Juan Francisco Arzola-González, Guillermo Rodríguez-Domínguez, Eugenio Alberto AragónNoriega, Gilberto Genaro Ortega-Lizárraga, Horacio Alberto Muñoz-Rubi, Jorge Saul Ramirez-Perez y Darío ChávezHerrera

Medicina Veterinaria / Veterinary Medicine

Physiological response to thermal stress in hair-sheep ewes during subtropical summer Indicadores fisiológicos de respuesta al estrés térmico en ovejas de pelo durante el verano subtropical Javier Alejandro Gómez-Guzmán, José Fernando Vázquez-Armijo, Javier Hernández-Meléndez, Ana Laura LaraRivera and Gaspar Manuel Parra-Bracamonte.

Producción Animal / Animal Production

Eficiencia en la producción porcina en países de Europa. Casos de Dinamarca y Polonia

Efficiency in swine production in European countries. Cases of Denmark and Poland

Juan Cabas-Monje, Luis Améstica-Rivas, Jonathan Labra-Hernández, Bouali Guesmi y José María Gil. 


\section{EDITORIAL}

\section{La revista científica evoluciona para adecuarse a estos nuevos tiempos}

Ya en 1.950, el gran biólogo y naturalista Charles Darwin nos indicaba las evidencias que presentaban las especies para poder sobrevivir, debían evolucionar y adaptarse a las condiciones del medio en el que vivían, como si tuvieran características acordes a sus necesidades. Entre las enseñanzas que Darwin nos dejó, destaca el hecho de que realmente la evolución existe y que la vida es algo dinámico: "Las especies no se mantienen estáticas en el tiempo, sino que van evolucionando y que la selección natural es el mecanismo que permite dicha evolución».

Así como, las especies evolucionan en el tiempo para no extinguirse o desaparecer, la Revista Científica (RC) de la Facultad de Ciencias Veterinarias (FCV) de la Universidad del Zulia (LUZ), se adecua a estos nuevos tiempos que se viven en nuestro país. Venezuela durante estas dos últimas décadas, ha atravesado por la peor crisis política, económica y social que se haya vivido en esta nación; la más desbastadora desde mediados del siglo XX de un país que no está experimentando una guerra, más grave que la gran depresión en los Estados Unidos, peor que la crisis económica de 1985-1994 de Brasil o que la crisis hiperinflacionaria en Zimbabue de 2008-2009. Diversos investigadores han comparado aspectos de la crisis, como el desempleo y la contracción del PIB, con la posguerra de Bosnia y Rusia, Cuba y Albania tras el colapso de la Unión Soviética. Marcada por una fuerte hiperinflación, sueldos de $\$ 10$ mensuales, aumento de la pobreza, reaparición de enfermedades erradicadas, delincuencia e incremento de la mortalidad, trayendo como resultado una emigración masiva del país y a esto le sumamos la pandemia del COVID-19.

Todos estos elementos han repercutido en todos los aspectos de la vida del venezolano, y la $R C$ de la FCV-LUZ no ha sido la excepción a esta crisis; no obstante, el gran equipo de edición se ha negado rotundamente a permitir que desaparezcan más de 30 años de trabajo que han rendido frutos, logrando obtener más de 21 reconocimientos en índices nacionales e internacionales. Dicha evolución ha pasado en primer lugar por cambiar el formato físico, por un nuevo formato digital, más adelante se cambió la cantidad de números anual a partir de 2020 y ahora en 2021, nos abrimos a un sistema más interactivo entre los investigadores y nuestra revista, mediante la creación de un COMITÉ DE EDITORES POR SECCIONES, que nos permitirá una más temprana respuesta a las autores y más rápida decisión del arbitraje. Los artículos continuarán siendo de acceso abierto (open access), y estará gratuitamente abierta para el mundo científico, sin la necesidad de ningún tipo de suscripción. No obstante, a partir de este año se solicitará un pequeño aporte de los autores o instituciones, para procesamiento de artículos (APC Article Processing Charge), incorporando nuevas herramientas tecnológicas e identificadores tales como el ORCID y CrossRef, buscando promover y mejorar la comunicación y la investigación científica, a través de una mejora en la identificación de nuestras publicaciones.

\section{¡Evolucionamos para no extinguirnos!}

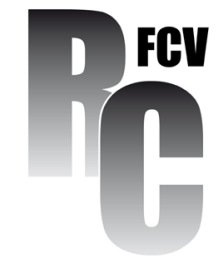

Dr. José Atilio Aranguren-Méndez

Miembro del Comité de Editores 


\title{
Modelo de distribución espacial de Panstrongylus geniculatus Latreille 1811 (Hemiptera: Reduviidae: Triatominae) vector del agente de la Enfermedad de Chagas en Venezuela
}

\author{
Spatial distribution model of Panstrongylus geniculatus Latreille 1811 (Hemiptera: Reduviidae: \\ Triatominae) vector of Chagas Disease agent in Venezuela
}

\author{
Evelyn Tineo-González', Yasmín Contreras-Peña ${ }^{1}$, Matías Reyes-Lugo ${ }^{2}$, Antonio Morocoima ${ }^{3}$ y Leidi Herrera *
}

${ }^{1}$ Instituto Pedagógico de Caracas, Universidad Pedagógica Experimental Libertador - Caracas, Venezuela. ${ }^{2}$ Sección de entomología médica "Pablo Anduze", Instituto de Medicina Tropical, Facultad de Medicina, Universidad Central de Venezuela - Caracas, Venezuela.

${ }^{3}$ Centro de Medicina Tropical de Oriente, Universidad de Oriente, Núcleo Anzoátegui - Barcelona, Anzoátegui, Venezuela.

${ }^{4}$ Laboratorio de Biología de Vectores y Parásitos, Instituto de Zoología y Ecología Tropical, Facultad de Ciencias, Universidad Central de Venezuela - Caracas, Venezuela. *Correo electrónico: herrerleidi@gmail.com

\begin{abstract}
RESUMEN
Panstrongylus geniculatus es un triatomino, vector del Trypanosoma cruzi, agente etiológico de la Enfermedad de Chagas, propio de los corredores biológicos que se dan entre ciclos de transmisión urbano y periurbano en Venezuela. Los modelos de nicho ecológico y distribución potencial de especies permiten conocer la relación entre los factores climáticos y la presencia real de las especies. El modelo de distribución geográfica potencial para $P$. geniculatus, generado mediante MAXENT, mostró áreas con condiciones bioclimáticas próximas a su nicho ecológico; así, definió una amplia distribución potencial con énfasis en la zona norte costera de Venezuela (estados Lara, Yaracuy, Carabobo, Aragua, Miranda, Distrito Capital, Vargas, Monagas y Sucre) con probabilidades de media a muy altas $(0,56-1)$. También predijo áreas con condiciones de idoneidad en estados occidentales y orientales a pesar de que los registros reales son escasos. La isotermalidad y temperatura máxima del mes más caliente contribuyeron en $43,4 \%$ al establecimiento del modelo, en tanto que variables relacionadas con la precipitación, contribuyeron en $56,6 \%$. Esto coincide con el hecho de que los triatominos son termo-tolerantes y se distribuyen en función de la temperatura, la cual también condiciona el número de triatominos infectados. Las áreas geográficas idóneas del país serían zonas de riesgo para la infestación triatomínica y la transmisión de $T$. cruzi, por coincidencia con la zona de mayor densidad de la poblacional humana, lo cual requeriría afinar estrategias de vigilancia entomológica y control epidemiológico.
\end{abstract}

Palabras clave: DIVA GIS; MAXENT; Panstrongylus geniculatus; Trypanosoma cruzi; áreas de riesgo

\begin{abstract}
Panstrongylus geniculatus is a triatomine vector of Trypanosoma cruzi, an etiological agent of Chagas disease, typical of biological corridors between urban and peri-urban transmission cycles in Venezuela. Ecological niche and potential species distribution models allow to know the relationship between climatic factors and the actual presence of species. The potential geographical distribution model for $P$. geniculatus, generated by MAXENT showed areas with bioclimatic conditions close to their ecological niche; thus, it defined a wide potential distribution with emphasis on the Northern coastal zone of Venezuela (Lara, Yaracuy, Carabobo, Aragua, Miranda, Capital District, Vargas, Monagas and Sucre States) with medium to very high probabilities $(0.56-1)$. It, also predicted areas with suitability conditions in Western and Eastern States even though actual records are scarce. The isothermality and maximum temperature of the hottest month, contributed $43.4 \%$ to the model; variables related to precipitation contributed $56.6 \%$. This coincides with the fact that triatomines are thermotolerant and are distributed according to temperature, which also conditions the number of infected triatomines. The ideal geographic areas of the country would constitute risk areas for triatomine infestation and the transmission of $T$. cruzi, coinciding with the area with the highest density of the human population, which would consider fine-tuning strategies for entomological surveillance and epidemiological control.
\end{abstract}

Key words: DIVA GIS; MAXENT; Panstrongylus geniculatus; Trypanosoma cruzi; risk areas

Recibido: $12 / 02 / 2020 \quad$ Aceptado: $11 / 11 / 2020$ 


\section{INTRODUCCIÓN}

El género Panstrongylus BERG, 1879 (Hemiptera: Reduviidae: Triatominae) está conformado por insectos hematófagos, hemimetábolos, de amplia y exclusiva distribución en América, ocupando zonas desde el sur de México hasta el norte de Argentina [20].

En Venezuela, existen cinco especies del género, a saber: $P$. chinai, $P$. geniculatus, $P$. lignarius, $P$. rufotuberculatus y $P$. martinezorum, siendo $P$. geniculatus la más abundante, con una distribución coincidente con la de otros triatominos, tales como Rhodnius prolixus STÅL, 1859 o Triatoma maculata ERICHSON 1848 [3, 8, 34].

P. geniculatus Latreille 1811 ha sido incriminado como vector del hemoflagelado Trypanosoma cruzi (Eukarya: Kinetoplastea: Trypanosomatidae), agente etiológico de la tripanosomiasis americana o Enfermedad de Chagas $(\mathrm{ECH})$, una zoonosis que afecta entre 6 a 7 millones de personas, mayormente de zonas rurales y suburbanas de centro y Suramérica, con viviendas deficientes en construcción y servicios y cercanas a áreas ricas en flora y fauna las cuales soportan los nichos de triatominos [36].

La existencia de un corredor para $P$. geniculatus, entre la vivienda y el ambiente circundante rodeado de vegetación, atraídos esencialmente por la luz artificial, constituye un factor de riesgo discutido en la transmisión de $T$. cruzi, por lo cual el análisis de los hábitats reales y potenciales de esta especie es de imperiosa necesidad [1, 2, 7, 18, 33].

El modelado de nicho ecológico (MNE) y los Modelos de Distribución de Especies (MDE) son herramientas que han permitido conocer la distribución de vectores y su relación con el espacio geográfico, así como la identificación de las condiciones ambientales ad hoc para su presencia y predicción de hábitats potenciales de vectores que constituirían riesgo epidemiológico $[10,26,31,32]$.

Algunos antecedentes de estas aplicaciones se han centrado en insectos del género Haemagogus, Culex, Aedes, vectores del virus de fiebre amarilla, Mayaro, Dengue y Zika, respectivamente, y en especies de triatominos vectores del agente de la $\mathrm{ECH}[4$, 16, 24, 37].

En el presente trabajo se analizó la distribución geográfica de $P$. geniculatus en Venezuela, basados en registros bibliográficos existentes y de los laboratorios que realizan estudios de campo, para luego asociarlos a variables bioclimáticas características de las regiones de presencia. Los MNE apoyados en sistemas de información geográfica DIVA GIS y MAXENT [26, 32, 37], permitieron predecir la presencia de la especie y las variables bio climatológicas, en especial en áreas con escasos registros, o áreas con ausencias pero con idoneidad para la aparición de la especie, abriendo la necesidad de vigilancia en zonas de presencia real y potencial de $P$. geniculatus, en tanto es un vector que cobra cada vez mayor importancia en los ciclos de transmisión de T. cruzi.

\section{MATERIALES Y MÉTODOS}

\section{Registros de distribución de la especie}

Se construyó una base de datos con los registros de presencia de $P$. geniculatus, a escala nacional a partir de los datos de registro de presencia desde 2012 hasta 2019 del laboratorio de Biología de Vectores y Parásitos del Instituto de Zoología y Ecología Tropical (IZET-UCV) y reportes bibliográficos, recogiéndose 149 puntos o localidades de muestreo no redundantes y georeferenciados mediante sistemas de información geográfica.

\section{Software de modelación y capas ambientales}

El software DIVA-GIS 7.3.0 de formato libre fue utilizado para la generación de mapas ráster de distribución real de la especie; el software MAXENT (algoritmo de Máxima Entropía o de distribución más uniforme posible) se usó para modelar con salida acumulativa, la distribución potencial, obteniéndose una aproximación al NE mediante la relación entre los puntos de presencia y las variables ambientales, para predecir áreas con condiciones idóneas para la presencia de $P$. geniculatus [19].

Las capas de datos ambientales utilizadas son de amplia cobertura global en formato ráster correspondiendo a 19 variables de las disponibles en Global Climate Data-WorldClim (http://www. wordclim.org), compatibles con el área geográfica de Venezuela y con una resolución espacial de 1 kilometros $(\mathrm{km})$ en el Ecuador, resultantes de la interpolación de datos de temperatura media (máximos y mínimos), precipitación mensual y datos de altitud, desde el año 1950 hasta el 2000 [19](TABLA I).

\section{Construcción y evaluación del modelo}

Mediante DIVA-GIS se transformó la base de datos de presencia de $P$. geniculatus georreferenciados en archivo Excel de tipo .csv (archivos de valores separados por coma) para la conversión de las variables bioclimáticas al formato ASCII ( ${ }^{*}$.asc) luego de lo cual se efectuó una corrida de 10 modelos, usando los parámetros estándar de funcionamiento de MAXENT, tales como 1000 iteraciones, umbral de convergencia de $1,0 \times 10-5$, uso de $75 \%$ de los registros para la calibración del modelo y de $25 \%$ para su evaluación.

Se realizó el análisis de los parámetros estadísticos arrojados por MAXENT en el modelo inicial, a fin de cumplir los requerimientos básicos para la escogencia de las variables predictivas. Pruebas de correlación de Sperman con el software PAST 2.1, fijaron el índice de correlación < 0,75 como un criterio de selección de variables ambientales de mínima colinealidad y de valor predictivo. Adicionalmente se evaluó el porcentaje de contribución y de mejor resultado para el modelo mediante la prueba Jackknife para el estadístico AUC (Area Under the Curve), identificándose como variables más predictivas a aquellas con los valores más altos en la distribución de los datos $(<0,80)[25,29]$.

Con las variables escogidas se realizó una corrida de 10 réplicas, lo cual generó un modelo para la distribución de $P$. geniculatus siguiendo los criterios de Plasencia-Vázquez [29].

Esta información estadística se contrastó con las variables de mayor relevancia biológica en función de datos bioecológicos para $P$. geniculatus, tales como distribución o presencia en hábitats específicos, reproducción y sobrevivencia, todos asociados a temperatura y humedad $[6,21,22]$. 
TABLA I

Variables bioclimáticas (WorldClim) utilizadas en la generación del modelo de distribución espacial de Panstrongylus geniculatus en venezuela

\begin{tabular}{|c|c|}
\hline Variable & Definición \\
\hline Bio1 & Temperatura media anual \\
\hline Bio2 & Rango de temperatura diurno medio (Temp. Máx-Temp. Mín) \\
\hline Bio3 & Isotermalidad (Bio2 / Bio7) (* 100) \\
\hline Bio4 & Estacionalidad de la temperatura (desviación standard*100) \\
\hline Bio5 & Temperatura máxima del mes más caliente \\
\hline Bio6 & Temperatura mínima del mes más frío \\
\hline Bio7 & Rango de temperatura anual (Bio5 - Bio6) \\
\hline Bio8 & Temperatura promedio del trimestre más húmedo \\
\hline Bio9 & Temperatura promedio del trimestre más seco \\
\hline Bio10 & Temperatura promedio del trimestre más cálido \\
\hline Bio11 & Temperatura promedio del trimestre más frío \\
\hline Bio12 & Precipitación anual \\
\hline Bio13 & Precipitación del mes más húmedo \\
\hline Bio14 & Precipitación del mes más seco \\
\hline Bio15 & Estacionalidad de la precipitación (coeficiente de variación) \\
\hline Bio16 & Precipitación del trimestre más húmedo \\
\hline Bio17 & Precipitación del trimestre más seco \\
\hline Bio18 & Precipitación del trimestre más cálido \\
\hline Bio19 & Precipitación del trimestre más frío \\
\hline
\end{tabular}

El modelo generado se evaluó en cuanto a la sensibilidad y la especificidad de las predicciones mediante la validación a partir de la curva ROC (receiver operating characteristic), replicado diez veces mediante la opción validación cruzada con diferentes subconjuntos de entrenamiento y validación, obteniéndose un valor promedio. Se utilizó el valor de AUC como medida de la actuación del modelo, para revelar que mientras más cercano el valor está a 1 se tendría un modelo de muy buena aproximación a la realidad, en tanto que el valor cercano a 0,5 indicaría un modelo de una aproximación deficiente [13].

La salida .asc del modelo promedio de MAXENT se convirtió mediante DIVA GIS en un mapa binario con un umbral de corte del percentil 10 (umbral 10 percentil training presence) que limitó las posibles áreas de distribución, mostrando áreas de presencia o ausencia basadas en un modelo de calibración. Utilizando las capas shapefile a nivel de Municipios se modelaron algunas zonas seleccionadas del mapa nacional, con registros de presencia y de interés por la endemicidad en cuanto a la especie, a pesar de ser poco consideradas en la vigilancia entomológica, a fin de conocer como el modelo revelaría áreas de idoneidad potencial para la presencia de la especie aún en ausencia de registros, pudiendo abrir la posibilidad de presencia real de la misma.

\section{RESULTADOS Y DISCUSIÓN}

El análisis de registros de laboratorio y bibliográficos de presencia de $P$. geniculatus mediante DIVA-GIS 7.3.0, reveló un mapa de distribución real de la especie, en el cual las áreas de los mayores registros (>15) resultaron ser Aragua, Carabobo, Distrito Capital, Lara, Miranda, Portuguesa, Sucre y Yaracuy; las áreas de registro medio a alto (entre 5 y 15) resultaron ser Zulia, Táchira, Mérida, Trujillo, Barinas, Cojedes, Guárico, Anzoátegui, Monagas, Bolívar y Amazonas. Eventualmente el modelo mostró áreas de muy escaso o nulo registro de la especie (<5) en Apure, Delta Amacuro, Nueva Esparta y región de la Guayana Esequiba (FIG. 1). 


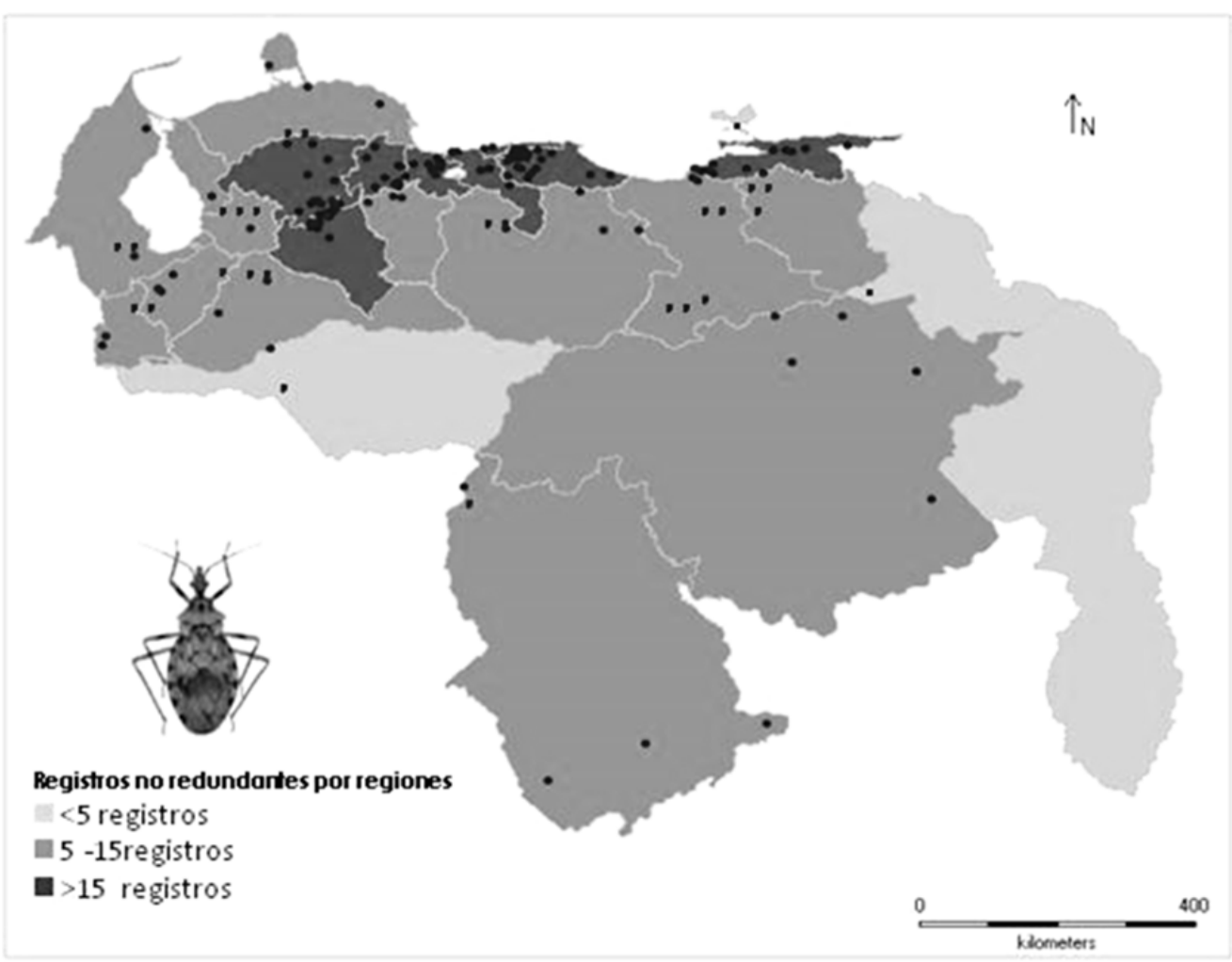

FIGURA 1. Distribución de Panstrongylus geniculatus en venezuela mostrando puntos de presencia registrados (no redundantes) con DIVA GIS 7.3.0

De la evaluación estadística de las covariables ambientales se obtuvo un subconjunto de siete variables que mostraron alta contribución e independientes en cuanto a la correlación entre sí, a saber: Isotermalidad (bio3), temperatura máxima del mes más caliente (bio5), precipitación del trimestre más seco (bio17), precipitación anual (bio12), precipitación del trimestre más frío (bio19), precipitación del trimestre más húmedo (bio16) y precipitación del mes más seco (bio14). En más detalle, la isotermalidad y temperatura máxima del mes más caliente, contribuyeron al modelo en su conjunto, en un 43,4 \%, mientras que las cinco variables restantes, relacionadas con la precipitación (anual; del mes más seco; del trimestre más húmedo; del trimestre más seco y del trimestre más frío), contribuyeron con un 56,6 \% para el modelo (TABLA II).

El modelo de la distribución geográfica potencial de $P$. geniculatus mostró áreas con condiciones bioclimáticas próximas a su NE (FIG. 2), es decir, áreas óptimas para la presencia de la especie. De esta manera, el modelo predijo que la zona norte costera de Venezuela en los estados Lara, Yaracuy, Carabobo, Aragua, Miranda, Distrito Capital, Vargas, Monagas y Sucre sería la más idónea para la presencia de la especie, con probabilidad $>$ de 0,75 y las áreas con condiciones de idoneidad de media a alta, estarían en el este de los estados Táchira y Mérida, Norte de Zulia, Sur de Falcón y Norte de Anzoátegui con probabilidades entre $0,56-0,75$.

La evaluación del modelo presentó un valor del área bajo la curva (AUC) de 0,930, superior al parámetro estocástico establecido por el programa $(A \cup C=0.50)$ mostrando alta sensibilidad (baja tasa de omisión) y alta especificidad (baja tasa de error) (FIG. 3).

TABLA II

Contribución porcentual de las covariables (WorldClim) utilizadas para modelar la distribución potencial de Panstrongylus geniculatus en venezuela

\begin{tabular}{cc}
\hline Covariable bioclimática o ambiental & $\begin{array}{c}\text { Contribución } \\
\text { al modelo (\%) }\end{array}$ \\
\hline bio3 (isotermalidad) & 23,8 \\
bio5 (temperatura máxima- mes más caliente) & 19,6 \\
bio17 (precipitación del trimestre más seco) & 17,5 \\
bio12 (precipitación anual) & 14,2 \\
bio19 (precipitación - trimestre más frío) & 12,6 \\
bio16 (precipitación - trimestre más húmedo) & 6,7 \\
bio14 (precipitación - mes más seco) & 5,6 \\
\hline
\end{tabular}




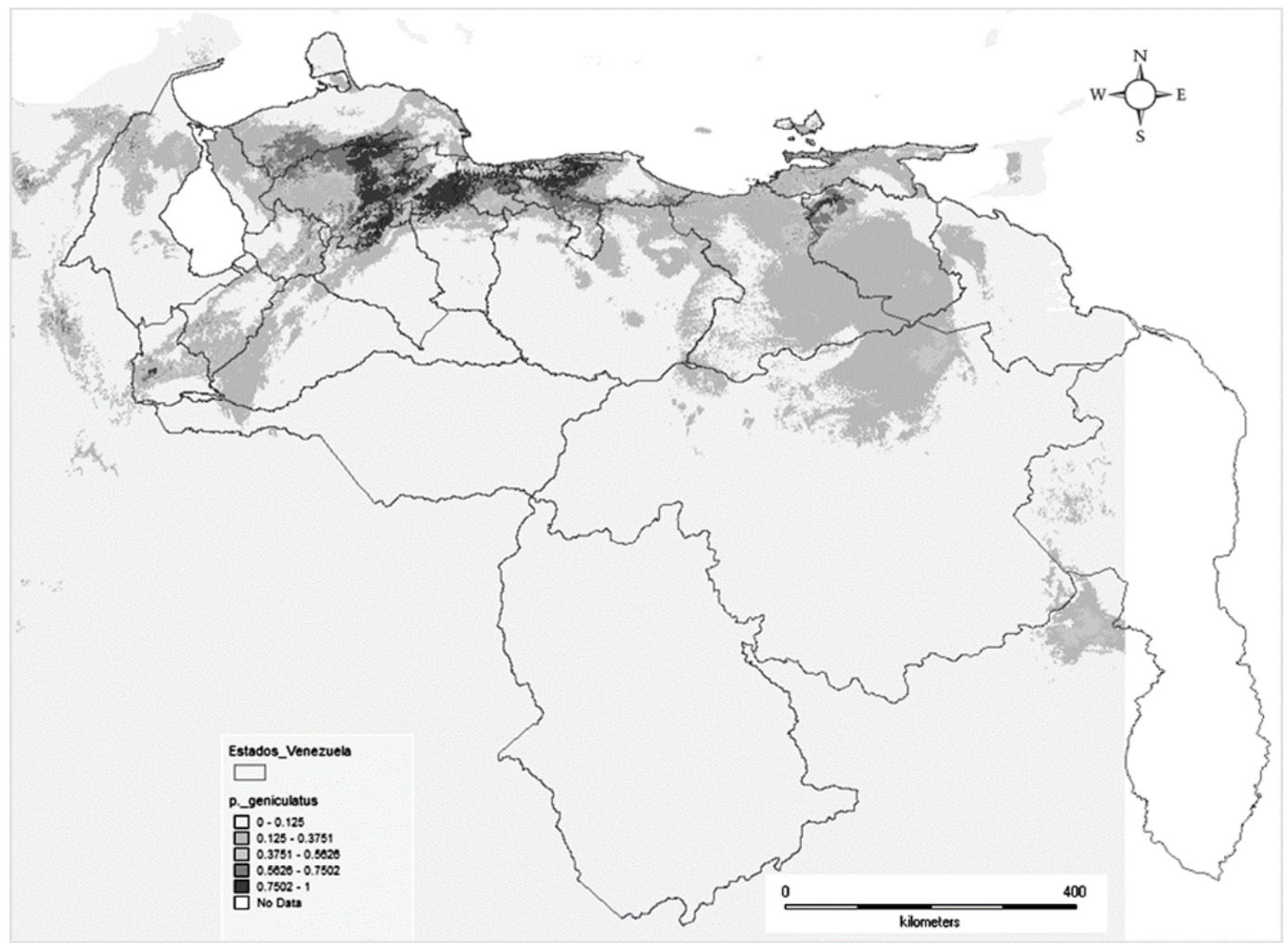

FIGURA 2. Modelo de distribución de áreas de idoneidad para la presencia de Panstrongylus geniculatus generadas con las variables Bio3, Bio5, Bio12, Bio14, Bio16, Bio17 Y Bio19 de WorldClim (MAXENT- mbral de corte del percentil 10, la escala de grises indica la probabilidad de presencia de la especie de 0 a 1)

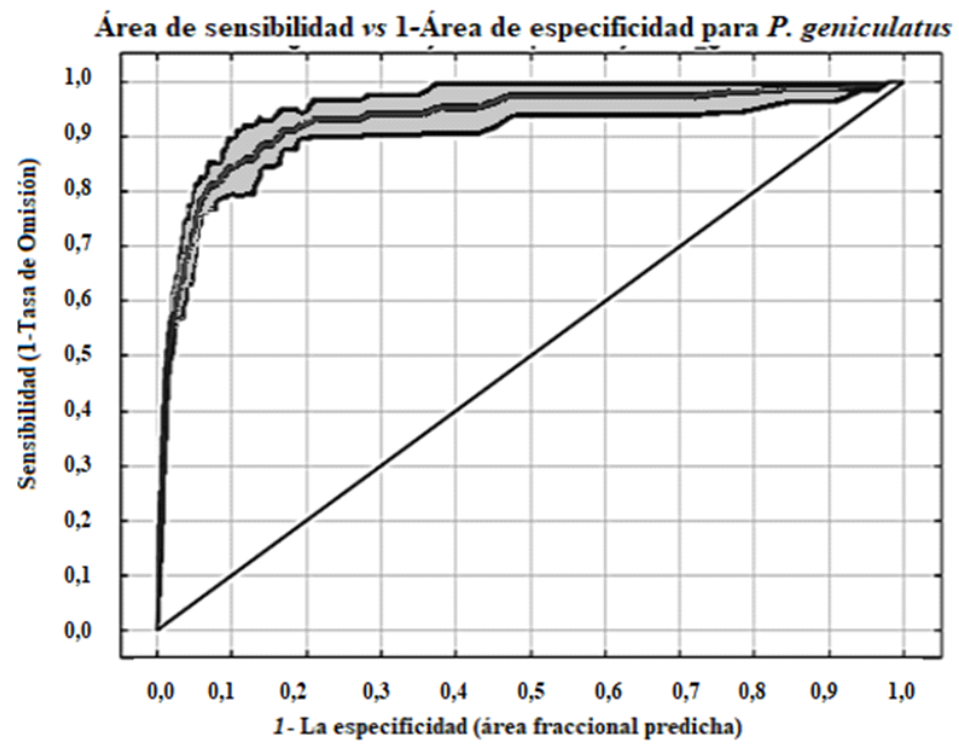

Promedio $(A U C)=0,930$-Linea gris intensa; Media +/- una desviación estandar de 0,034-Área gris

FIGURA 3. Gráfico de evaluación estadística de robustez para el modelo de probabilidad de aparición aleatoria de Panstrongylus geniculatus en su mayor abundancia, con alta sensibilidad (baja tasa de omisión) y alta especificidad (baja tasa de ausencia). ( $A \cup C=0,50$ es el valor más elevado que el parámetro predicho al azar) 
La capacidad predictiva del modelo se analizó particularmente con la superposición de los mapas de Municipios del estado Anzoátegui, Sucre y Monagas (capas shapefile) zonas de alta endemicidad de la especie, revelándose áreas en las que no hay registros de presencia, pero si condiciones ecológicas idóneas para su potencial aparición (FIG.4).

$P$. geniculatus posee la distribución geográfica más amplia en América, dentro de la subfamilia Triatominae, abarcando Argentina, Bolivia, Brasil, Colombia, Costa Rica, Ecuador, Guatemala, Perú y Venezuela [5].

En Venezuela, se consideraba a $R$. prolixus, el triatomino de mayor domiciliación en la mayoría de los estados, sin embargo, esta especie ha ido disminuyendo con el control químico y la sustitución progresiva de los ranchos rurales (piso de tierra, techo de palma y pared de bahareque) por viviendas de concreto pero con calidad deficiente en su construcción, especialmente en paredes y pisos, lo que ha favorecido que esta especie altamente domiciliada, comience con más frecuencia a presentarse en simpatría con $P$. geniculatus, aún en estados de escasos registros de ésta última como Apure, Barinas, Nueva Esparta y Falcón, en este último en zonas xerofitas y bosques desde 60 hasta 1.500 metros sobre el nivel del mar (m.s.n.m) [33].
$P$. geniculatus es muy común en las madrigueras de Dasypus novencinctus (cachicamo), Didelphis marsupialis (zarigüeya o rabipelado) y Rattus rattus (rata casera), reservorios de importancia para el T. cruzi en ecótopos silvestres, corredores periurbanos y ambientes urbanos. En estos ecótopos se mantiene un continuo de humedad y temperatura, especialmente en casas de construcción precaria, en las cuales se favorecería su instalación con fuentes seguras de ingesta sanguínea: gallinas, perros, zarigüeyas, roedores y humanos [7, 17, 20, 33]. A ello se une la importancia de $P$. geniculatus por su rol creciente en asociación con casos de transmisión vía oral de $T$. cruzi, en Venezuela [12].

La introducción de adultos de $P$. geniculatus en regiones urbanas y periurbanas del Distrito Capital y los estados Aragua, Vargas y Miranda, ha sido consecuencia de la dramática reducción de la oferta sanguínea en medios silvestres, lo cual favorece la visita a la vivienda para el repasto sanguíneo sobre humanos, animales domésticos y sinantrópicos [33].

El modelo predictivo generado desde DIVA GIS y MAXENT reveló que la zona norte costera de Venezuela, sería un área con alta idoneidad ambiental para la presencia de $P$. geniculatus, así como algunas áreas de los estados occidentales Táchira, Mérida,

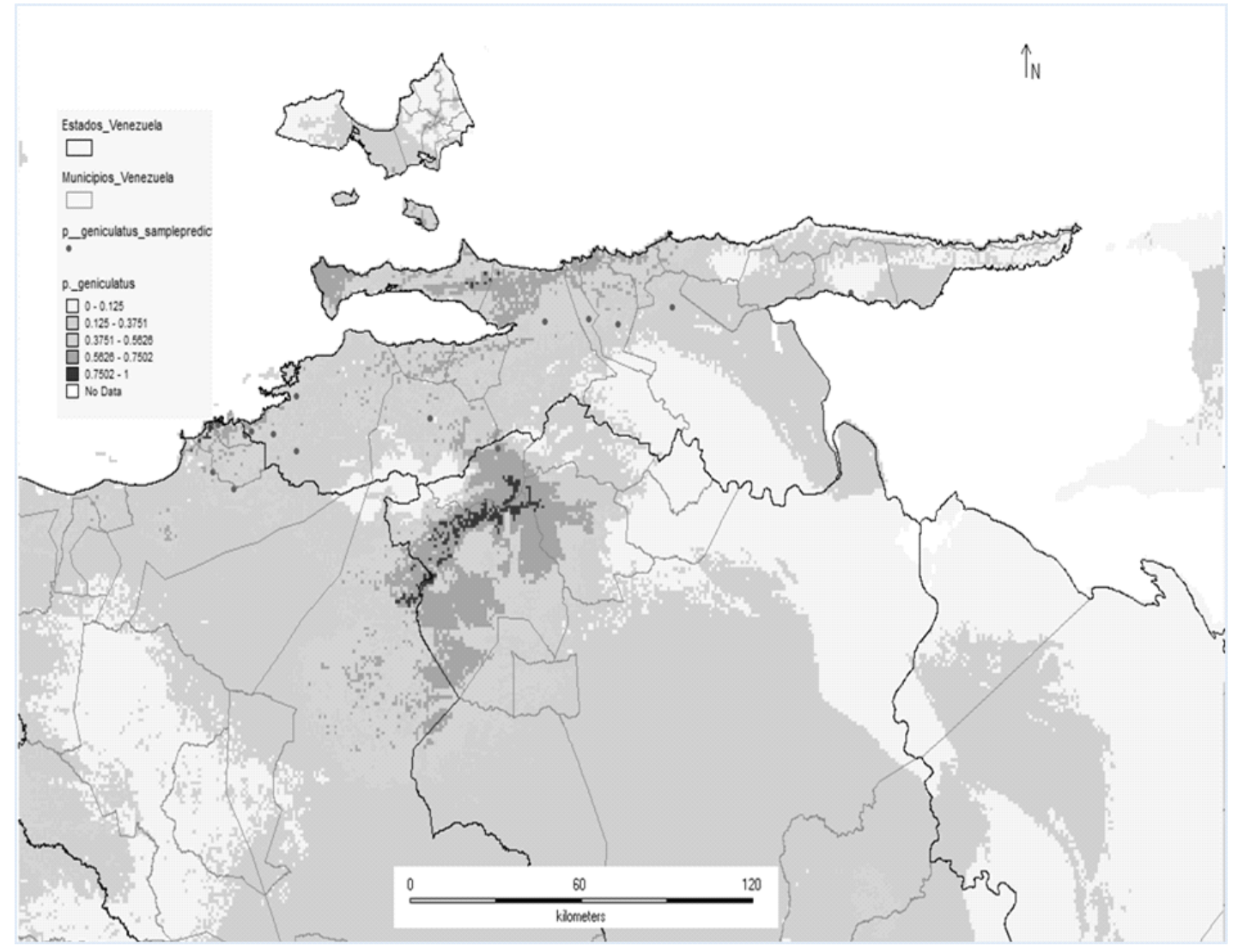

FIGURA 4. Mapa predictivo de areas idóneas de distribución para Panstrongylus geniculatus con los límites por estado y municipio, en los municipios Sucre y Montes (estado Sucre); municipios Aguasay, Bolívar, Caripe y Ezequiel Zamora (estado Monagas) todos con ausencia de registros. (Los puntos indican los registros de presencia; umbral de corte del percentil 10; la escala de grises indica la probabilidad de encontrar a la especie de 0 a 1) 
Zulia y el sur del estado Falcón, a pesar de que los registros reales en éstos últimos son más escasos, quizás por sub-registro de la especie, la cual como se ha visto en los puestos comunitarios de notificación, ha aumentado en frecuencia de aparición intra y peridomiciliar con la antropización del ambiente, la desforestación y/o movilización de la mastofauna de la cual se alimenta (datos no mostrados).

Bajo condiciones de laboratorio, esta especie exige alta humedad $\left(70 \pm 5 \%\right.$,) temperatura de $26 \pm 1{ }^{\circ} \mathrm{C}$ y fotoperiodo $12: 12$ cuando se le alimenta semanalmente [23, 35]. Esto coincide con las condiciones de las áreas de presencia real y potencial de mayor abundancia (región centro-norte de Venezuela) modeladas en el presente trabajo, las cuales además tienen altitudes entre 0 a 2.000 m.s.n.m, $24^{\circ} \mathrm{C}$ en promedio anual de temperatura, humedad media relativa de $70 \%$ y precipitaciones medias anuales de 500 milímetro cúbicos $\left(\mathrm{mm}^{3}\right)$. En estas áreas existen bosques secos, húmedos y/o caducifolios, alternantes con sabanas secundarias producto de la urbanización [15].

El modelo de distribución usó como variables predictivas marcadoras de idoneidad ambiental para la presencia de $P$. geniculatus, en orden de importancia, la isotermalidad, temperatura máxima del mes más caliente, precipitación anual, precipitación del trimestre más húmedo y precipitación del trimestre más seco, tal y como ha sido encontrado para la especie en otras regiones de América [9, 30]. Debido a la potencialidad predictiva de estos parámetros, resulta conveniente considerarlos de manera rutinaria dentro de los programas de vigilancia entomo-epidemiológica.

La influencia de estos parámetros, coincide con la característica de los triatominos de ser termo-tolerantes y con una distribución condicionada por la temperatura e indirectamente por la altitud [6]. Más específicamente la temperatura actúa sobre el transporte de moléculas, la actividad enzimática y la expresión proteica en estos insectos, lo que ha sido descrito como condicionantes entre otros aspectos, del desarrollo de T. cruzi en su interior [11].

Los triatominos infectados pueden aparecer con mayor probabilidad en los meses más cálidos, siendo $24-27^{\circ} \mathrm{C}$ un rango de temperatura adecuado, asociado a rangos altitudinales de 100 a 1.800 metros $(\mathrm{m})$ y a la vez coincidentes con ambientes de buena disponibilidad de fauna de mamíferos para el repasto sanguíneo en ambientes silvestres como en corredores peri-domiciliares [14].

La temperatura podría ser así un selector importante de subpoblaciones de triatominos infectados y la existencia de los rangos idóneos referidos, en diferentes áreas geográficas, llevaría a considerar a estas zonas de riesgo y de obligada vigilancia entomológica. A lo expuesto se une que la distribución real y potencial de $P$. geniculatus se mostró coincidente con la alta densidad poblacional humana en Venezuela [28], lo cual indicaría la necesidad de estudiar la asociación entre esta especie y los asentamientos humanos, por su importancia creciente como vector del agente de la $\mathrm{ECH}$.

En este sentido Reyes-Lugo [33] señala que, las abundancias de adultos de $P$. geniculatus incursionando durante las noches en el ambiente domiciliar, incrementan cuando las fuentes de ingesta sanguínea animal escasean en el ambiente peridomiciliar, como consecuencia de la reducción, por acción humana, de los hábitats de las especies que son la fuente primaria de ingesta sanguínea para este vector.
Los modelos de distribución potencial de vectores tienen relevancia en la vigilancia epidemiológica [16, 24, 30], como el presente, en el cual se ubican áreas idóneas predichas por el modelo, para la presencia de $P$. geniculatus, sea por dispersión natural de la especie y cohabitación o sucesión de otras poblaciones de triatominos minimizadas por control químico, como es el caso de R. prolixus.

Una particularización en el uso del modelo generado lo constituye la región oriental, sobre la que se generó un mapa de las zonas silvestres, periurbanas o urbanas, idóneas, superponiendo capas shapefile, en aquellos Municipios con escasos registros de presencia, pero con condiciones ecológicas idóneas para existencia de $P$. geniculatus.

Así, se revelaron áreas de necesaria vigilancia como los municipios Sucre y Montes (Estado Sucre) y municipios Aguasay, Bolívar, Caripe, y Ezequiel Zamora (Estado Monagas) en las cuales habría que concentrar esfuerzos en la búsqueda de $P$. geniculatus y corroborar si existe en simpatría con otro vector potencial como T. maculata, lo cual ha sido reportado por varios autores [27].

En una parte importante del espacio geográfico descrito se sabe de la presencia de $P$. geniculatus mientras que en otras zonas predichas, falta por verificar su presencia, lo cual requeriría un muestreo más continuo, intenso y siempre con miras hacia la actualización del catastro triatomínico, precisamente en estas localidades nuestro modelo sería de elevada utilidad.

\section{CONCLUSIONES}

Los parámetros ambientales isotermalidad, temperatura máxima del mes más caliente, y las relacionadas con la precipitación como la precipitación anual, la del mes más seco, la del trimestre más húmedo, la del trimestre más seco y la del trimestre más frío, son los que más aportan al modelo propuesto. Por lo que resulta conveniente considerarlas de manera rutinaria dentro de los programas de vigilancia entomo-epidemiológica para esta especie de triatomino trasmisor de la $\mathrm{ECH}$

Concomitantemente, la capacidad predictiva de estos modelos se potenciará en la medida en que se le incorporen datos de información demográfica y condiciones socioeconómicas de las áreas vulnerables a la aparición de esta zoonosis. Por otra parte, resultan pertinentes estos modelos habidas cuentas del cambio climático global que ha favorecido la dispersión de insectos transmisores de patógenos hacía lugares donde antes no los había. Este fenómeno está bien documentado como es el caso del Aedes aegypti transmisor de Dengue, Chikungunya, Zika, Fiebre Amarilla y Mayaro hacía regiones hasta hace poco de clima templado. Por lo expuesto, contar con esta herramienta de abordaje de distribución espacial de insectos vectores, es de elevada importancia por su capacidad predictiva de eventos entomo-epidemiológicos como parte fundamental de las estrategias preventivas dentro de los Programas de Manejo Integral de Vectores, las cuales en un momento determinado podrían marcar la diferencia entre la activación o no de focos de transmisión urbanos o periurbanos de la $\mathrm{ECH}$. 


\section{AGRADECIMIENTOS}

A la Unidad de Sistemas Información Geográfica (UniSig), Centro de Ecología del Instituto Venezolano de Investigaciones Científicas (IVIC).

\section{REFERENCIAS BIBLIOGRAFICAS}

[1] ALARCÓN DE NOYA, B.; DÍAZ-BELLO, Z.; COLMENARES, C.; RUIZ-GUEVARA, R.; MAURIELLO, L.; MUÑOZCALDERÓN, A.; NOYA, O. Update on oral Chagas disease outbreaks in Venezuela: epidemiological, clinical and diagnostic approaches. Mem. Inst. Oswaldo Cruz. 110: 377-86. 2015.

[2] ALDANA, E.; AVENDAÑO-RANGEL, F.; LIZANO, E.; RODRÍGUEZ-BONFANTE, C.; BONFANTE-CABARCAS, R. Panstrongylus geniculatus eggs (Heteroptera, Reduviidae, Triatominae) from a Chagas' endemic area in the CenterWest of Venezuela. Acta Micros. 20:103-11. 2011.

[3] AYALA, J.; MATTEI, R.; MATTEI, R. Descripción de la hembra de Panstrongylus martinezorum Ayala, 2009 (Hemiptera: Reduviidae, Triatominae) con comentarios sobre la distribución geográfica de la especie en el estado Amazonas, Venezuela. Bol. Soc. Entomol. Aragon. 54:383-389. 2014

[4] BAAK-BAAK, CM.; MOO-LLANES, DA.; CIGARROATOLEDO, N.; PUERTO, F.; MACHAIN-WILLIAMS, C; REYES-SOLIS, G.; NAKAZAWA, YJ.; ULLOA-GARCIA, A.; GARCIA-REJON, JE. Ecological Niche Model for predicting distribution of disease vector mosquitoes in Yucatán State, México. J. Med. Entomol. 54: 854-61. 2017.

[5] CÁCERES, AG.; VEGA, S.; ANCCA, J.; PINTO, J.; VELA, G.; CÁRDENAS, V.; RUIZ, J.; ALVA, P.; RUIZ, J.; ALVARADO, A.; ARÉVALO, H.; CRUZADO, F.; VELA, F.; NÁQUIRA, C. Aspectos entomológicos de la Enfermedad de Chagas en Huallaga y Picota, San Martín, Perú. An. Fac. Med. 71: 28-36. 2010.

[6] CARCAVALLO, R.; CURTO DE CASAS, S.; SHERLOCK, I.; GALÍNDEZ, I.; JURBERG, J.; GALVAO, C.; MENA-SEGURA, C. Geographical distribution and alti-latitudinal dispersion of Triatominae. In: CARCAVALLO, R.; GALINDEZ, I., JURBERG, J.; LENT, H. (Eds.). Atlas of Chagas' disease vectors in the America. Vol. III. Río de Janeiro, Edit. Fiocruz. 1217 pp. 1999.

[7] CARRASCO, H.; TORRELLAS, A.; GARCIA, A.; SEGOVIA, M.; FELICIANGELI, M.D. Risk of Trypanosoma cruzi I (Kinetoplastida: Trypanosomatidae) transmision by Panstrongylus geniculatus (Hemiptera: Reduviidade) in Caracas (Metropolitan District) and neighboring States, Venezuela. Int. J. Parasitol. 5:1379-84. 2005.

[8] CAZORLA-PERFETTI, D.; NIEVES-BLANCO, E. Triatominos de Venezuela: aspectos taxonómicos, biológicos, distribución geográfica e importancia médica. Avan. Cardiol. 30:34769.2010.

[9] CECCARELLI, S.; RABINOVICH, JE. Global climate change effects on Venezuela's vulnerability to Chagas Disease is linked to the geographic distribution of five triatomine species. J. Med. Entomol. 52:1333-43. 2015.
[10] CONTRERAS-MEDINA, R. Los métodos de análisis biogeográfico y su aplicación a la distribución de gimnospermas en México. Intercien. 31:176-86. 2006.

[11] DE FUENTES-VICENTE, J. A.; GUTIÉRREZ-CABRERA, A. E.; FLORES-VILLEGAS, A. L.; LOWENBERGER, C.; BENELLI, G.; SALAZAR-SCHETTINO, P. M.; CÓRDOBAAGUILAR, A. What makes an effective Chagas disease vector? Factors underlying Trypanosoma cruzi - triatomine interactions. Acta Trop. 83: 23-31. 2018.

[12] DÍAZ-BELLO, Z.; ZAVALA-JASPE, R.; REYES-LUGO, M.; COLMENARES, C.; NOYA-ALARCÓN, O.; NOYA, O.; HERRERA, L.; ALARCÓN DE N, B. Urban Trypanosoma cruzi Oral Transmission: from a Zoonotic Founder Focus to the Largest Microepidemic of Chagas Disease. SOJ Microbiol. Inf. Dis. 4: 1-9. 2016.

[13] ELITH, J.; GRAHAM, C.H.; ANDERSON, R.; DUDÍK. M.; FERRIER, S.; GUISAN, A.; HIJMANS, R.; HUETTMANN, F.; LEATHWICK, J. R.; LEHMANN, A.; LI, J.; LOHMANN, L.G.; LOISELLE, B.A.; MANION, G.; MORITZ, C.; NAKAMURA, M.; NAKAZAWA, Y. McC, J.; OVERTON, M.; TOWNSEND PETERSON, A.; PHILLIPS, SJ.; RICHARDSON, K.; SCACHETTI-PEREIRA, R.; SCHAPIRE, R.E.; SOBERÓN, J.; STEPHEN W.; WISZ, M.S.; ZIMMERMANN, N.E. Novel methods improve prediction of species' distributions from occurrence data. Ecography. 29: 129-51. 2006.

[14] ELLIOT, S.L.; RODRIGUES, J.D.O.; LORENZO, M.G.; MARTINS-FILHO, O.A.; GUARNERI, A.A. Trypanosoma cruzi, etiological agent of Chagas Disease, is virulent to its triatomine vector Rhodnius prolixus in a temperature-dependent manner. Plos Neglect. Trop. D. 9: e0003646. 2015.

[15] EWEL, J.J.; MADRIZ, A.; TOSI, J.A. Memoria explicativa sobre el mapa ecológico. Zonas de vida de Venezuela. Fondo Nacional de Investigaciones Agropecuarias, Ministerio de Agricultura y Cría, Caracas-Venezuela. 270 pp. 1976.

[16] GURGEL-GONÇALVES, R.; GALVÃO, C.; COSTA, J.; PETERSON, T. Geographic distribution of Chagas Disease vectors Brazil. Bases on ecological niche modeling. J. Trop. Med. 2012: ID 705326. 2012.

[17] HERRERA, L. Una revisión sobre reservorios de Trypanosoma (Schizotrypanum) cruzi (Chagas, 1909), agente etiológico de la enfermedad de Chagas. Bol. Mal. Sal. Amb. 50:3-15. 2010.

[18] HERRERA, L.; URDANETA-MORALES, S. Synanthropic rodent reservoirs of Trypanosoma cruzi in the valley of Caracas, Venezuela. Rev. Inst. Med.Trop. São Paulo. 39: 279-282.1997.

[19] HIJMANS, R.; CAMERON, S.; PARRA, J.; JONES, P.; JARVIS, A. Very high resolution interpolated climate surfaces for global land areas. Intl. J. Climatol. 5: 1965-78. 2005.

[20] JURBERG, J.; GALVÃO, C. Biology, ecology and systematics of Triatominae (Heteroptera: Reduviidae) vectors of Chagas disease and implications for human health. Denisia. 19: 1096-1116. 2006.

[21] JURBERG, J.; RODRIGUES, J.M.S., MOREIRA, F.F.F., DALE, C., CORDEIRO, I.R.S., LAMAS, V.D. JR, GALVÃO, C.; ROCHA, D.S. Vetores conhecidos no Brasil. En: Atlas 
iconográfico dos triatomíneos do Brasil (Vetores da Doença de Chagas no Brasil). Laboratório Nacional e Internacional de Referência em Taxonomia de Triatomíneos IOC-FIOCRUZ. Rio de Janeiro. 58 pp. 2014.

[22] LEITE, G.R.; DOS SANTOS, C.B.; FALQUETO, A. Insecta, Hemiptera, Reduviidae, Panstrongylus geniculatus: geographic distribution map. Check List. 3: 147-152. 2007

[23] LENT, H.; WYGODZINSKY, P. Revision of the triatominae (Hemiptera, Reduviidae) and their significance as vector of Chagas' disease. Bull. Am. Mus. Nat. His. 163: 123-520. 1979.

[24] LIRIA, J.; NAVARRO, J. Modelo de nicho ecológico en Haemagogus WILLISTON (Diptera: Culicidae), vectores del virus de la fiebre amarilla. Rev. Biomed. 21:149-161. 2010.

[25] MANEL, S.; CERI, H.; ORMEROD, S.J. Evaluating presenceabsence models in ecology: the need to account for prevalence. J. App. Ecol. 38: 921-31. 2001.

[26] MORALES, N. Modelos de distribución de especies: Software Maxent y sus aplicaciones en Conservación. Rev. Cons. Amb. 2: 1-5. 2012.

[27] MOROCOIMA, A.; DE SOUSA, L.; HERRERA, L.; ROJAS, L.; VILLAOBOS, M.; CHIQUE, J.; BARROYETA, R.; BONOLI, S. Simpatría de triatominos (Reduviidae) y escorpiones (Buthidae) en Cocos nucifera y Acrocomia aculeata (Aracaceae) de Anzoátegui, Venezuela. Bol. Malariol. Salud Amb. 51:18798.2011.

[28] MINISTERIO DEL PODER POPULAR DE PLANIFICACIÓN. INSTITUTO NACIONAL DE ESTADÍSTICA (I.N.E.) Censo Poblacional de Vivienda 2011. Venezuela. En Línea https:// bit.ly/2Zl46cb/ 08-05-2020.

[29] PLASENCIA-VÁZQUEZ, A.; ESCALONA, G. Y; ESPARZAOLGUÍN, L. Modelación de la distribución geográfica potencial de dos especies de psitácidos neotropicales utilizando variables climáticas y topográficas. Act. Zool. Mex. 30: 471-90. 2014.
[30] PEREIRA, J.; ALMEIDA, P.; DE SOUSSA, A.; BOMFIM, R.; GURGEL-GONÇALVES, R. Climatic factors influencing triatomine occurrence in Central-West Brazil. Mem. Inst. Oswaldo Cruz. 108: 335-341.2013.

[31] PETERSON, A.; OBERÓN, J.; PEARSON, R.; ANDERSON, R.; MARTÍNEZ-MEYER, E.; NAKAMURA, M.; BASTOS, M. Ecological Niches and Geographic Distributions. In: Monographs in Population Biology. Series. 49. Ed. Princeton University Press, New Jersey. 306 pp. 2011.

[32] PLISCOFF, P.; FUENTES-CASTILLO, F. Modelación de la distribución de especies y ecosistemas en el tiempo y en el espacio: una revisión de las nuevas herramientas y enfoques disponibles. Rev. Geo. Norte Grande. 48:61-79. 2011.

[33] REYES-LUGO, M. Panstrongylus geniculatus Latreille 1811 (Hemiptera: Reduviidae: Triatominae), vector de la enfermedad de Chagas en el ambiente domiciliario del centro-norte de Venezuela. Rev. Biomed. 20: 180-205. 2009.

[34] SOTO-VIVAS, A. Clave pictórica de triatóminos (Hemiptera: Triatominae) de Venezuela. Bol. Malariol. Salud Amb. 49:259-274.2009.

[35] VIVAS-MEDINA, R.J. Establecimiento de colonias de Panstrongylus geniculatus en laboratorio para el estudio del efecto de variables climáticas sobre su ciclo de vida. Universidad de Tolima. Tolima- Colombia. Tesis de Grado 145 pp. 2017.

[36] WORLD HEALTH ORGANIZATION (WHO). Chagas Disease (American trypanosomiasis) Fact sheet. 2020. On line:http:// www.who.int/news-room/fact-sheets/detail/chagas-disease. (American-trypanosomiasis) 22-09-2020.

[37] YÁNEZ-CAJO, D.; MORENO, M.; CHAGUAMATE, L.; VALENCIA, N.; RUEDA-AYALA, V. Aplicación de Modelos de Nicho Ecológico para estudios Epidemiológicos: Triatoma dimidiata, vector de la Enfermedad de Chagas en Ecuador. Rev. Politec. 37: 1-5. 2016. 



\title{
Biometría y longitud de migración de Penaeus stylirostris (Crustacea: Penaeidae) en tres zonas de captura en la costa de Sinaloa, México
}

\author{
Biometric and at migration of Penaeus stylirostris (Crustacea: Penaeidae) in three catch \\ zones on the coast of Sinaloa, Mexico
}

\author{
Yanira Leyva-Vázquez', Juan Francisco Arzola-González ${ }^{*}$, Guillermo Rodríguez-Domínguez', \\ Eugenio Alberto Aragón-Noriega ${ }^{2}$, Gilberto Genaro Ortega-Lizárraga ${ }^{3}$, Horacio Alberto Muñoz-Rubi ${ }^{3}$, \\ Jorge Saul Ramirez-Perez ${ }^{1}$ y Darío Chávez-Herrera ${ }^{3}$
}

\begin{abstract}
${ }^{1}$ Posgrado en Doctorado en Ciencias en Recursos Acuáticos, Facultad de Ciencias del Mar, Universidad Autónoma de Sinaloa, Mazatlán, Sinaloa, México. ${ }^{2}$ Centro de Investigaciones Biológicas del Noroeste, Unidad Guaymas. Estero Bacochibampo, Guaymas, Sonora, México. ${ }^{3}$ Centro Regional de Investigación Acuícola y Pesquera, Instituto Nacional de Pesca y Acuacultura. Mazatlán, Sinaloa, México. *Correo electrónico: farzola@uas.edu.mx
\end{abstract}

\begin{abstract}
RESUMEN
En México, el recurso pesquero más importante es Penaeus stylirostris (camarón azul), siendo aprovechado a su máximo sustentable. $P$. stylirostris es considerada por sus tallas máximas registradas, la especie de camarón prioritaria para la alimentación humana y muy cotizada en los mercados nacional (México) e internacional. El objetivo fue determinar las relaciones biométricas y talla de migración del camarón azul en tres zonas de pesca (bahía, ribera y altamar) del sistema lagunar Santa María La Reforma (SMLR), Sinaloa, México. Estas zonas son utilizadas como áreas de protección, alimentación y crecimiento del camarón azul. Se analizaron las temporadas 2016 a 2018. La captura de camarón en aguas protegidas se realizó mediante embarcaciones menores a 8 metros $(\mathrm{m})$ de eslora utilizando atarraya suripera. En ribera, en embarcaciones de $12 \mathrm{~m}$ y en altamar en barcos (CRIAP Mazatlán) en la plataforma continental frente a SMLR. A los especímenes se les diferenció el sexo y se determinó la proporción sexual $\left(\mathrm{X}^{2}\right)$, se les determinó la longitud total $(\mathrm{LT})$ en milímetros $(\mathrm{mm})$ y el peso total $(\mathrm{PT}) \mathrm{g}$. Se obtuvieron las relaciones biométricas y se estimó el tipo de crecimiento relativo del camarón azul. Por zona de pesca, se estimó la talla de longitud de migración $\left(\mathrm{LT}_{50 \%}\right)$ de $P$. stylirostris por el método logístico. Se analizaron 32.346 organismos, con una variación mínima y máxima de LT de 65 y $245 \mathrm{~mm}$, respectivamente, los mayores ejemplares en promedio correspondieron a altamar $(183,03 \mathrm{~mm})$ y los menores a bahía $(144,18 \mathrm{~mm})$. Se encontraron diferencias significativas en las tallas medias entre las zonas $(P<0,0001)$ y sexos $(P<0,001)$. La proporción de hembras respecto a machos, resultó mayor en casi todas las zonas. Se obtuvo una alta dependencia entre la longitud y peso, se presentó un crecimiento alométrico positivo $(\mathrm{P}=0,05)$ y se estimó una talla promedio de migración de $159,2 \mathrm{~mm}$, además por su tallas y abundancia de $P$. stylirostris, representa una especie de interés comercial y alimenticia para los pescadores de la costa de Sinaloa, México.
\end{abstract}

Palabras clave: Tallas; relación longitud-peso; Penaeus stylirostris; laguna costera; Pacífico mexicano

\begin{abstract}
In Mexico, blue shrimp Penaeus stylirostris the most important fishing resource, being harvested at its maximum sustainability. $P$. stylirostris is considered because the máximum recorded sizes, the priority shrimp specie for human consumption and therefore, highly valued in the national (Mexico) and international markets. The objetive was to analize: biometric relationships and size at migration of the blue shrimp in three catch areas (bay, litoral and marine or offshore) from Santa María La Reforma (SMLR) lagoon, Sinaloa, Mexico. The zones were, used as areas for protection, feeding and growth of blue shrimp. Shrimp catch was analyzed in three-year period (2016 - 2018 seasons). The catches in protected water were obtained by, boats smaller than 8 meters $(\mathrm{m})$, using "suripera" nets. On the littoral area a $12 \mathrm{~m}$ boats were used at offshore zone catches were by a research vessels (CRIAP Mazatlan) on the continental zone off SMLR. In $P$. stylirostris organisms, sex differentiaton and sex ratio $\left(\mathrm{X}^{2}\right)$ were measured. The organisms were determined by the total length (TL) in millimeters $(\mathrm{mm})$ and their total weight $(\mathrm{W})$ in grams. Biometric relationships were obtained and relative growth of the Blue shrimp was estimated. By fishing area, the migration size $\left(\mathrm{TL}_{50 \%}\right)$ of $P$. stylirostris was estimated by the logistic method. 32.345 organisms were analyzed, the greatest value was $L=245 \mathrm{~mm}$ recorded at marine and lowest value was $T L=65 \mathrm{~mm}$ inside the bay. On average the largest specimens correspond to the offshore (183.03 $\mathrm{mm}$ ) and the smallest one to the bay $(144.18 \mathrm{~mm})$. The means of TL were significant different between the fishing zone $(P<0.0001)$ and among sex $(P<0.001)$. The proportion of females with respect to the males was higher in almost all zones. High dependence between the variables (TL-W) were obtained, indicating isometric growth $(P=0.05)$, The mean migration size of $159.2 \mathrm{~mm}(T L)$ was estimated, furthermore due to its sizes and abundance of $P$. stylirostris, represents a species of commercial and nutritional interest for fishermen of the coast of Sinaloa, Mexico.
\end{abstract}

Key words: Size; length-weight relationships; Penaeus stylirostris; coastal lagoon; Mexican Pacífic.

Recibido: 08/03/2020 Aceptado: 25/11/2020 


\section{INTRODUCCIÓN}

La pesquería del camarón es de tipo secuencial, es decir; esta pesquería es aprovechada por diferentes flotas y artes de pesca durante dos fases de su ciclo de vida del camarón (Penaeus spp.). Como adulto, es capturado por barcos y embarcaciones menores (eslora inferior a 10,5 metros -m-) de acuerdo a la Ley General de Pesca y Acuacultura Sustentables 2.018 -LGPAS- [11] en altamar, y como juveniles en lagunas costeras y esteros. Todo ello con la finalidad de consumo para alimentación humana y para comercialización. Lo cual, genera una alta actividad económica y social la pesquería del camarón. Dentro de estas especies, resalta Penaeus stylirostris (camarón azul) por sus máximas tallas en longitud total registradas $[2,15,17,18]$, abundancia y alto valor proteico; como un recurso acuático de interés económico en el noroeste del Golfo de California y Pacifico mexicano, asimismo, en los mercados nacional e internacional.

Las costas de México presentan franjas litorales con una extensión de 8.475 kilómetros $(\mathrm{km})$ a lo largo del Océano Pacífico y 3.294 km a lo largo Golfo de México y Océano Atlántico, de manera que la pesca constituye una de las actividades de mayor relevancia en México. En México, la pesquería más importante en términos económicos y de mayor impacto social es la pesca del camarón (Penaeus spp.) conforme a su valor, se posiciona en primer lugar, con una participación del $44 \%$ del valor total de la producción pesquera (PP), superando tan solo en 2017 los 865 millones de dólares. En lo que refiere a las exportaciones también ocupa el primer lugar, lo que convierte en el producto pesquero nacional más importante que se comercializa en el ámbito internacional, siendo Estados Unidos de América (EUA), Vietnam y Francia sus principales destinos [17]. En 2.017, la PP nacional de camarón fue aproximadamente 77.925 toneladas (t), de las cuales, $32.881 \mathrm{t}$, correspondieron a la captura en mar abierto (altamar), y 45.044 t, a la producción en esteros y bahías [9].

En el Pacífico mexicano, la pesquería del camarón abarca desde la zona del alto Golfo de California, en el delta del Río Colorado (EUA), hasta la frontera con Guatemala, incluyendo la costa occidental de Baja California Sur y prácticamente todos los sistemas lagunares del estado de Sinaloa $[4,13]$. Su captura está representada principalmente por las especies: camarón blanco ( $P$. vannamei), camarón azul ( $P$. stylirostris), camarón café $(P$. californiensis) y camarón rojo o cristal ( $P$. brevirostris); siendo el camarón azul el más importante y la especie preeminente para la mayoría de los pescadores del noroeste de México [2].

De acuerdo a la Carta Nacional Pesquera (CNP) [5], la captura de este recurso durante el periodo 2000 - 2016 superó las 30.000 t anuales en el Pacifico mexicano, y los estados de Sinaloa y Sonora son los principales productores con 43 y $38 \%$ de la captura, respectivamente. Sin embargo, la máxima captura registrada fue durante la temporada 2011 - 2012, aproximadamente $53.347 \mathrm{t}$. No obstante, en este documento vinculante de la LGPAS [11] se establece que el estatus de la pesquería de camarón en su conjunto, se considera aprovechada a su máximo sustentable.

En Sinaloa, para su explotación pesquera participan principalmente dos tipos de flotas: a) flota ribera o flota artesanal y b) flota industrial también llamada de altamar. La pesca realizada por la flota ribera ocurre en los esteros, estuarios, lagunas y aguas marinas costeras [17]. En el sur de Sinaloa, la pesca se dirige principalmente a los juveniles, los pescadores construyen barreras artificiales en los esteros que permiten el reflujo de agua llamadas "tapos" para evitar que los camarones juveniles se dirijan hacia el mar abierto. En dichos tapos, la pesca se realiza con atarrayas y en embarcaciones menores llamadas canoas [3, 6, 7, 8, 16]. En el resto del estado de Sinaloa, la captura ribereña se realiza utilizando artes de pesca conocidos como chinchorros, atarrayas, atarrayas suriperas y "changos"; la pesca se dirige principalmente a los juveniles de etapa tardía, pre-adultos y adultos, a bordo de embarcaciones menores denominadas pangas ( $7 \mathrm{~m}$ de eslora) con motor (YAMAHA F90BETL, JAPÓN) fuera de borda de 90 caballos de fuerza (HP). Mientras que la flota de Altamar o industrial, se realiza en mar abierto y se dirige a los adultos utilizando embarcaciones mayores (18 a 23 m de eslora) equipadas con dos redes de arrastre con una autonomía de 30 a 40 días (d) en el mar [4].

Durante la actividad pesquera del camarón, las embarcaciones artesanales por su autonomía y características físicas ejercen su esfuerzo pesquero en zonas cercanas a la costa donde habitan los camarones juveniles o adultos. Mientras, que la flota industrial, por su mayor autonomía y tamaño opera generalmente en aguas profundas, a una mayor distancia de la costa, en zonas donde con frecuencia ocurren los adultos. Por lo anterior, esta pesquería se considera de tipo secuencial, lo que refleja la complejidad de los problemas que surgen cuando distintos grupos sociales, en zonas de pesca diferentes, aplican diferentes artes o métodos de pesca especializados para la captura de individuos de edades diferentes llegando a generar conflicto entre ambos sectores [12].

En camarones peneidos, la estructura de tallas ha sido analizada en $P$. vannamei por Ramos-Cruz [21] y en $P$. stylirostris [17]. Las relaciones biométricas han sido analizadas en especies distintas de peneidos por el modelo lineal $[15,21]$ y potencial en $P$. vannamei [3]. En $P$. stylirostris, Alcántara-Razo [1] obtuvo la ecuación potencial resultante de longitud-peso. Félix-Ortiz y col. [18] determinaron por sexos diferencias significativas en el coeficiente de determinación entre la longitud y peso. Muñoz-Rubí y col. [17] analizaron la correlación de longitud-peso, reportaron una relación alométrica positiva. Las investigaciones de tallas de migración de peneidos y en particular $P$. stylirostris sobre el seguimiento de tallas en dos zonas de captura en la franja litoral del Pacífico mexicano son muy limitados, a excepción de los trabajos donde se han analizado las tallas por separado para juveniles en las principales lagunas costeras del noroeste $[6,7$, $8,12,13]$ y como adultos en el Golfo de California [15, 18, 19] y Pacífico mexicano [1, 20, 21].

La pesquería de camarón está totalmente dirigida a la extracción con fines de alimentación humana y comercialización, sobretodo del camarón azul por sus tallas y abundancia, es necesario analizar algunos de sus principales aspectos poblacionales y con ello, argumentos biológicos-pesqueros que permitan regular su administración del camarón peneido por cada especie $(P$. vannamei, $P$. stylirostris, $P$. californiensis y $P$. brevirostris) y debido a su importancia pesquera con fines de alimentación y comercialización del camarón azul, el objetivo fue analizar la biometría y talla de longitud de migración de $P$. stylirostris en el seguimiento, dentro y fuera de una bahía y altamar en el litoral costero de Sinaloa, México. 


\section{MATERIALES Y MÉTODOS}

\section{Muestreos de campo}

Se analizó la información de muestreos en aguas protegidas y de ribera en la laguna Santa María La Reforma (SMLR), Sinaloa, México, entre las temporadas 2016 - 2018 durante las mareas altas (Luna nueva y Luna llena). La laguna se ubica geográficamente entre los $24^{\circ} 42^{\prime}$ y $25^{\circ} 30^{\prime} \mathrm{N}$ y los $107^{\circ} 53^{\prime}$ y $108^{\circ} 26^{\prime}$ $\mathrm{O}$, la cual se caracteriza por presentar una amplia variedad de ambientes costeros interrumpidos por cuerpos acuáticos como lagunas, esteros y marismas, sitios de gran importancia para la abundancia y crecimiento de $P$. stylirostris (FIG 1).

Para los muestreos en aguas protegidas se utilizaron embarcaciones menores de $8 \mathrm{~m}$ de eslora en la captura de camarón, el arte utilizado fue la atarraya "suripera" con tiempo de lance de $10 \mathrm{~min}$ ( $\mathrm{min}$ ). Los muestreos de ribera, se realizaron en embarcaciones de $12 \mathrm{~m}$ de eslora y a profundidades de 4,5; 7,5; 12 y $18 \mathrm{~m}$ con un periodo de arrastre de $30 \mathrm{~min}$. Los muestreos de altamar se efectuaron mediante cruceros de prospección (barcos de camarón) del programa Camarón del Pacífico (Centro Regional de Investigación Acuícola y Pesquera -CRIAP-Mazatlán) sobre la plataforma continental frente a la laguna SMLR, con un tiempo de arrastre de $60 \mathrm{~min}$. La posición de arrastre se determinó con un posicionador geográfico GPS (GPS GP1020 Garmin, Estados Unidos). En los tres casos de muestreo, la captura de camarón se depositó en la cubierta de la embarcación y se procedió a la separación del camarón azul. Los organismos fueron depositados en una hielera con datos de campo y fueron transportados en un tiempo de 40 min al laboratorio del Programa Camarón del CRIAP-Mazatlán.

\section{Muestreos biológicos}

Los organismos de camarón azul fueron diferenciados sexualmente por dimorfismo sexual por sus apéndices abdominales,

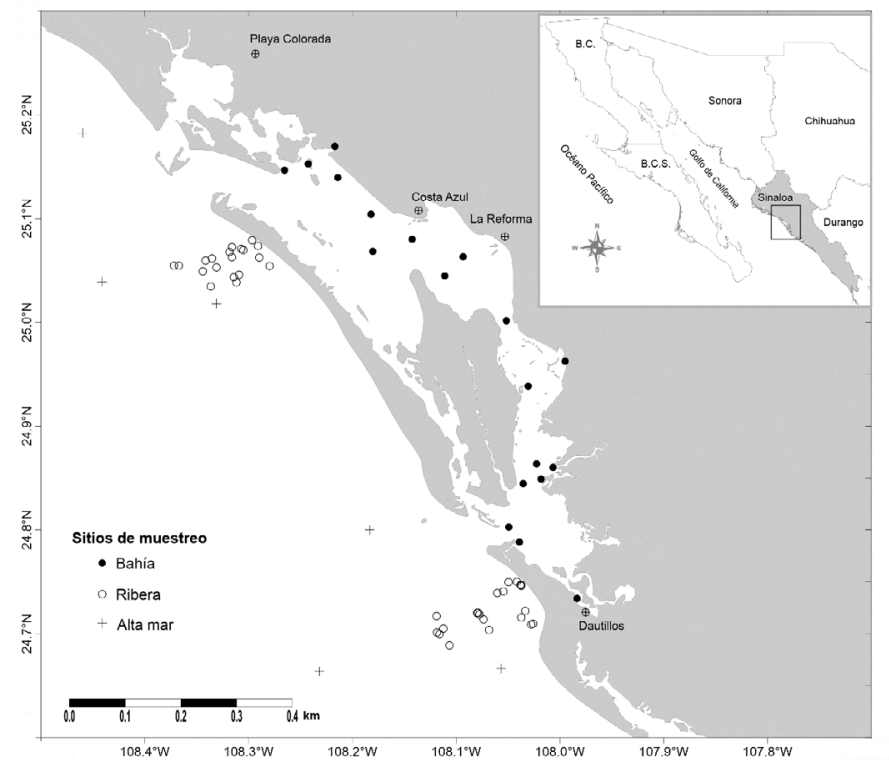

FIGURA 1. Localización del área de estudio en machos los endopóditos del primer par de pleópodos están fusionados para formar el petasma, en hembras todos sus pleópodos son birrámeos. Para la estimación de la proporción de sexos se realizó la prueba de bondad de ajuste Ji-cuadrado $\left(x^{2}\right)$ con corrección para continuidad de Yates [24] con la finalidad de poder comparar y determinar si la proporción de sexos difiere en teoría de 1:1, mediante la ecuación:

$$
X^{2}=\sum \frac{\left(\left|f_{1-} f_{2}\right|-0,5\right)^{2}}{f_{2}}
$$

A los organismos se les determinó la longitud total (LT) en $\mathrm{mm}$ con un ictiómetro (Aquatic Bio Tecnologyy iK2, España) su peso (PT) se calculó con una balanza digital $(0,1$ gramos [g] de sensibilidad) (Ohaus Compass H 8.109, China). Con los datos de LT se realizaron histogramas de frecuencia con un intervalo de frecuencia de $5 \mathrm{~mm}$. La forma de crecimiento se verificó con la ecuación que describe la relación de longitud y peso. Por cada relación morfométrica, se obtuvieron los coeficientes de determinación $\left(r^{2}\right)$ mediante la siguiente ecuación:

$$
y=a x^{b}
$$

Dónde:

$\mathrm{y}=$ Corresponde al peso, $\mathrm{PT}$.

$\mathrm{a}=$ Ordenada al origen.

$\mathrm{b}=$ Pendiente.

$\mathrm{x}=$ Corresponde a longitud, LT.

Se estimó los intervalos de confianza (IC) para el coeficiente b al $95 \%$, se utilizó el error típico (Et) y se realizó la prueba t-Student [24].

$$
I C=b \pm E t^{*} t_{n-1(95 \%)}
$$

Para la estimación de talla de longitud de migración de $P$. stylirostris entre las zonas de bahía y ribera, la distribución de frecuencias de tallas se estandarizó al mismo tamaño de muestra en ambas zonas de pesca, es decir, la misma proporción de individuos por cada intervalo de talla. Estos datos fueron ajustados al modelo logístico para estimar la talla (LT) de migración al $50 \%$ para $P$. stylirostris en bahía y ribera, mediante la ecuación:

Donde:

$$
M_{L t}=\frac{1}{1+\left(e^{-\left(\left(L T-L_{50 \%}\right) / \phi\right)}\right)}
$$

$\mathrm{M}_{\mathrm{Lt}}=\mathrm{El}$ porcentaje de migración a la talla LT.

$\mathrm{L}_{50 \%}=$ Talla de migración.

$\Phi=$ Parámetro de ajuste.

El modelo logístico fue ajustado maximizando el logaritmo de probabilidad de una función binomial por el método iterativo de Newton.

A los datos de LT de $P$. stylirostris por zona de pesca se les realizaron pruebas de normalidad (Lillieford) y homocedasticidad (Bartlet) [24], posteriormente se aplicó prueba de KolmogorovSmirnov (PKS) [24] para las diferencias de tallas entre zonas de pesca y sexos. En todos los casos se utilizó un nivel de significancia ( $\alpha$ ) de 0,05 [24] y el ajuste de medias se calculó con el paquete Statistica V.7,0 [23]. 


\section{RESULTADOS Y DISCUSIÓN}

Se analizaron en total 32.346 camarones de $P$. stylirostris en las tres zonas de captura (bahía, ribera y altamar) y entre 2016 y 2018. El más alto porcentaje de captura fue en bahía $(70,8 \%)$ y el menor en altamar (5,9\%). Por sexo, las más abundantes fueron $55,3 \%$ (hembras) y los menores $44,7 \%$ (machos). Por zonas de captura, la bahía representó la mayor abundancia con 22.916 camarones, seguido por ribera con 7.524 organismos y en altamar con 1.906 ejemplares de camarón azul. En la proporción de sexos, las hembras fueron mayormente abundantes que los machos en las capturas de la bahía y ribera, mientras que, en altamar, la proporción sexual se encuentra en equilibrio, ya que no resultaron con diferencias significativas la proporción de hembras y machos de camarón azul (TABLA I).

Es evidente que la mayor captura de camarón azul se presentó en la zona de bahía y el menor en altamar, esto debido a que esta especie durante su desarrollo en la fase juvenil ingresa a las principales zonas de bahía, lagunas y estuarios del Pacífico mexicano para su crecimiento, y posteriormente como adulto retorna a mar abierto (altamar) a completar su ciclo de vida [19, 20]. Aunque, el camarón azul durante su fase de juvenil, requiere de un mayor tiempo de entre 6 y 8 meses (mes), en donde constantemente $P$. stylirostris, $P$. vananmei y $P$. californiensis son capturados por los pescadores del noroeste de México [17]. Ramírez-Rojo y Aragón-Noriega [19] señalaron una mayor abundancia de $P$. stylirostris en la zona estuarina del Delta del Río Colorado (alto Golfo de California), al igual que RábagoQuiroz y col. [18], quienes indicaron a L. vannamei y L. stylirostris como las especies más abundantes en el Golfo de California. En bahía Navachiste, Muñoz-Rubí y col. [17] estimaron una mayor abundancia del camarón azul, con una variación máxima en septiembre y una menor en abril.

En el presente estudio, los menores porcentajes de captura en la zona de altamar comparado con bahía y ribera, están relacionados entre factores con el arte de pesca, donde en estas dos últimas zonas de pesca es comúnmente utilizar por los pescadores la atarraya para la captura de camarón comercial en bahías y ribera, teniendo como consecuencia una mayor abundancia de camarón juvenil en ambas zonas, es evidente que estas capturas de juveniles repercuten en la incidencia del reclutamiento hacía la zona marina (altamar) para completar su fase de adulto.
Incluso, en la actualidad se ha observado que las capturas de los organismos grandes (reproductores) por los pescadores de barcos se han reducido drásticamente.

Las mayores tallas (LT) en promedio resultaron en altamar $(183,0 \mathrm{~mm})$ y las menores medias a bahía con 144,2 mm. Por zona y sexo, en hembras las mayores medias se ubicaron en ribera y altamar con 176,7 y $187,4 \mathrm{~mm}$, respectivamente. Aunque en bahía los machos resultaron mayores en tallas que las hembras. Sin embargo, al analizar los datos se encontraron diferencias estadísticas entre las tallas por sexo entre las zonas de captura.

Al analizar estadísticamente los datos de promedios de tallas (LT), se encontró que existen diferencias significativas entre las tallas promedio de LT entre las zonas de muestreo (Prueba de Kolmogorov-Smirnov PKS, P < 0,0001). La prueba de comparación muestra que el valor de la probabilidad $(P)$ es menor que el nivel de significancia $(\alpha=0,05)$ en todos los casos, por lo que se concluye que hay diferencias significativas en la distribución de tallas entre las tres zonas (TABLA II).

\section{Tabla II}

Comparación de la estructura de tallas de la LT de Penaeus stylirostris de bahía, ribera y altamar.

Valor P. de ANDEVA de una vía, Kolmogorov-Smirnov

\begin{tabular}{cccc}
\hline & Bahía & Ribera & Altamar \\
\hline Bahía & & $\mathrm{P}<0,0001$ & $\mathrm{P}<0,0001$ \\
Ribera & 0,491 & & $\mathrm{P}<0,0001$ \\
Altamar & 0,537 & 0,224 & \\
\hline
\end{tabular}

El organismo más grande capturado fue hembra con $245 \mathrm{~mm}$ de LT en la zona de altamar y el más pequeño coincidió en hembra con $65 \mathrm{~mm}$ de LT. Además, las hembras en promedio son más grandes que los machos, tanto en ribera como en altamar, pero no así en bahía, donde en promedio son ligeramente más grandes los machos que las hembras. En lo que respecta a la comparación

Tabla I

Número de organismos y proporción sexual de Penaeus stylirostris por zona de captura, estimación de la prueba $\chi^{2}$ y su valor de probabilidad

\begin{tabular}{|c|c|c|c|c|c|c|}
\hline \multirow[b]{2}{*}{ Zona } & \multirow[b]{2}{*}{ Machos } & \multirow[b]{2}{*}{ Hembras } & Proporción & \multirow[b]{2}{*}{$\mathbf{X}^{2}$} & \multirow[b]{2}{*}{ Probabilidad } & \multirow[b]{2}{*}{ Determinación } \\
\hline & & & $\begin{array}{c}\text { Macho-Hembra } \\
\text { : }: \Phi\end{array}$ & & & \\
\hline Bahía & 9868 & 13047 & $1: 1,32$ & 440,75 & 0,0000 & Significativo \\
\hline Ribera & 3625 & 3899 & $1: 1,07$ & 9,9055 & 0,0016 & Significativo \\
\hline Altamar & 955 & 951 & 1:0,99 & 0,0047 & 0,9452 & No significativo \\
\hline General & 14448 & 17897 & $1: 1,23$ & 367,56 & 0,0000 & Significativo \\
\hline
\end{tabular}


de la estructura de tallas por sexo para cada zona, la prueba Kolmogorov-Smirnov (PKS) mostró que los valores menores del estadígrafo "D" ocurrieron en las zonas de bahía y las diferencias más significativas ocurrieron en altamar, aunque respecto a la temporada de pesca (tiempo) se presentaron diferencias significativas entre sexos (TABLA III).

La distribución de tallas de $P$. stylirostris en las tres zonas de pesca se ubicaron entre 65 y $245 \mathrm{~mm}$ de LT. Las mayores capturas de organismos pequeños correspondieron a la zona de bahía, aunque los camarones azules más grandes (tallas) se recolectaron en las tres zonas de pesca, sin embargo, en bahía el intervalo de tallas fue de 65 a $230 \mathrm{~mm}$ de LT. Por sexos, coincidió la mayor frecuencia modal en $160 \mathrm{~mm}$ de LT. En ribera, la distribución de tallas en LT fue entre 100 y $240 \mathrm{~mm}$ y la mayor frecuencia de moda coincidió también en hembras y machos en $170 \mathrm{~mm}$ de LT. En altamar, se observaron dos grupos modales correspondiendo a hembras y machos, aunque por sexo también se detectaron dos grupos modales, en hembras de 160 y $220 \mathrm{~mm}$, mientras en machos fueron de 165 y 205 mm de LT (FIG 2).

La amplia distribución de tallas de $P$. stylirostris registradas en las tres zonas de pesca permiten señalar que las capturas de camarón azul se encuentran enfocadas principalmente a sus dos fases de desarrollo (juvenil y adulto). Sin embargo, las fluctuaciones de las tallas (grupos modales) que se observaron en bahía, ribera y altamar, es posible que estén relacionados con el reclutamiento de los organismos que van ingresando a la zonas de pesca (tallas pequeñas), asimismo, con las capturas de organismos con tallas mayores por las embarcaciones en la zona de ribera, pero principalmente por los pescadores de altamar (barcos camaroneros). En esta última zona de pesca se detectaron dos grandes grupos modales en longitud de camarón azul que corroboran lo señalado anteriormente, es decir, en hembras dos grupos modales en tallas (LT) de 160 y $220 \mathrm{~mm}$, y en machos, dos grupos de modas en 165 y 205 mm (LT). Además,

Tabla III

Número de organismos, longitud total $(\mathrm{mm})$, promedio, desviación estándar y probabilidad (Kolmogorov-Smirnov) por tiempo, zona de captura y sexo de Penaeus stylirostris

\begin{tabular}{|c|c|c|c|c|c|c|c|c|c|c|}
\hline Tiempo & Zona & Sexo & $\mathbf{n}$ & Min & LT Max & Media & $\mathrm{DE}( \pm)$ & Estadígrafo D & $P(\alpha=0,05)$ & Determinación \\
\hline \multirow{6}{*}{2016} & \multirow{2}{*}{ Bahía } & M & 2885 & 70 & 213 & 145,0 & 23,0 & \multirow{2}{*}{0,119} & \multirow{2}{*}{$<0,0001$} & \multirow{2}{*}{ ** } \\
\hline & & $\mathrm{H}$ & 3489 & 65 & 227 & 141,7 & 27,8 & & & \\
\hline & \multirow{2}{*}{ Ribera } & $M$ & 929 & 110 & 215 & 167,2 & 15,9 & \multirow{2}{*}{0,147} & \multirow{2}{*}{$<0.0001$} & \multirow{2}{*}{$\star \star$} \\
\hline & & $\mathrm{H}$ & 985 & 97 & 233 & 174,1 & 22,1 & & & \\
\hline & \multirow{2}{*}{ Altamar } & M & 281 & 115 & 205 & 169,1 & 14,0 & \multirow{2}{*}{0,168} & \multirow{2}{*}{0,0004} & \multirow{2}{*}{$\star *$} \\
\hline & & $\mathrm{H}$ & 329 & 105 & 245 & 176,1 & 20,0 & & & \\
\hline \multirow{6}{*}{2017} & \multirow{2}{*}{ Bahía } & $\mathrm{M}$ & 4113 & 82 & 200 & 148,1 & 20,2 & \multirow{2}{*}{0,094} & \multirow{2}{*}{$<0,0001$} & \multirow{2}{*}{ ** } \\
\hline & & $\mathrm{H}$ & 4963 & 76 & 215 & 148,9 & 23,8 & & & \\
\hline & \multirow{2}{*}{ Ribera } & $M$ & 1765 & 120 & 233 & 173,8 & 15,0 & \multirow{2}{*}{0,197} & \multirow{2}{*}{$<0,0001$} & \multirow{2}{*}{ ** } \\
\hline & & $\mathrm{H}$ & 1864 & 120 & 238 & 181,3 & 18,2 & & & \\
\hline & \multirow{2}{*}{ Altamar } & $\mathrm{M}$ & 344 & 130 & 220 & 186,0 & 20,9 & \multirow{2}{*}{0,378} & \multirow{2}{*}{$<0,0001$} & \multirow{2}{*}{ ** } \\
\hline & & $\mathrm{H}$ & 305 & 110 & 240 & 193,8 & 29,9 & & & \\
\hline \multirow{6}{*}{2018} & \multirow{2}{*}{ Bahía } & $M$ & 2870 & 87 & 216 & 145,2 & 21,2 & \multirow{2}{*}{0,172} & \multirow{2}{*}{$<0,0001$} & \multirow{2}{*}{$* *$} \\
\hline & & $\mathrm{H}$ & 4595 & 75 & 230 & 137,1 & 26,7 & & & \\
\hline & \multirow{2}{*}{ Ribera } & M & 931 & 120 & 220 & 169,9 & 19,5 & \multirow{2}{*}{0,107} & \multirow{2}{*}{$<0,0001$} & $t+$ \\
\hline & & $\mathrm{H}$ & 1050 & 130 & 240 & 174,7 & 23,5 & & & n \\
\hline & & $\mathrm{M}$ & 330 & 130 & 225 & 180,8 & 21,5 & ר? & & \\
\hline & & $\mathrm{H}$ & 317 & 140 & 240 & 192,4 & 26,8 & & & \\
\hline
\end{tabular}

**diferencias significativas 

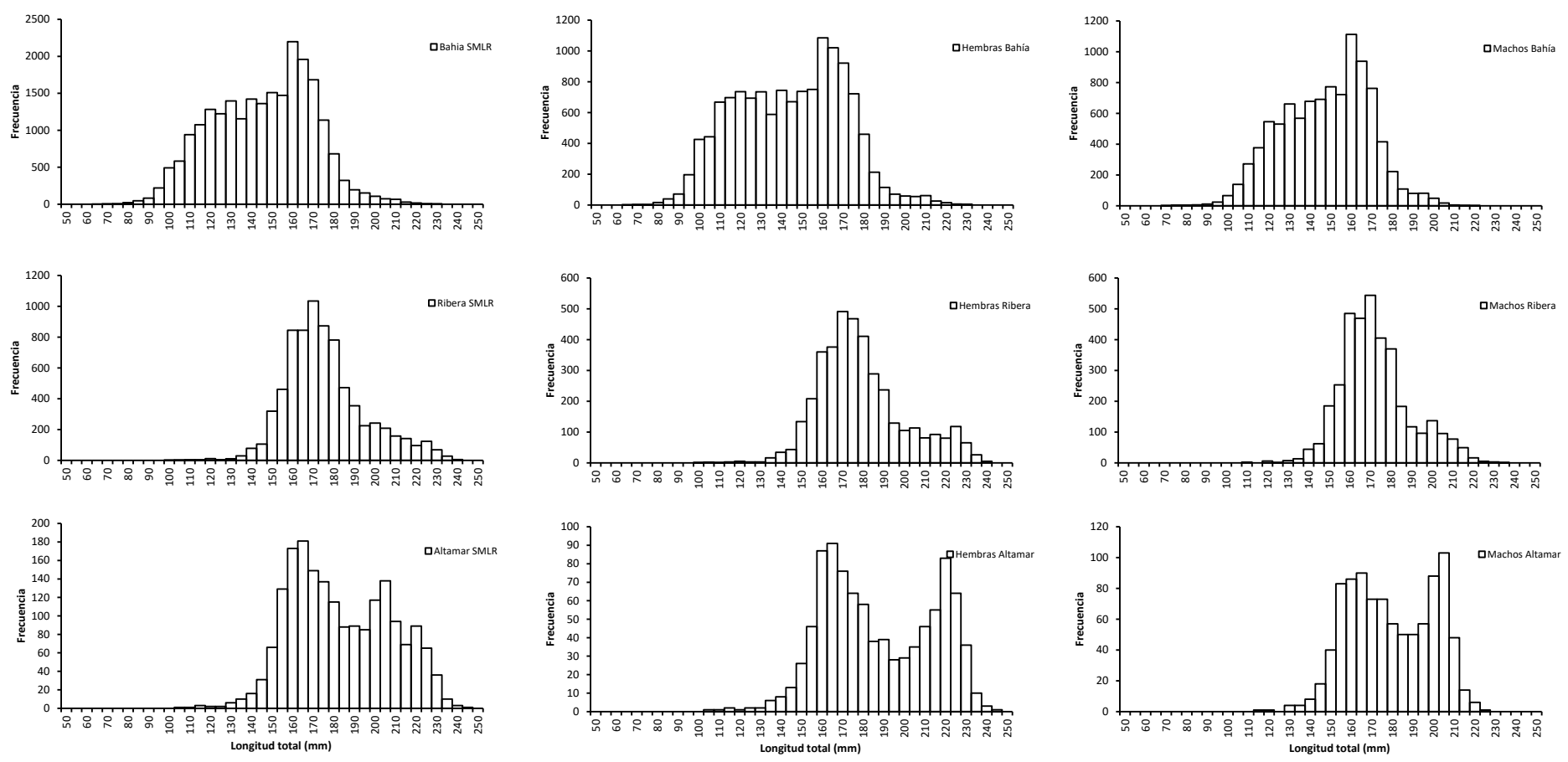

FIGURA 2. Distribución de frecuencia de longitud total (LT) en milímetros $(\mathrm{mm})$ del camarón azul Penaeus stylirostris por zonas (bahía, ribera y altamar) y por sexos entre las temporadas de pesca 2016 - 2018

en la zona de ribera se observó ligeramente el cubrimiento entre dos grupos modales lo que podría ser hembras y machos, los cuales se detectaron en la zona de altamar. Esta distribución de tallas aquí registradas del camarón azul, es posible que puedan ser interpretados como fases del desarrollo de los organismos en bahía y ribera hacia la zona de altamar. Esto fue señalado por Félix-Ortiz y col. [12, 13] quienes indicaron ingresos y salidas de juveniles de camarones comerciales de peneidos de las principales lagunas costeras del Pacífico mexicano.

Al relacionar los datos morfométricos de LT y $\mathrm{PT}$, la ecuación resultante fue tipo potencial, además los valores del coeficiente de determinación $\left(r^{2}\right)$, fueron indicativos del grado de asociación entre ambas variables, es decir, el nivel de dependencia del peso respecto a la longitud del camarón azul en la costa de Sinaloa (TABLA IV).

En análisis biológico-pesquero las biometrías en especies comerciales son de suma importancia para establecer medidas de protección de acuerdo a sus tallas, al correlacionar variables morfométricas entre longitud y peso se obtiene el modelo de tipo potencial [14, 22], coincidiendo en este sentido todas las ecuaciones entre dichas variables de $P$. stylirostris en bahía, ribera y sexo. Además, se obtuvieron coeficientes de determinación $\left(r^{2}\right)$ por encima de 0,94 y por debajo de 0,97, lo que indica una alta dependencia entre las tallas de longitud y peso en $P$. stylirostris. Los valores de la pendiente (b) resultaron por arriba del valor de tres, lo que determina que el camarón azul presenta un tipo de crecimiento alométrico positivo tanto para hembras como machos $(P=0,05)$ en bahía y ribera. Ramos-Cruz y col. [21] en camarón blanco $P$. vannamei por sexos, estimaron un $r^{2}$ mínimo de 0,94 para hembras y de 0.95 en machos. Los resultados aquí de isometría difieren de López-Martínez y col. [15] quienes señalaron en camarón $L$. stylirostris capturado en la pesquería del Golfo de California un crecimiento de tipo isométrico. Mientras en diferentes especies de peneidos comerciales, Rábago-Quiroz y col. [18] estimaron un alto $r^{2}$ entre longitudes y peso por arriba de 0,974 , además estos autores difieren de este estudio al indicar un crecimiento isométrico para todas las especies de camarones comerciales del Pacifico mexicano.

La talla de longitud $\left(\mathrm{LT}_{50 \%}\right)$ de migración del camarón azul entre las zonas de ribera y bahía durante 2016 - 2018 (FIG 3), resultó en

Tabla IV

Relaciones biométricas entre PT-LT, ecuación y coeficiente de determinación $\left(r^{2}\right)$ por zona de captura y sexo en Penaeus stylirostris

\begin{tabular}{ccccc}
\hline Zona & Sexo & $\mathbf{N}$ & Ecuación & $\mathbf{r}^{2}$ \\
\hline Bahía & Ambos & 22918 & PT $=0,000001 \mathrm{LT}^{3.3343}$ & 0,9759 \\
Ribera & Ambos & 7524 & PT $=0,000004 \mathrm{LT}^{3.1221}$ & 0,9516 \\
Bahía & $\mathrm{H}$ & 13047 & $\mathrm{PT}=0,000001 \mathrm{LT}^{3.3324}$ & 0,9788 \\
Bahía & $\mathrm{M}$ & 9863 & $\mathrm{PT}=0,000001 \mathrm{LT}^{3.3347}$ & 0,9693 \\
Ribera & $\mathrm{H}$ & 3899 & $\mathrm{PT}=0,000004 \mathrm{LT}^{3.1199}$ & 0,9569 \\
Ribera & $\mathrm{M}$ & 3627 & $\mathrm{PT}=0,000005 \mathrm{LT}^{3.1167}$ & 0,9400 \\
\hline
\end{tabular}



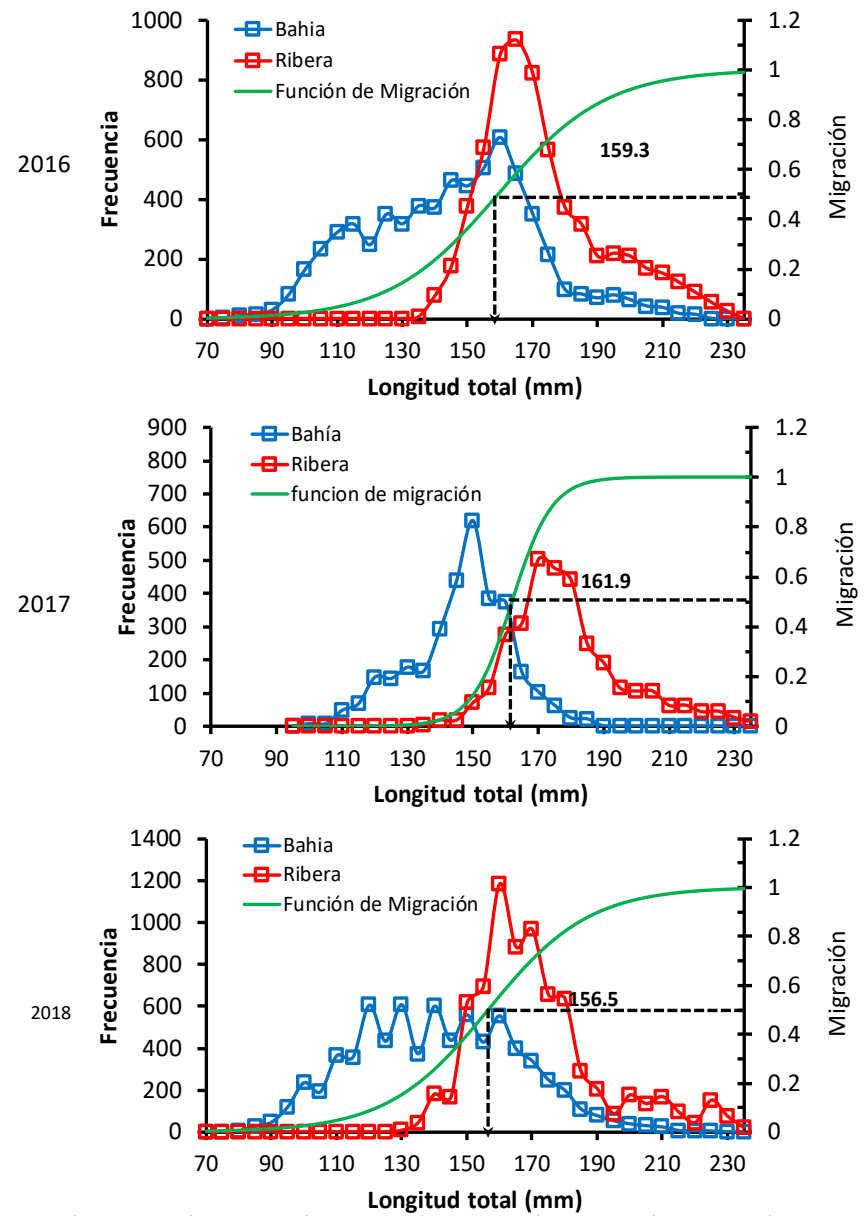

FIGURA 3. Estimación de talla de longitud total $(\mathrm{mm})\left(\mathrm{It}_{50 \%}\right)$ de migración de Penaeus stylirostris en bahía Santa María La Reforma, Sinaloa entre 2016 y 2018

promedio la LT en 159,2 mm, aunque la talla mínima estimada en LT fue 156,5 mm (2018) y la máxima en LT fue 161,9 mm (2017) en $P$. stylirostris para la costa de Sinaloa.

La distribución de tallas de manera general permiten estimar una talla de longitud de migración de $P$. stylirostris entre la zona de bahía, ribera y altamar (mar adentro y la plataforma continental), observándose camarones azules pequeños en $65 \mathrm{~mm}$ (LT) en bahía y posiblemente estos mismos en $105 \mathrm{~mm}$ (LT) en altamar, mientras que los camarones azules grandes en $230 \mathrm{~mm}$ (LT) en bahía, estos posiblemente registraron tallas de $245 \mathrm{~mm}$ (LT) en altamar. Lo que indica que la población de $P$. stylirostris emigró desde la zona de bahía cuando son juveniles y posteriormente como adultos se desplazaron hacía mar adentro y la plataforma continental (altamar).

De acuerdo a Dall y col. [10], el camarón azul presenta su fase adulta o reproductora en hábitat oceánica, las hembras liberan los cigotos al medio (altmar), donde ocurren sus fase larvales, cuando presentan la fase de poslarva, éstas ingresan a los ecosistemas estuarinos (bahía y ribera) para continuar con su crecimiento juvenil y finalmente retornar al océano como preadultos, en este caso, aproximadamente a los $159,2 \mathrm{~mm}$ de LT.

\section{CONCLUSIONES}

En la presente investigación se observó que $P$. stylirostris debido a su estructura de tallas en las zonas y por sexos, se puede determinar que la población se distribuye de acuerdo a sus tallas en la zona de bahía, ribera y altamar, aunque no se descartan que se presenten organismos que coincidan con tallas entre las tres zonas mencionadas. Además, por su abundancia y tallas, el camarón azul representa un interés para consumo alimenticio y económico durante sus fases juvenil y adulta para los pescadores de la costa de Sinaloa.

\section{AGRADECIMIENTO}

Al Consejo Nacional de Ciencia y Tecnología (CONACYT) por la beca otorgada al primer autor (CVU 490690), al programa Camarón del Pacífico CRIAP-Mazatlán y al Instituto Nacional de Acuacultura y Pesca (INAPESCA) por la proporción de datos y al Cuerpo Académico Consolidado Manejo de Recursos Pesqueros (UAS-CA-2104).

\section{REFERENCIAS BIBLIOGRÁFICAS}

[1] ALCÁNTARA-RAZO, E. Índice de producción de huevos, reclutamiento reproductor y distribución de la biomasa de camarón azul Penaeus stylirostris en el frente costero de Agiabampo, Sonora-Sinaloa, México. Centro Interdisciplinario de Ciencias Marinas, Instituto Politécnico Nacional. La Paz, BCS. Tesis de Grado. 75 pp. 2005

[2] ARAGÓN-NORIEGA, E.A. Crecimiento individual de camarón blanco Litopenaeus vannamei y camarón azul Litopenaeus stylirostris (Decapoda: Penaeidae) con un enfoque multimodelo. Latin Ame. J. Aquatic Res. 44 (3): 480-486. 2016.

[3] ARAGÓN-NORIEGA, E.A.; MENDIVIL-MENDOSA, J.E.; ALCÁNTARA-RAZO, E.; VALENZUELA-QUIÑONEZ, W.; FELIX-ORTIZ, A. Multi-criteria, approach to estimate the growth curve in the marine shrimp: Penaeus vannamei (Decapoda, Penaeidae). Crustaceana. 90 (11-12): 15171531. 2016.

[4] ARANCETA-GARZA, F.; ARREGUÍN-SÁNCHEZ, F.; PONCE-DÍAZ, G.; SEIJO, J.C. Natural mortality of three commercial penaeid shrimps (Litopenaeus vannamei, $L$. stylirostris and Farfantepenaeus californiensis) of the Gulf of California using gnomonic time divisions. Scientia Marina. 80 (2): 199-206. 2016.

[5] CARTA NACIONAL PESQUERA (CNP). Acuerdo por el que se da a conocer la Actualización de la Carta Nacional Pesquera 2018. Diario Oficial de la Federación. México, D.F. Junio 11: Pp 27-106. 2018.

[6] CHAPA-SALDAÑA, H. La distribución geográfica de los camarones del Pacífico y el problema de las artes fijas. Escuela Nacional de Ciencias Biológicas, Instituto Politécnico Nacional. Tesis de Grado. 112 pp. 1956.

[7] CHAPA-SALDAÑA, H. El cultivo empírico del camarón en la zona de los tapos como posible solución al problema social pesquero. En: Pesca, Medio Ambiente y Sustentabilidad 
en Sinaloa. Cruz-Torres, M.L.; Morán-Angulo, R.E. (Eds.). Universidad Autónoma de Sinaloa. Pp. 79-94. 2007a.

[8] CHAPA-SALDAÑA, H. Estudio de la pesca artesanal de camarón por artes fijas en Sinaloa y Nayarit. En: Serie Lagunas Costeras de Sinaloa. Páez-Osuna, F. (Ed.). Colegio de Sinaloa e Instituto de Ciencias del Mar y Limnología de la Universidad Autonoma Nacional de México. Pp. 1-106. 2007b.

[9] COMISIÓN NACIONAL DE ACUACULTURA Y PESCA (CONAPESCA). Anuario Estadístico de Acuacultura y Pesca 2013. Dirección General de Planeación, Programación y Evaluación. Dirección de Evaluación y Programas Estratégicos. Secretaría de Agricultura, Ganadería, Desarrollo Rural, Pesca y Alimentación. México, D.F. 299 pp. 2017.

[10] DALL, W.; HILL, B.J.; ROTHLISBERG, P.C.; STAPLES, D.J. Life Histories. The biology of the Penaeidae. (Advances in Marine Biology V 27). Academic Press. London. Pp 283-314. 1990.

[11] DIARIO OFICIAL DE LA FEDERACIÓN (DOF). Ley General de Pesca y Acuacultura Sustentables. Secretaría de Agricultura, Ganadería, Desarrollo Rural, Pesca y Alimentación. Ciudad de México, México. 268 pp. 2018.

[12] FÉLIX-ORTIZ, J.A.; SIU-QUEVEDO, E.; CASTAÑEDALOMAS, N.; RODRÍGUEZ-DOMÍNGUEZ, G.; RODRÍGUEZMONTES DE OCA, G.; ARAGÓN-NORIEGA, E.A. Species composition and timing of peneid shrimp post-larvae (Decapoda: Penaeidae) in the two zones of the Mexican Pacific Coast. Crustaceana. 87 (7): 801-813. 2014.

[13] FÉLIX-ORTIZ, J.A.; ARAGÓN-NORIEGA, E.A.; CASTAÑEDA-LOMAS, N.; VALENZUELA-QUIÑONEZ, W.; SIU-QUEVEDO, E. Effect of tidal hour on the abundance of penaeid shrimp postlarvae (Decapoda, Penaeidae) along the Mexican Pacific coast. Crustaceana. 90 (2): 167-176. 2017.

[14] GUTIÉRREZ-RUBIO Y.; PÉREZ-GONZÁLEZ, R.; CAMPOS, E.; ARZOLA-GONZÁLEZ, J.F. Estructura de tallas y relaciones biométricas del cangrejo roca Grapsus grapsus en las islas Lobos, Venados y Pájaros, Sinaloa, México. Hidrobiol. 28 (1): 31-36. 2018.

[15] LÓPEZ-MARTÍNEZ, J.; RÁBAGO-QUIROZ, C.; NEVÁREZMARTÍNEZ, M.O.; GARCÍA JUÁREZ, A.R.; RIVERA-PARRA, G.; CHÁVEZ-VILLALBA, J. Growth, reproduction, and size at first maturity of blue shrimp, Litopenaeus stylirostris (Stimpson, 1874) along the east coast of the Gulf of California, Mexico. Fisheries Res. 71: 93-102. 2005.
[16] MORÁN-ANGULO, R.E.; FLORES-CAMPAÑA, L.M. La Pesca en Sinaloa: breve historia y búsqueda del episteme. Ra Ximhai. 11 (3): 57-72. 2015.

[17] MUÑOZ-RUBÍ, H.A.; CHÁVEZ HERRERA, D.; VILLEGASHERNÁNDEZ, F. Variación en la abundancia, la reproducción y la estructura de tallas del camarón azul Litopenaeus stylirostris en la bahía de Navachiste, Sinaloa, México. Cienc. Pesq. 27 (1): 9-13. 2019.

[18] RÁBAGO-QUIROZ, C.; ZEPEDA-BENÍTEZ, V.Y.; LÓPEZ-MARTÍNEZ, J.; PADILLA-SERRATO, J. Biometric relationships for commercially important penaeid shrimp species on the east coast of the Gulf of California. Latin Ame. J. Aquatic Res. 47 (4): 716-722. 2019.

[19] RAMÍREZ-ROJO, R.A.; ARAGÓN-NORIEGA, E.A. Ecología de postlarvas de camarón azul (Litopenaeus stylirostris) y camarón café (Farfantepenaeus californiensis) en el Estuario del Rio Colorado. Cien. Mar. 32 (1A): 45-52. 2006.

[20] RAMOS-CRUZ, S. Composición por tallas, edad y crecimiento de Litopenaeus vannamei (Natantia: Penaeidae), en la laguna Mar Muerto Oaxaca-Chiapas, México. Rev. Biol. Trop. 48 (4): 873-882. 2000.

[21] RAMOS-CRUZ, S. Aspectos biológicos y poblacionales del camarón blanco Litopenaeus vannamei (Boone 1931), durante la veda de 2006 en el Golfo de Tehuantepec, México. Oceánides. 27 (1): 11-24. 2012.

[22] RODRÍGUEZ-DOMÍNGUEZ, G.; CASTILLOVARGASMACHUCA, S.G.; PÉREZ-GONZÁLEZ, R.; ARAGÓN-NORIEGA, E. A. Allometry in Callinectes bellicosus (Stimpson, 1859) (Decapoda: Brachyura: Portunidae): singlepower model versus multi-model approach. J. Crust. Biol. 38 (5): 574-578. 2018.

[23] STATSOFT. 2004. Statistics for Windows, Manual ver. 7.0. StatSoft Inc., Tulsa, Oklahoma, USA.

[24] ZAR, J.H. Variance analysis. Biostatistical analysis. PrenticeHall. Upper Saddle River, USA. 960 pp. 2009. 


\title{
Physiological response to thermal stress in hair-sheep ewes during subtropical summer
}

\author{
Indicadores fisiológicos de respuesta al estrés térmico en ovejas de pelo durante el verano \\ subtropical
}

\author{
Javier Alejandro Gómez-Guzmán', José Fernando Vázquez-Armijo², Javier Hernández-Meléndez³, Ana Laura Lara-Rivera ${ }^{4}$ \\ and Gaspar Manuel Parra-Bracamonte ${ }^{1 *}$ \\ ${ }^{1}$ Centro de Biotecnología Genómica, Instituto Politécnico Nacional. México. ${ }^{2}$ Centro Universitario UAEM Temascaltepec, Universidad

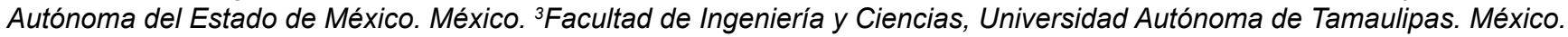 \\ ${ }^{4}$ Facultad de Ciencias Biológicas, Universidad Autónoma de Nuevo León. México. *E-mail: gparra@ipn.mx.
}

\begin{abstract}
With the aim to assess the effect of short-term thermal stress on physiological traits of ewes an experiment was designed. Fourteen hair sheep ewes were selected during early reproductive management and randomly segregated in two groups. Control group (CG) with indoor conditions, and an experimental group (EG) under continuous outdoor conditions without shadow accessing during 14 days (d). Respiratory frequency (RF), rectal temperature (RT) and infrared image temperatures were estimated. Traits were measured for $8 d$ twice a d (9:00 am and 15:00 pm). Environmental temperature and humidity were monitored, and temperature and humidity index was estimated. All physiological and environmental traits showed significantly variation by group and time of measurement $(P<0.001)$. RT and RF were significantly higher for $E G$ and during pm measurements. Environmental conditions indicated thermal stress conditions for outdoor EG during the afternoon was related ultimately with respiratory mechanism as the main indicator of continuous thermal stress. Head infrared image temperature was a good predictor of body temperature.
\end{abstract}

Key words: Heat stress; infrared thermography; respiratory frequency; rectal temperature

\section{RESUMEN}

Con el objetivo de evaluar el efecto a corto plazo del estrés térmico continuo sobre las variables fisiológicas en ovejas, se diseñó un experimento. Catorce ovejas de pelo fueron seleccionadas durante el manejo reproductivo temprano y aleatoriamente segregadas en dos grupos. El grupo Control (CG) con condiciones de sombra y el grupo experimental (EG) en condiciones de exterior sin acceso a sombra durante 14 días (d). La frecuencia respiratoria (FR), temperatura rectal (TR) y temperaturas infrarrojas fueron estimadas. Las variables fueron medidas durante $8 \mathrm{~d}$ dos veces por d (9:00 am and 15:00 pm). La temperatura y humedad ambiental fue monitoreada y el indice de temperatura y humedad fue estimada. Todas las variables mostraron variación significativa por grupo y tiempo de medición $(P<0,001)$. TR y RF fueron significativamente mayores en EG y durante las mediciones en la tarde. Las condiciones ambientales sugieren que el estrés térmico en condiciones exteriores durante la tarde se relaciona más claramente con mecanismo de respiración como principal indicador del estrés térmico a corto plazo. La temperatura infrarroja de la cabeza fue un mejor predictor de temperatura corporal.

Palabras clave: Estrés térmico; frecuencia respiratoria; temperatura rectal; termografía infrarroja 


\section{INTRODUCTION}

Under the global warming scenario, different environments suppose a threat for domestic livestock. Among all the stress conditions, high temperatures are considered the most severe for animal production [4]. Additionally, humidity, radiation, precipitation and wind intensity affect livestock production. Specific weather conditions in particular regions, specifically the air temperature and humidity have direct influence on animal production [1, 23]. The exposure to high temperatures produces significant and drastic changes on biological functions of sheep (Ovis aries), including efficiency in feed use, water metabolism and mineral equilibrium alterations and important consequences in endocrine, metabolite and blood physiology [15].

Animals have a variety of physiological mechanisms for thermolysis, when these mechanisms are not enough to relieve the effect of heat load, body temperature (BT) can rise to the point where animal welfare is compromised [1]. BT is a good measure of heat tolerance in animals, since it is the result of all processes of heat gain and loss in the body. Changes in heart rate (HR), respiratory frequency (RF) and rectal temperature (RT) are the key parameters that indicate the mechanism of physiological adaptation in small ruminants [24]. In environments with heat stress (HS), RF is the first thermoregulation mechanism used by ruminants to help them maintain $\mathrm{BT}$; the panting is a physiological medium recognized as a response to increased environment heat through a substantial increasing in RF [17].

Some studies has assessed the physiological effect of temperature stress on sheep supporting the negative effect on hypothalamus-pituitary-gonads axis [2,21]. Some of these effects are related to the increasing in glucocorticoid level as a stress response stimulating hypothalamus for somatostatin secretion inhibiting growth hormone [11]; additionally, most productive losses in sheep come from a variety of reproductive problems associated thermic stress. In females it directly affects the presence and duration of estrus, displaying low growth of the dominant follicle and reduced concentrations of gonadotropin-releasing and luteinizing hormones, reflected in a lower estrogen synthesis [9].

The corporal temperature observed by different methods such as rectal and thermographic infrared images and RF has been used as indicators of short-term thermic stress in different reproductive and growth stages in sheep [28], but not in early stage of pregnancy. In Pelibuey ewes, the available research indicate that this breed show more effective BT regulation under artificial conditions of environmental hyperthermia [20], less effects on progesterone levels [16] and their embryo percentage apparently is less influenced by artificial hyperthermia [27]. However all these evidences have been assessed under artificial conditions in climate chamber-induced short term hyperthermia but not under natural environment conditions.

The aim of the present study was to estimate the physiological response during early reproductive management of ewes subjected to continuous TS during late summer under exterior management conditions in subtropical late summer, under the hypothesis that, physiological traits of Pelibuey ewes were affected by continuous TS during the studied period.

\section{MATERIALS AND METHODS}

The experiment was conducted during late summer at experimental farm of Facultad de Ingeniería y Ciencias-Universidad Autónoma de Tamaulipas, located in northeast Mexico (2356' N, 9906' W), at 190 meters above sea level. The climate was considered sub-tropical, which is semi-arid and sub-humid, with summer rains and sporadic winter rains. The average annual temperature is $23^{\circ} \mathrm{C}$ with a total annual rainfall of 800 millimeters $(\mathrm{mm})$.

Fourteen hair sheep ewes (2-3 years old and 3-4 body condition score) were treated with an intravaginal sponge impregnated with 20 milligrams $(\mathrm{mg})$ of chronolone (Chronogest $\AA$ CR, Intervet $\AA$ Productions SA, Igoville, France) [22] for 14 days (d). Twenty four hours $(\mathrm{h})$ before sponge withdrawal, 400 international units (IU) of equine chorionic gonadotropin (eCG) (Folligon $®$, Intervet $\circledast$, Boxmeer, Holland) were applied. Ewes in estrus were mated by natural mating around $24 \mathrm{~h}$ after the onset of estrus. After copula, ewes were divided into two groups $(n=7)$. A control group $(C G)$ was managed in a confined system and were kept in roofed pens. A second experimental group (EG) was maintained in a confined system and were kept in unroofed pen from 7:00 am to 7:00 pm, under continuous TS stimulus. Both groups had free access to water and the same isocaloric and iso-protein diet.

The experiment was conducted during eight $d$ of September, measuring twice a d (9:00 am and 15:00 pm) physiological traits of RT and RF; also, BT by infrared images (II), considering the nose, eye, head, back, belly and hip. RT was estimated using a digital thermometer (Neutek MT-201C, Citisalud S.A. de C.V., Mexico). RF, was estimated visually. The II were collected using a Flir 2 camera (Willsonville, Oregon, USA) and processed with Flir Tools software. Complementarily, environmental temperature and humidity were monitored by a hygrothermometer Thermotracker Higro (Culiacan, Sinaloa, México). Configuration of sensors and processing of data will be completed using Thermotracker Pro 3.0 software. Temperature and humidity index (ITH) was computed using the formula described by Mader [14] using the formula \{ITH $=[0.8 \times$ ambient temperature $]+[(\%$ relative humidity $\div 100) \times$ (ambient temperature -14.4$)]+46.4\}$.

All statistical analysis were performed in SAS software ver. 9.0 (Statistical Analysis System, Cary, NC, USA). A mixed model for repeated measures was fitted using the MIXED procedure as:

$$
Y_{i j k}=G_{i}+T_{i}+\beta_{1} I T H_{k}+\varepsilon_{i j k}
$$

Where: Y: physiological and environmental response variables, $G=$ fixed effect of $i$-the group (CG and EG), $T=$ fixed effect of $j$-th time of measurement (am and pm), and the ITH as linear covariate (only for physiological traits). The repeated effect of sheep-day measured adjusted by a Compound Symmetry covariance structure was considered given its best AIC and BIC statistics. Least square means were estimated and compared by a t test with a Tukey adjustment. Pearson correlation coefficients were computed for all variables using the CORR procedure.

\section{RESULTS AND DISCUSSION}

Least square means by group and time of measurement comparison are showed in TABLE I. Both factors were important for all physiological traits evaluated $(P<0.01)$. All temperature estimates (rectal and infrared) were significantly different among 
TABLE I

Effect of the group and the measurement time on physiological traits in hair sheep ewes

\begin{tabular}{ccccc}
\hline \multirow{2}{*}{ Traits } & \multicolumn{2}{c}{ Group } & \multicolumn{2}{c}{ Time } \\
\cline { 2 - 5 } & CG & EG & am & pm \\
\hline RT & $39.34 \pm 0.09 \mathrm{a}$ & $39.65 \pm 0.08 \mathrm{~b}$ & $39.19 \pm 0.12 \mathrm{a}$ & $39.81 \pm 0.10 \mathrm{~b}$ \\
RF & $79.64 \pm 2.65 \mathrm{a}$ & $108.26 \pm 2.22 \mathrm{~b}$ & $67.59 \pm 4.77 \mathrm{a}$ & $120.32 \pm 379 \mathrm{~b}$ \\
Eye & $36.90 \pm 0.32 \mathrm{a}$ & $38.70 \pm 0.26 \mathrm{~b}$ & $36.20 \pm 0.53 \mathrm{a}$ & $39.40 \pm 0.42 \mathrm{~b}$ \\
Nose & $35.77 \pm 0.27 \mathrm{a}$ & $37.36 \pm 0.22 \mathrm{~b}$ & $34.78 \pm 0.48 \mathrm{a}$ & $38.34 \pm 0.37 \mathrm{~b}$ \\
Head & $36.14 \pm 0.43 \mathrm{a}$ & $38.82 \pm 0.37 \mathrm{~b}$ & $35.50 \pm 0.63 \mathrm{a}$ & $39.46 \pm 0.51 \mathrm{~b}$ \\
Belly & $36.25 \pm 0.27 \mathrm{a}$ & $38.47 \pm 0.22 \mathrm{~b}$ & $35.83 \pm 0.49 \mathrm{a}$ & $38.89 \pm 0.38 \mathrm{~b}$ \\
Back & $36.74 \pm 0.63 \mathrm{a}$ & $41.06 \pm 0.53 \mathrm{~b}$ & $36.70 \pm 1.06 \mathrm{a}$ & $41.11 \pm 0.85 \mathrm{~b}$ \\
Hip & $35.89 \pm 0.69 \mathrm{a}$ & $41.14 \pm 0.59 \mathrm{~b}$ & $35.99 \pm 1.11 \mathrm{a}$ & $41.04 \pm 0.90 \mathrm{~b}$ \\
\hline
\end{tabular}

RT: Rectal temperature, ${ }^{\circ} \mathrm{C}, \mathrm{RF}$ : Respiratory frequency, times by minute. CG: Control group.

EG: Experimental group

groups $(P<0.001)$. Temperature indicators showed in general that EG and pm measured ewes had the higher LSmeans. RT showed averaged increasing values of $0.3^{\circ} \mathrm{C}$ for EG compared to $\mathrm{CG}$ and $0.6^{\circ} \mathrm{C}$ during $\mathrm{pm}$. Infrared temperature recording, showed the same pattern or differences, between experimental groups and time of measurement; however, nose had sustained lower temperatures than other corporal sites, with the highest temperatures recorded in ewe back and hip (TABLE I). The most important observed change was in RF; showing a significantly increasing in EG ewes maintained in outdoor conditions, speeding their respirations in almost $30 \%$, and even more during pm measurements (44\%).

Differences in environmental recorded traits prevalent during the experiment in both, experimental groups and time of measurement are presented in TABLE II. Prevalent conditions showed that temperatures during morning measurement in CG were slightly higher than those observed in $E G(P<0.001)$, with higher percentage of humidity for animals maintained under outdoor conditions. However, temperature conditions were consistently higher with almost 10 degrees of difference for outdoor conditions with lower humidity, producing significantly higher ITH estimates (TABLE II).
Correlations among measured indicators are presented in TABLE III. RT showed significant but moderate and low correlations with infrared temperature indicators in CG and significant but low correlations in EG. Interestingly, RF showed moderate to high correlations with infrared temperatures in $C G$, and a significant correlation $(P<0.001)$ of 0.70 with ITH. Conversely, moderate correlations were observer in EG among RF and all infrared temperatures, except with ITH showing a slightly high correlation with ITH $(P<0.001)$. In both, CG and EG, all infrared temperatures were highly correlated $(r>0.7)$. groups. Head infrared temperature showed to be a reliable indicator given its high correlation with all other infrared temperature indicators $(r>0.82)$.

Comfort zone of livestock it is defined as that area with a temperature range, within which the animal can stay without the need to activate its thermal self-regulation mechanisms [3]. The neutral environmental temperature (ET) for sheep was 13 to $31^{\circ} \mathrm{C}$. Therefore, in this study the ET during the morning was not sufficient for the sheep to be under thermal stress; however, in the EG during most of the afternoon an upper difference of $9,2{ }^{\circ} \mathrm{C}$ was observed over the CG with shade availability. Those conditions kept EG ewes in TS during the experiment.

TABLE II

Differences in meteorological parameters between morning and afternoon in both groups sensors during the study

\begin{tabular}{cccc}
\hline Time & Trait & CG & EG \\
\hline \multirow{3}{*}{ am } & Temperature ${ }^{\circ} \mathrm{C}$ & $24.60 \pm 0.27 \mathrm{a}$ & $22.99 \pm 0.25 \mathrm{~b}$ \\
& Humidity $\%$ & $87.64 \pm 0.97 \mathrm{a}$ & $95.06 \pm 0.90 \mathrm{~b}$ \\
& ITH & $75.11 \pm 0.26 \mathrm{a}$ & $73.06 \pm 0.24 \mathrm{~b}$ \\
\cline { 2 - 4 } $\mathrm{pm}$ & Temperature ${ }^{\circ} \mathrm{C}$ & $28.13 \pm 0.18 \mathrm{a}$ & $37.32 \pm 0.16 \mathrm{~b}$ \\
& Humidity $\%$ & $77.72 \pm 0.57 \mathrm{a}$ & $49.24 \pm 0.53 \mathrm{~b}$ \\
& ITH & $79.39 \pm 0.18 \mathrm{a}$ & $87.33 \pm 0.17 \mathrm{~b}$ \\
\hline
\end{tabular}

CG: Control group. EG: Experimental group 
TABLE III

Pearson correlation coefficient among studied physiological traits and ith environmental variable in two assessed groups

\begin{tabular}{|c|c|c|c|c|c|c|c|c|c|}
\hline & RT & $\mathbf{R F}$ & Nose & Eye & Head & Back & Hips & Belly & ITH \\
\hline RT & & $0.51 * * *$ & $0.59 * * *$ & $0.57 * \star \star$ & $0.61 * * *$ & $0.53 * * *$ & $0.53 * * *$ & $0.40 * *$ & $0.29 *$ \\
\hline RF & $0.42 * *$ & & $0.73 * * *$ & $0.73 * * *$ & $0.81 * * *$ & $0.77 * \star *$ & $0.79 * * *$ & $0.79 * * *$ & $0.70 * * *$ \\
\hline Nose & $0.27 *$ & $0.55 * \star \star$ & & $0.85 * * *$ & $0.94 * \star \star$ & $0.84 * * *$ & $0.85 * * *$ & $0.80 * \star \star$ & $0.54^{* * *}$ \\
\hline Eye & 0.36 * & $0.52 * * *$ & $0.79 * * *$ & & $0.89 * * *$ & $0.76 * * *$ & $0.80 * * *$ & $0.73 * * *$ & $0.48 * * *$ \\
\hline Head & 0.36 * & $0.54 * * *$ & $0.82^{* \star *}$ & $0.92 * * *$ & & $0.91 * * *$ & $0.92 * * *$ & $0.88 * * *$ & $0.54^{* \star *}$ \\
\hline Back & $0.41 * *$ & $0.49 * * *$ & $0.65^{* * *}$ & $0.74 * \star \star$ & $0.87 * \star \star$ & & $0.95 * \star \star$ & $0.87 * \star \star$ & $0.46 * *$ \\
\hline Hips & $0.39 *$ & $0.46 * *$ & $0.70 * \star *$ & $0.80 * * *$ & $0.88 * * *$ & $0.89 * \star \star$ & & $0.89 * * *$ & $0.51 * * *$ \\
\hline Belly & 0.36 * & $0.60 * \star \star$ & $0.79 * * *$ & $0.79 * * *$ & $0.84 * * *$ & $0.79 * * *$ & $0.82 * * *$ & & $0.56 * * *$ \\
\hline ITH & 0.17 & $0.72 * * *$ & $0.51 * * *$ & $0.45^{* *}$ & $0.48 * * *$ & $0.43 * *$ & $0.40 *$ & $0.48 * * *$ & \\
\hline
\end{tabular}

Control group: Above diagonal, Experimental group: Below diagonal. RT: Rectal temperature, RF: Respiratory frequency,

ITH, Temperature and humidity index. ${ }^{*} \mathrm{P}<0.05$. $* * \mathrm{P}<0.010$. $* * * \mathrm{P}<0.001$

Some indices have been developed to assess TS. The most common empirical model of heat load is the ITH, which is a combination of temperature and humidity effects in a single value associated with the heat load level and has been used to assess stress [23]. It is established that an ITH of 74 or less is considered normal, 75 to 78 corresponds to an alert stage, 79 to 83 to a danger stage and an ITH equal to or greater than 84 is an emergency [14]. Under these parameters, outdoor EG ewes were borderline a normal and under an ITH above normal and the shadow group was close to being in alert stage. It is considered that due to the decrease in humidity in the CG the temperature is greater and that is enough for the ITH to increase in this group. It is known that according to environmental principles, these variables are inversely proportional [26]. However, the environmental conditions (EC) during afternoon resulted in an ITH which might be dangerous for ewes.

An increase in RT is considered a good indicator of TS in animals. Significant increases in RT associated to ITH during the summer indicate that the animals were in conditions of thermal stress [19]. The EC that were presented in this study allowed to suggest that the increase in RT within both groups was directly related to the increase in ET and ITH. In addition, under the condition of the present study, the significant increase in RT was observed in the EG over the CG; this increase is due to the lack of the body's ability to maintain its thermal equilibrium [6]. Macías et al. [12] reported that in non-lactating ewes the differences in RT increase over the course of the $\mathrm{d}$, being smaller in the morning and greater in the afternoon during the summer season. Similarly, in the study by Silva et al. [26], significant effects of higher RT values were observed in the hottest $h$ of the $d$ which is consistent with the present values observed in both groups during the afternoon.

In the other hand, regarding RF, the criteria for co-monitoring RF as an indicator of stress range from $<61-80$ breaths/minute ( $\mathrm{min}$ ) for medium-high stress and 81-120 breaths/min for high stress [25]. Under this criterion, in the present study the CG presented medium high stress levels and the EG a high stress; the same result can be observed by the time of measurement, since in the morning ewes were in medium high stress and in the afternoon at a high stress level. It is known that sheep that are exposed to high ambient temperatures increase their efforts to dissipate body heat, resulting in an increase in RF [7]. In the present study it was observed that the increase in the ET and ITH during morning and afternoon caused the ewes to present significant increase in the RF, which shows the importance of RF as a mechanism of heat loss in small ruminants. Macias et al. [12] reported that in non-lactating females differences in RF increased during the warmer $h$ during the $d$ due to the activation of mechanisms for heat loss.

For the estimation of animal heat tolerance, RT and RF are the best physiological variables. However, the assessment of adaptability can be complemented with variables such as heart rate and surface temperature [5]. It has also been observed that thermographic evaluation surveys in sheep can adequately assess temperature gradients and identify breeds that have better heat tolerance [10]. Given to a high correlation between environmental indices and sheep surface temperature, the importance of establishing indicative values of thermal discomfort to adopt measures to mitigate thermal stress and not compromise the productive performance has been stated [23]. In the present assessment, the temperature on the hair surface shows significant differences within both groups and time of measurement; this agrees well to the results by Macias et al. [13] reporting lower BT during the mornings and higher at noon. This is because the variation in temperature in animals is influenced by the oscillation of the ambient temperature during the $d$ [18]. In this study, higher temperatures were obtained on the surface of the animal in the EG, which was directly exposed to solar irradiation unlike the group that had access to the shade in the hottest $h$ of the $d$. Solar radiation together with a high ambient temperature is considered to be an important factor for the increase in the temperature of the animal surface. This is due to vasodilation caused by blood capillaries, which increase blood flow to the surface of the animal as a way of 
heat dissipation [8]. In addition, it was observed that within the CG the surface temperature was lower than the RT, which is consistent with that reported by Piccione et al. [26]. Most importantly, the present results showed that within the $E G$, the head temperature showed a moderate correlation RF and ITH $(r \approx 0,50)$, maintaining a high correlation with the other infrared temperature indicators, which can serve as non-invasive means to detect the presence of TS within the flock.

Although it was not possible to assess the punctual effect of continuous TS on reproductive performance of the studied ewes, the results suggest through the physiological traits that some possible effects would be expected. Previous studies in Pelibuey breed have assessed the effect of chamber-induced short term hyperthermia on some reproductive traits. These available research indicate that this breed show more effective BT regulation under artificial conditions of environmental hyperthermia [20], has less effects on progesterone levels during gestational period [16] and that its embryo development percentage apparently is less influenced by artificial hyperthermia [27]. However since these evidences have been assessed under artificial conditions did not allow to fully understand the magnitude of real environmental hyperthermia on ewes performance.

\section{CONCLUSIONS}

Results showed that continuous environmental TS has important effects on physiological traits of Pelibuey ewes during late summer. The main effects of this continuous short-term TS are more observed in RF and BT. Increasing the RF was the best mechanism for heat removal for the ewes during the present study. It also establishes the use of novel methods such as thermal infrared imaging as non-invasive effective was of detection of TS. Finally, the importance of roofed facilities to avoid heat loading in animals was considered, since it was observed that the experimental group presented TS conditions that could possibly damage its production and reproduction.

\section{ACKNOWLEDGEMENTS}

Authors want to thank the Instituto Politécnico Nacional (SIP20195038) and Universidad Autónoma del Estado de México (4766/2019CIB) for the financial support to this study. Fisrt author acknowledges the scholarship granted by the Consejo Nacional de Ciencia y Tecnología-CONACYT, Mexico.

\section{BIBLIOGRAPHIC REFERENCES}

[1] BERIHULAY, H.; ABIED, A.; HE, X.; JIANG, L.; MA, Y. Adaptation Mechanisms of Small Ruminants to Environmental Heat Stress. Anim. 9:75. 2019.

[2] BERNABUCCI, U; LACETERA, N.; BAUMGARD, L.H.; RHOADS, R.P.; RONCHI, B.; NARDONE, A. Metabolic and hormonal acclimation to heat stress in domesticated ruminants. Anim. 4:1167-1183. 2010.

[3] CEDEÑO, A.J.R. Efecto del estrés calórico en el bienestar animal, una revisión en tiempo de cambio climático. Rev. Espamcien. 2(1):15-25. 2011.

[4] DANGI, S.S.; GUPTA, M.; DANGI, S.K.; CHOUHAN, V.S.; MAURYA, V.P.; KUMAR, P.; SINGH, G.; SARKAR, M.
Expression of HSPs: an adaptive mechanism during long-term heat stress in goats (Capra hircus). Int. J. Biomet. 59:10951106. 2015.

[5] DANTAS, N.L.B.; DE SOUZA, B.B.; DA SILVA, M.R.; DE ASSIS-SILVA, G.; DA SILVA-PIRES, J.P.; BATISTA, L.F.; FREITAS, M.; FURTADO, D.A. Effect of the environment and diet on the physiological variables of sheep in the Brazilian semi-arid region. Semin. Ciên. Agrár. 40:971-980. 2019.

[6] DE, K.; KUMAR, D.; BALAGANUR, K.; SAXENA, V.K.; THIRUMURUGAN, P.; NAQVI, S.M.K. Effect of thermal exposure on physiological adaptability and seminal attributes of rams under semi-arid environment. J. Therm. Biol. 65:113118. 2017.

[7] DE, K.; KUMAR, D.; SAXENA, V.K.; NAQVI, S.M.K. Study of circadian rhythmicity of physiological response and skin temperature of sheep during summer and winter in semi-arid tropical environment. Physiol. Behavior. 169:16-21. 2017.

[8] DE, K.; SAXENA, V.K.; KUMAR, D.; MOHAPATRA, A.; BALAGNUR, K.; NAQVI, S.M.K. Oscillatory thermo-regulatory behavior of fecundity-gene-introgressed sheep in the hot semi-arid region. J. Vet. Behavior. 33: 75-80. 2019.

[9] GASTELUM-DELGADO, M.A.; AVENDAÑO-REYES, L.; ÁLVAREZ-VALENZUELA, F.D.; CORREA-CALDERÓN, A.; MEZA-HERRERA, C.A.; MELLADO, M.; MACÍAS-CRUZ, $U$. Conducta estral circanual en ovejas Pelibuey bajo condiciones áridas del noroeste de México. Rev. Mex. Cien. Pec. 6:109-118. 2015.

[10] JÚNIOR, C.C.; LUCCI, C.M.; PERIPOLLI, V.; TANURE, C.B.; RIBEIRO, L.M.C.S.; BARBOSA, T.M.; RAMOS, A.F.; LOUVANDINI, H.; MCMANUS, C. Laser and thermographic infrared temperatures associated with heat tolerance in adult rams. Small Rumin. Res. 132:86-91. 2015.

[11] KUMAR, B.; MANUJA, A.; AICH, P. Stress and its impact on farm animals. Front. BioSci. 4:1759-1767. 2012.

[12] MACÍAS-CRUZ, U.; CORREA-CALDERÓN, A.; MELLADO, M.; MEZA-HERRERA, C.A.; ARÉCHIGA, C.F.; AVENDAÑOREYES, L. Thermoregulatory response to outdoor heat stress of hair sheep females at different physiological state. Int. J. Biometeor. 62(12): 2151-2160. 2018.

[13] MACÍAS-CRUZ, U.; GASTÉLUM, M.A.; AVENDAÑO-REYES, L.; CORREA-CALDERÓN, A.; MELLADO, M.; CHAYCANUL, A.; ARECHIGA, C.F. Variaciones en las respuestas termoregulatorias de ovejas de pelo durante los meses de verano en un clima desértico. Rev. Mex. Cien. Pec. 9:738753. 2018.

[14] MADER, T.L.; DAVIS, M.S.; BROWN-BRANDL, T. Environmental factors influencing heat stress in feedlot cattle. J. Anim. Sci. 84:712-719. 2006.

[15] MARAI, I.F.M.; EL-DARAWANY, A.A.; FADIEL, A.; ABDELHAFEZ, M.A.M. Reproductive performance traits as affected by heat stress and its alleviation in sheep. Trop. Subtrop. Agroecosyst. 8(3):209-234. 2018. 
[16] MENDOZA, M. R.; MONTALDO, H. H.; SÁNCHEZ, J. A. B.; MENDOZA, J. H. C. R.; CERÓN, J. H. Serum progesterone levels in Pelibuey and Suffolk ewes under thermal stress. Vet. Méx. 40: 197-202. 2009.

[17] NEJAD, J.G.; SUNG, K.I. Behavioral and physiological changes during heat stress in Corriedale ewes exposed to water deprivation. J. Anim. Sci. Technol. 59(1): 13. 2017.

[18] PICCIONE, G.; GIANESELLA, M.; MORGANTE, M.; REFINETTI, R. Daily rhythmicity of core and surface temperatures of sheep kept under thermoneutrality or in the cold. Res. Vet. Sci. 95:261-265. 2013.

[19] RATHWA, S.D.; VASAVA, A.A.; PATHAN, M.M.; MADHIRA, S.P.; PATEL, Y.G.; PANDE, A.M. Effect of season on physiological, biochemical, hormonal, and oxidative stress parameters of indigenous sheep. Vet. World 10:650. 2017.

[20 ]ROMERO, R. D.; PARDO, A. M.; MONTALDO, H. H.; RODRÍGUEZ, A. D.; CERÓN, J. H. Differences in body temperature, cell viability, and HSP-70 concentrations between Pelibuey and Suffolk sheep under heat stress. Trop. Anim. Health Prod. 45: 1691-1696. 2013.

[21] ROMO-BARRON, C.B.; DIAZ, D.; PORTILLO-LOERA, J.J.; ROMO-RUBIO, J.A.; JIMENEZ-TREJO, F.; MONTEROPARDO, A. Impact of heat stress on the reproductive performance and physiology of ewes: a systematic review and meta-analyses. Int. J. Biometeor. 63:1-14. 2019.

[22] SCUDAMORE, C.L. Intravaginal sponge insertion technique. Vet. Rec. 123: 554. 1988.
[23] SEIXAS, L.; DE MELO, C.B.; TANURE, C.B.; PERIPOLLI, V.; MCMANUS, C. Heat tolerance in Brazilian hair sheep. Asian-Austral. J. Anim. Sci. 30:593. 2017.

[24] SEJIAN, V.; KUMAR, D.; GAUGHAN, J.B.; NAQVI, S.M. Effect of multiple environmental stressors on the adaptive capability of Malpura rams based on physiological responses in a semiarid tropical environment. J. Vet. Behav. 17:6-13. 2017.

[25] SILANIKOVE, N. Effects of heat stress on the welfare of extensively managed domestic ruminants. Livest. Prod. Sci. 6: 1-18. 2008.

[26] SILVA, A.L.; SANTANA, M.; SOUSA, P.; ALMEIDA-JÚNIOR, T.F.; FARIAS, L.; SOUSA-JÚNIOR, S.C. Avaliação das variáveis fisiológicas de ovinos Santa Inês sob influência do ambiente semiárido piauiense. J. Anim. Behav. Biometeor. 3: 69-72. 2015.

[27] TABAREZ-ROJAS, A.; PORRAS-ALMERAYA, A.; VAQUERAHUERTA, H.; HERNÁNDEZ-IGNACIO, J.; VALENCIA, J.; ROJAS-MAYA, S.; HERNÁNDEZ-CERÓN, J. Desarrollo embrionario en ovejas Pelibuey y Suffolk en condiciones de estrés calórico. AgroCien. 43: 671-680. 2009.

[28] VICENTE-PÉREZ, R.; MACÍAS-CRUZ, U.; AVENDAÑOREYES, L.; CORREA-CALDERÓN, A.; LUNA-PALOMERA, C.; CHAY-CANUL, A.J. Relación de temperatura rectal y frecuencia respiratoria con temperaturas de pelo obtenidas por termografía en ovejas gestantes estresadas por calor. ITEA 115: 219-230. 2019. 


\title{
Eficiencia en la producción porcina en países de Europa. Casos de Dinamarca y Polonia
}

\author{
Efficiency in swine production in European countries. Cases of Denmark and Poland
}

\author{
Juan Cabas-Monje ${ }^{1 *}$, Luis Améstica-Rivas², Jonathan Labra-Hernández², Bouali Guesmi ${ }^{3}$ y José María Gil ${ }^{3}$ \\ ${ }^{1}$ Facultad de Ciencias Empresariales, Departamento de Gestión Empresarial, Grupo de Investigación en Agronegocios, Universidad \\ del Bío-Bío. Región de Nuble, Chile. ${ }^{2}$ Facultad de Ciencias Empresariales, Departamento de Gestión Empresarial, Universidad del \\ Bío-Bío. Región de Ñuble, Chile. ${ }^{3}$ Center for Agro-Food Economics and Development (CREDA-UPC-IRTA). Castelldefels, España. \\ *Correo electrónico: jcabas@ubiobio.cl
}

\begin{abstract}
RESUMEN
La carne de cerdo $(\mathrm{CdC})$ es el segundo tipo de carne producido en el mundo, siendo Europa la segunda región en importancia productiva después de Asia. Dentro del mercado europeo de CdC, Dinamarca y Polonia son dos actores relevantes que presentan algunas diferencias en sus sistemas productivos (SP). El objetivo fue estudiar las variables que explican el comportamiento de la producción de carne porcina y la eficiencia técnica relativa de los SP tomando en cuenta las diferencias en los sistemas. Se utilizó modelos de frontera estocástica de producción del tipo Translog, para muestras de productores porcinos en el periodo 2010-2015. Los resultados indican que las muestras de productores de ambos países presentan niveles de eficiencia altos, con valores de 0,899 y 0,859 para Dinamarca y Polonia, respectivamente. Los factores más importantes que explican la producción de cerdos son los alimentos y el capital. Además, Polonia presenta crecimiento tecnológico significativo en el periodo estudiado sin mostrar cambios en la eficiencia, mientras que, Dinamarca no presenta progreso tecnológico y adicionalmente muestra una baja en la eficiencia técnica relativa en el periodo.
\end{abstract}

Palabras clave: Eficiencia técnica; frontera estocástica; producción porcina

\begin{abstract}
Pork is the second type of meat produced in the world, with Europe being the second most important Region after Asia. Within the European pork meat market, Denmark and Poland are two relevant players with some differences in their production systems (PS). The objective of this research was to study the variables that explain the behavior of pig meat production and the relative technical efficiency of the PS, taking into account the differences in the systems. Stochastic production frontier models of the Translog type were used for samples of swine producers in the period 20102015. The results indicate that the samples of producers from both Countries present high levels of efficiency, with values of 0.899 and 0.859 for Denmark and Poland, respectively. The most important factors that explain pig production are food and capital. In addition, Poland presents significant technological growth in the period without changes in efficiency, while Denmark does not present significant technological progress and a decrease in relative technical efficiency in the period.
\end{abstract}

Key words: Technical efficiency; stochastic frontier; pig production 


\section{INTRODUCCIÓN}

La CdC (Sus scrofa domestica) es el segundo tipo de carne más producida en el mundo tras la carne de ave, con un pronóstico de una producción de 101 millones de toneladas (Mill Ton) para el año 2020, abarcando con ello aproximadamente el $30 \%$ de la producción mundial de carne. Europa es la segunda región de mayor producción de carne porcina a nivel mundial, después de Asia, concentrando el 27,1\% del mercado global [15]. La producción en Europa es liderada por Alemania con un total de $21,9 \%$ de la producción de la Comunidad Europea (CE), seguida por España con el 19,5 \% y Francia con el 9,2 \%. Polonia es el cuarto mayor productor en la región con un 8,3 \% de la producción del año 2019, mientras que, Dinamarca está en el sexto lugar con un $6,3 \%$ [25].

Dinamarca y Polonia, además de ser importantes en el mercado de carne porcina presentan ciertas características particulares en su sistema productivo (SP) y comercializador, que resulta de interés estudiarlo. En Dinamarca, la industria porcina desempeña un papel relevante en la economía local, donde más del $90 \%$ de su producción se exporta a 120 mercados de todo el mundo, esto representa más del $19 \%$ del total de productos alimentarios exportados [11]. Si se consideran los valores productivos en términos per-cápita, Dinamarca es la mayor potencia en el mundo. Lidera en rendimiento por lechones destetados por cada cerda en reproducción al año(a) y tiene un SP con el más avanzado desarrollo tecnológico, bajo estricta legislación ambiental y sanitaria, y concentrado principalmente en grandes explotaciones. Tiene una estructura cooperativa, en la que los criadores son propietarios de la producción, los mataderos y las empresas de elaboración de alimentos. Es decir, presentan una estructura totalmente integrada [14].

Polonia ha experimentado cambios estructurales importantes en las últimas dos décadas, aumentando la concentración de la producción en granjas de mayor tamaño. Pero, en comparación con otros países de la Unión Europea, la producción sigue presentando una estructura muy fragmentada, con escalas de producción muy bajas, lo que lleva a importar grandes cantidades de lechones para la cría y carne principalmente desde Dinamarca. A lo anterior, se suma el hecho de una integración vertical y horizontal poco desarrollada, con escasa colaboración entre productores de cerdos y procesadores de carne [19, 26].

Aún cuando Polonia incrementó su participación en el mercado europeo, pasando del 7,8 \% en 2010 a 8,3 \% en 2019, Dinamarca la disminuyó de un $7,5 \%$ a un $6,3 \%$ en 2019 . Se considera a Dinamarca como un referente mundial en términos de su SP y en su estructura cooperativa, y a Polonia como un país que debe mejorar para alcanzar niveles de desarrollo superiores [25].

Como una forma de profundizar en el conocimiento de los SP de cerdos de ambos países, esta investigación tuvo como propósito estudiar las variables que explican el comportamiento de la producción de carne porcina y la eficiencia técnica relativa de los SP, de tal manera de contribuir a la discusión sobre la eficiencia técnica en la producción porcina, considerando que la literatura en este tema es escasa y donde en las estimaciones se han utilizado, tanto las aproximaciones paramétricas de frontera estocástica [17, 18, 30, 31], como no paramétricas (Análisis Envolvente de Datos, DEA) [7] y Análisis de Eficiencia Multidireccional (MEA) [23]. Es decir, la eficiencia técnica se debe entender como la capacidad de la empresa para utilizar de mejor forma posible los recursos disponibles para alcanzar un determinado nivel de producción [13]. En particular, se quiere determinar la relevancia de los factores productivos como trabajo, capital, alimento, costos de insumos y progreso tecnológico en la producción porcina en ambos países, así como el nivel de eficiencia de los productores y su evolución en el tiempo.

\section{MATERIALES Y MÉTODOS}

\section{Producción de carne de cerdo}

La producción de CdC es la segunda a nivel mundial después de la producción de carne de ave. En el año 2018, la producción total de carne alcanzó los 342,2 Mill Ton, de las cuales, 127,3 Mill Ton correspondió a carne de ave y 120,9 Mill Ton fueron de CdC [15]. En tercer lugar, está la producción de carne bovina (Bos taurus) y en cuarto lugar la producción de ovino (Ovis aries). Es importante mencionar que, las estimaciones realizadas por la Organización de las Naciones Unidas para la Alimentación y la Agricultura (FAO) señalan que por segundo año consecutivo, la producción mundial de carne caerá, alcanzando 333 Mill Ton en el año 2020, lo que corresponde a un 1,7 \% menos que la estimación del año 2019 [15]. Una explicación de esto sería la fuerte caída en la producción de carne porcina, concentrada principalmente en los países asiáticos afectados por la peste porcina africana [15].

Por otra parte, la expansión de la producción de carne ha sido afectada negativamente por la pandemia del COVID-19, que ha impactado a la sociedad mundial. Los efectos de la crisis sanitaria y económica han repercutido, tanto en la oferta como en la demanda de productos cárnicos. Los consumidores están evaluando sus prácticas de compra y consumo de carne poniendo cada vez más atención a los temas de salud, seguridad alimentaria, sustentabilidad, confianza y valor. El desempleo, la recesión económica y la disminución de la actividad de hotelería y restauración ha afectado directamente la compra de carne. A lo anterior se suma el distanciamiento social, el cierre de los mercados locales y la escasez de trabajadores en los mataderos y las plantas procesadores ha influido negativamente en la cadena de elaboración y en los niveles de producción [15].

Asia fue la región con mayor producción de CdC, abarcando el $49,6 \%$ de la producción mundial según una estimación de FAO [15]. China es el principal país productor con un total de 43.447 Mill Ton para el año 2019. Europa es la segunda región de mayor producción de carne porcina a nivel mundial, concentrando el $27,1 \%$ del mercado global. Esta producción es liderada por los países de la Unión Europea junto al Reino Unido. No obstante, dado los cambios experimentados en el mercado de la carne derivados del COVID-19, se proyecta para el año 2020 que la producción asiática disminuirá en cerca de 9.000 Mill Ton [15].

Respecto a producción de CdC para los países de la Unión Europea (incluido Reino Unido), Alemania corresponde al principal país productor de CdC en el año 2019 con un total de 21,9\% de la producción de la Comunidad Europea (CE), seguida por España con el $19,5 \%$ y Francia con el 9,2 \%. Polonia es el cuarto mayor productor en la región con un 8,3 \%, mientras que, Dinamarca está en el sexto lugar con un 6,3\%. Polonia ha incrementado su participación en el mercado regional pasando del 7,8 \% en 2010 al 8,3 \% en 2019. Por el contrario, Dinamarca ha disminuido 
su participación en la producción de CdC en la Unión Europea pasando de un 7,5 a un $6,3 \%$ en 2019 [25].

\section{Eficiencia en la producción}

En el estudio de eficiencia existen diversas metodologías que permiten analizar el SP. Farrell [13] fue un pionero en este campo y a partir de su trabajo se han diseñado nuevas herramientas de análisis, entre ellas destacan el Análisis Envolvente de Datos (Data Envelopment Analysis, DEA por su sigla en inglés) como una aproximación no paramétrica [8], su modificación denominada Análisis de Eficiencia Multidireccional (Multidirectional efficiency analysis, MEA por su sigla en inglés) [2] o el Análisis de Fronteras Estocásticas (Stochastic Frontier Analysis, SFA por su sigla en inglés), en el cual se suele utilizar una forma funcional del tipo CobbDouglas y una metodología de estimación de Máxima Verosimilitud (MV) para medir la eficiencia [20, 27] o una especificación del tipo Translog con el método de MV [6], presentando ambos métodos (DEA y SFA) fortalezas y debilidades [5, 32].

En el ámbito de la investigación en producción de carne, por medio de una aproximación no paramétrica (DEA) se mide la eficiencia en la producción de porcinos y aves de engorde en el sector ganadero de Valencia, España [7]. El estudio concluye que las granjas de la comunidad Valenciana tienen un potencial significativo de mejora en ambos rubros, constatando que solo un $5,1 \%$ de las granjas de producción de cerdo son completamente eficientes.

En tanto, en una investigación para estudiar la eficiencia técnica en la producción de cerdo en Suecia se utilizó el análisis multidireccional [23]. Este estudio se centró en el proceso de producción dividido en las fases de: i) lechón, ii) crecimientofinalización y iii) finalización-parto, enfocándose en la eficiencia técnica de cada una de las entradas y salidas identificadas. Los resultados indican que las variables de instrucciones escritas para alimentación en la etapa de crecimiento-finalización y finalización-parto, así como las instrucciones escritas para prevenir enfermedades infecciosas en lechones, constituyen las variables con mayor contribución a la eficiencia técnica en producción de cerdos.

Por otra parte, en Nigeria utilizan una función de producción de frontera estocástica para estudiar la producción de cerdo [31]. En esta investigación se emplean variables de producción y características de los productores para estimar sus efectos en el SP. Los resultados muestran que la educación del productor contribuye positivamente a la eficiencia. Así también variables como insumos, mano de obra, medicamentos y vacunas tienen efectos positivos significativos en la producción, alcanzando una eficiencia técnica media de 0,97.

\section{Frontera estocástica de producción}

A fin de capturar los shocks exógenos que afectan a una empresa e identificar los errores de medición que pueden producirse, surge el modelo de frontera estocástica (MFE) de producción o modelo de error compuesto, el cual es una técnica estadística para estimar parámetros [1,24], en los que el error está compuesto de dos partes: i) un componente simétrico que captura los errores de medición además de los shocks externos, permitiendo una variación estocásticas, y ii) un componente unilateral que captura la ineficiencia [16].
La descripción del MFE junto con ejemplos aplicados en agricultura pueden ser encontrados en varios trabajos [10, 21, 22]. Un número considerable de estos estudios empíricos en agricultura emplean un SFA con forma funcional Cobb-Douglas, no obstante, también se puede suponer otra forma funcional como CES o elasticidad de sustitución, translogarítmica, entre otras.

La frontera estocástica de producción (FEP) está definida en la ecuación (1):

$$
\begin{aligned}
& Y_{i}=f\left(X_{i} ; \beta\right) e^{v-u} \\
& \text { Donde } v \sim N\left(0, \sigma_{v}^{2}\right), u \sim N^{+}\left(0, \sigma_{u}^{2}\right), i=1,2, \ldots, n .
\end{aligned}
$$

En la ecuación (1) $Y_{i}$ es la producción de CdC de cada individuo $i, X_{i}$ es el vector de insumos del productor $i, \beta$ son los parámetros de factores estimados. La función de producción es creciente y obligatoriamente cóncava, y si la producción real se desvía de la teóricamente posible, $-u \leq 0$ explica la ineficiencia técnica y $v$ explica el ruido estadístico, ambos independientes entre sí. Sí $u=0$ la unidad de estudio es eficiente, mientras que si $-u<0$ entonces existe ineficiencia y su distribución se asume semi-normal, truncada en 0 con una distribución concentrada en el semi-intervalo [0,infinito] [1, 5, 10, 24].

El método de máxima verosimilitud se propone para la estimación simultánea de los parámetros de la frontera estocástica y el modelo de ineficiencia. Los parámetros de varianza de la función de máxima verosimilitud son estimados a partir del modelo de varianza definido como $\sigma_{s}^{2}=\sigma_{v}^{2}+\sigma_{u}^{2}$, insumo para determinar el parámetro $\gamma=\frac{\sigma_{u}^{2}}{\sigma_{v}^{2}}$,el cual considera la proporción de la varianza total que es explicado por la varianza de las ineficiencias y considera valores entre 0 y 1 , en su descripción además se considera el parámetro $\lambda=\sqrt{\frac{\sigma_{u}^{2}}{\sigma_{v}^{2}}}$ que da una relación entre las varianzas componentes del error .

La eficiencia técnica (ET) puede ser medida a través de cociente entre la producción observada versus la FEP, como muestra la ecuación (2):

$$
E T=\frac{y}{f(x) e^{v}}=\frac{f(x) e^{-u} e^{v}}{f(x) e^{v}}=e^{-u}
$$

\section{Eficiencia con datos de panel y cambios en el tiempo}

Henningsen [17], siguendo el modelo desarrollado por Battese y Coelli [3], plantea que la función de frontera de producción con cambio tecnológico se puede estimar de diferentes maneras, sin embargo, todas derivan de la ecuación (3) que corresponde a su fórmula general

$$
\ln y_{k t}=\ln f\left(x_{k t}, t\right)-u_{k t}+v_{k t}
$$

donde el subíndice $k=1, \ldots, K$ indica la empresa, $t=1, \ldots, T$ indica el periodo de tiempo, y las otras variables son definidas como se mencionaron previamente. De esto se pueden obtener tres variantes que se especifican a continuación:

1.- Eficiencias individuales invariantes en el tiempo (timeinvariant), es decir, $u_{k t}=u_{k}$, lo que significa que cada empresa tiene una eficiencia fija individual que no varía en el tiempo;

2.- Eficiencias individuales variables en el tiempo (time-variant), es decir, $u_{k t}=u_{k} \exp (-\eta(t-T))$, lo que significa que cada empresa tiene una eficiencia individual y los términos de eficiencia 
de todas las empresas puede variar con el tiempo con la misma tasa (y en la misma dirección); y

3.- Eficiencias específicas de la observación, es decir, sin restricciones sobre $u_{k t}$, lo que significa que el término de eficiencia de cada observación se estima independientemente de las otras eficiencias de la empresa, de modo que básicamente se ignora la estructura de panel de los datos.

De tal forma, en esta investigación se utilizó una aproximación paramétrica de FEP para datos de panel de segunda generación, desarrollados por Battese y Coelli $[3,4]$ que se muestra en la ecuación (4) para estudiar la eficiencia en la producción de CdC en Polonia y Dinamarca. La estimación de los parámetros se realiza utilizando "Frontier Package 1.1-8" en R versión 3.6.3 [9, 28].

$$
\begin{aligned}
& \ln y_{k t}=\beta_{0}+\beta_{1} \ln \left(\text { feed }_{k t}\right)+\beta_{2} \ln \left(o i_{k t}\right)+\beta_{3} \ln \left(\operatorname{labor}_{k t}\right)+\beta_{4} \ln \left(\operatorname{cap1}_{k t}\right) \\
& +\beta_{5} \ln \left(\operatorname{cap} 2_{k t}\right)+\beta_{6} m \text { Year }+\beta_{11}\left(\ln \left(\text { feed }_{k t}\right)\right)^{2} / 2 \\
& +\beta_{22}\left(\ln \left(\text { oi }_{k t}\right)\right)^{2} / 2+\beta_{33}\left(\ln \left(\text { labor }_{k t}\right)\right)^{2} / 2 \\
& +\beta_{44}\left(\ln \left(\operatorname{cap} 1_{k t}\right)\right)^{2} / 2+\beta_{55}\left(\ln \left(\operatorname{cap} 2_{k t}\right)\right)^{2} / 2 \\
& +\beta_{12} \ln \left(\text { feed }_{k t}\right) \ln \left(\text { oi }_{k t}\right)+\beta_{13} \ln \left(\text { feed }_{k t}\right) \ln \left(\text { labor }_{k t}\right) \\
& +\beta_{14} \ln \left(\text { feed }_{k t}\right) \ln \left(\operatorname{cap}_{k t}\right)+\beta_{15} \ln \left(\text { feed }_{k t}\right) \ln \left(\operatorname{cap} 2_{k t}\right) \\
& +\beta_{23} \ln \left(o i_{k t}\right) \ln \left(\text { labork }_{k t}\right)+\beta_{24} \ln \left(o i_{k t}\right) \ln \left(\operatorname{capl}_{k t}\right) \\
& +\beta_{25} \ln \left(\text { oi }_{k t}\right) \ln \left(\operatorname{cap} 2_{k t}\right)+\beta_{34} \ln \left(\operatorname{labor}_{k t}\right) \ln \left(\operatorname{cap} 1_{k t}\right) \\
& +\beta_{35} \ln \left(\text { labor }_{k t}\right) \ln \left(\operatorname{cap}_{k t}\right)+\beta_{45} \ln \left(\operatorname{cap} 1_{k t}\right) \ln \left(\operatorname{cap} 2_{k t}\right) \\
& +\theta t+v_{k t}-u_{k t}
\end{aligned}
$$

\section{Descripción de variables utilizadas}

Los datos de producción porcina son obtenidos desde la Farm Accountancy Data Network (FADN) para el periodo 2010 al 2015, constituyendo un panel no balanceado con 91 empresas de Polonia y 92 empresas de Dinamarca, con un total de 396 y 358 observaciones, respectivamente. La TABLA I muestra el resumen de las variables utilizadas por año para Polonia y Dinamarca. La variable dependiente o explicada es la producción de cerdos medida como el ingreso total en euros. Se definen cinco factores productivos o insumos, el capital1, el capital2, el trabajo, alimento $\mathrm{y}$ otros insumos.

El capital1 comprende edificios, equipamiento, máquinas, tractores, etc. El capital2 incluye el número de equinos (Equus caballus), bovinos, ovinos, caprinos (Capra aegagrus hircus), cerdos y aves presentes en el sistema (promedio anual) que son convertidos en unidades de ganadería, la cual está expresada en euros. El trabajo se describe en unidades de trabajo anual AWU (sigla en inglés, annual work unit). La AWU corresponde al trabajo realizado por una persona empleada por tiempo completo en una explotación ganadera [12]. En tanto, la variable alimento corresponde al alimento de cerdos y aves expresado en euros. Finalmente, la variable otros insumos comprende otros costos específicos del ganado que incluye la asesoría veterinaria, la compra ocasional de animales y otros costos de producción. Todos los valores monetarios están expresados en euros del 2015.

\section{RESULTADOS Y DISCUSIÓN}

Se estimaron diferentes tipos de funciones, siendo las tipo CobbDouglas y Translog las más utilizadas para este tipo de análisis $[6,20,27]$. En este caso, la función Translog para ambos países otorga los mejores resultados. No obstante, existen diferencias entre los países utilizando diferentes test para determinar si las ineficiencias son significativas, así como también, la inclusión o no inclusión de la variable tiempo. Los resultados de estos test se muestran en la TABLA II para Polonia y Dinamarca. Respecto a Polonia, se puede concluir que el mejor modelo es una función con la inclusión de ineficiencias, específicamente, una de tipo Translog. En el análisis, se excluye la variable tiempo al no ser significativa. En el caso de Dinamarca, la inclusión de las ineficiencias otorga mejores resultados por medio de una función Translog incluyendo la variable tiempo.

La TABLA III presenta los coeficientes estimados del modelo de frontera estocástica de producción (MFEP) con forma funcional tipo Translog para la muestra de productores porcinos de Polonia. Se observa que las estimaciones de las elasticidades de producción en las medias de los términos lineales son positivas y estadísticamente significativas al nivel del $1 \%$ o del $5 \%$.

El efecto más importante corresponde al coeficiente del alimento (Infeed), con un valor de 0,363 , lo que significa que al aumentar $1 \%$ el factor productivo alimento, manteniendo los otros factores constantes, la producción porcina aumentará en 0,363 \%. El segundo en importancia es el capital2 (Incap2) con un valor de 0,289 , es decir, si aumenta en $1 \%$ el capital 2 la producción porcina aumentará en $0,289 \%$ dejando todos los otros factores constantes (ceteris paribus). Les siguen en importancia el capital1 (Incap1), otros insumos (Inoi) y el trabajo (Inlabor) con valores de 0,167, 0,155 y 0,081 , respectivamente.

La tasa anual (constante) de progreso tecnológico es significativa al nivel del $1 \%$, indicando un crecimiento tecnológico anual de $2,1 \%$ en la muestra de productores de Polonia. La sumatoria de las elasticidades de producción entrega el valor de la elasticidad de escala. La suma es levemente superior a la unidad (1,05499), lo que indica que la tecnología presenta rendimientos ligeramente crecientes de escala. Se aplicó una prueba estadística para probar si la elasticidad de escala difiere significativamente de uno (rendimientos constantes a escala). Dado que el valor de $t(2,144)$, es mayor que el t crítico $(1,965)$, y el $P$-valor $(0,035)$, es menor al nivel de significancia del $5 \%$, se rechaza la hipótesis nula de retornos constantes de escala y se concluye que la tecnología presenta retornos crecientes de escala (TABLA IV).

El parámetro gamma $(\mathrm{Y})$ es significativo al nivel del $1 \%$ y presenta un valor de 0,715 (TABLA III), lo que indica que, tanto el término de error aleatorio como la ineficiencia son importantes para explicar desviaciones desde la función de producción. El valor de gammaVar muestra que alrededor del 47,7 \% (TABLA III) de la varianza total es debido a la ineficiencia.

Para la muestra de productores de Dinamarca, la TABLA III presenta los coeficientes estimados del MFEP con forma funcional Translog. A diferencia del caso de Polonia, en este modelo se incluye la variable cambio de eficiencia en el tiempo (time). Al aplicar un likelihood ratio test se encontró que esta forma funcional fue significativamente mejor que el modelo sin esta variable para explicar las variaciones de la producción porcina. Los signos de los coeficientes lineales estimados son como se esperaba, es decir, positivos y significativos al nivel del $1 \%$, excepto para el coeficiente del cambio tecnológico que no es significativo.

Al igual que en el modelo de Polonia, los efectos más importantes correspondieron al coeficiente del alimento (Infeed) y al del 
TABLA I

Descripción de variables utilizadas, Polonia y Dinamarca

\begin{tabular}{|c|c|c|c|c|c|c|c|c|c|c|c|}
\hline \multirow[b]{2}{*}{ Item } & \multirow[b]{2}{*}{ Año } & \multicolumn{5}{|c|}{ Polonia } & \multicolumn{5}{|c|}{ Dinamarca } \\
\hline & & Mínimo & Mediana & Media & Máximo & $\begin{array}{c}\text { Desviación } \\
\text { estándar }\end{array}$ & Mínimo & Mediana & Media & Máximo & $\begin{array}{c}\text { Desviación } \\
\text { estándar }\end{array}$ \\
\hline \multirow{6}{*}{$\begin{array}{l}\text { Producción } \\
\text { de cerdo } \\
\text { (en miles } \\
\text { de Euros) }\end{array}$} & 2010 & 26,80 & 137,84 & 186,09 & 983,75 & 165,09 & 502,89 & 1489,28 & 1726,27 & 3665,16 & 894,33 \\
\hline & 2011 & 26,54 & 128,02 & 234,42 & 2492,10 & 388,70 & 400,64 & 1234,02 & 1466,76 & 3665,88 & 762,29 \\
\hline & 2012 & 24,15 & 136,56 & 214,94 & 1727,83 & 298,51 & 408,64 & 1229,60 & 1416,84 & 3799,17 & 748,08 \\
\hline & 2013 & 21,80 & 140,01 & 226,84 & 2414,85 & 370,44 & 248,01 & 1190,48 & 1437,86 & 4009,68 & 824,67 \\
\hline & 2014 & 33,98 & 160,64 & 224,41 & 1746,12 & 279,38 & 262,27 & 1233,70 & 1473,83 & 4845,18 & 909,85 \\
\hline & 2015 & 28,06 & 159,96 & 273,57 & 2190,39 & 388,08 & 247,55 & 1148,39 & 1397,32 & 5405,99 & 940,33 \\
\hline \multirow{6}{*}{ Trabajo } & 2010 & 1,00 & 2,00 & 2,70 & 12,91 & 2,07 & 1,60 & 4,67 & 5,83 & 14,53 & 3,33 \\
\hline & 2011 & 1,00 & 2,00 & 2,75 & 13,36 & 2,28 & 1,00 & 4,09 & 4,73 & 13,00 & 2,42 \\
\hline & 2012 & 1,00 & 2,04 & 2,77 & 13,23 & 2,41 & 1,00 & 4,60 & 4,93 & 12,96 & 2,41 \\
\hline & 2013 & 1,00 & 2,00 & 2,72 & 13,32 & 2,38 & 1,00 & 4,62 & 5,30 & 13,78 & 2,79 \\
\hline & 2014 & 1,00 & 2,00 & 2,75 & 12,32 & 2,24 & 1,05 & 4,69 & 5,51 & 13,00 & 2,84 \\
\hline & 2015 & 1,00 & 2,07 & 2,84 & 12,32 & 2,36 & 1,01 & 4,30 & 5,22 & 15,00 & 2,85 \\
\hline \multirow{6}{*}{$\begin{array}{l}\text { Alimento } \\
\text { (en Euros) }\end{array}$} & 2010 & 10,23 & 75,21 & 103,03 & 350,44 & 82,68 & 263,24 & 615,33 & 796,98 & 1764,79 & 467,60 \\
\hline & 2011 & 11,99 & 72,52 & 129,25 & 1363,62 & 212,26 & 216,81 & 590,82 & 710,63 & 2075,24 & 409,60 \\
\hline & 2012 & 9,15 & 84,14 & 125,19 & 1002,08 & 165,09 & 144,94 & 615,02 & 687,37 & 2063,60 & 413,95 \\
\hline & 2013 & 11,70 & 66,90 & 124,93 & 1423,28 & 188,56 & 118,14 & 604,00 & 697,54 & 2271,89 & 459,96 \\
\hline & 2014 & 12,41 & 88,61 & 128,98 & 1455,53 & 201,44 & 111,49 & 580,78 & 726,94 & 2827,29 & 535,03 \\
\hline & 2015 & 8,35 & 84,94 & 132,79 & 1048,27 & 181,86 & 129,85 & 553,00 & 670,44 & 2476,64 & 485,99 \\
\hline \multirow{6}{*}{$\begin{array}{l}\text { Capital } 1 \\
\text { (en miles } \\
\text { de Euros) }\end{array}$} & 2010 & 47,54 & 214,75 & 279,09 & 1047,53 & 219,19 & 186,15 & 2157,14 & 2595,26 & 7616,69 & 1880,18 \\
\hline & 2011 & 24,30 & 188,00 & 274,96 & 2052,18 & 305,86 & 153,89 & 1705,85 & 2032,33 & 7052,05 & 1454,40 \\
\hline & 2012 & 20,96 & 203,45 & 267,08 & 1865,90 & 269,75 & 6,61 & 1448,25 & 1789,36 & 6545,81 & 1370,64 \\
\hline & 2013 & 18,63 & 225,07 & 262,03 & 1801,80 & 246,40 & 2,67 & 1315,18 & 1725,51 & 6164,36 & 1277,61 \\
\hline & 2014 & 17,29 & 239,58 & 255,68 & 898,12 & 185,04 & 5,88 & 1098,07 & 1569,62 & 6304,92 & 1301,84 \\
\hline & 2015 & 15,79 & 245,81 & 283,89 & 1643,79 & 250,41 & 1,33 & 902,58 & 1230,04 & 4570,83 & 1026,63 \\
\hline \multirow{6}{*}{$\begin{array}{l}\text { Capital } 2 \\
\text { (en miles } \\
\text { de Euros) }\end{array}$} & 2010 & 4,21 & 49,12 & 61,27 & 358,57 & 59,40 & 184,95 & 543,14 & 600,35 & 1234,01 & 316,50 \\
\hline & 2011 & 3,29 & 41,10 & 63,50 & 610,18 & 95,97 & 164,79 & 477,98 & 537,41 & 1376,07 & 279,23 \\
\hline & 2012 & 4,16 & 34,41 & 61,73 & 430,51 & 81,19 & 155,50 & 442,73 & 511,00 & 1388,34 & 279,33 \\
\hline & 2013 & 5,30 & 36,36 & 62,13 & 459,90 & 82,85 & 85,72 & 455,62 & 540,10 & 1390,86 & 287,88 \\
\hline & 2014 & 6,51 & 51,37 & 68,16 & 423,15 & 74,99 & 49,19 & 469,31 & 556,87 & 1412,40 & 300,18 \\
\hline & 2015 & 5,86 & 50,46 & 75,93 & 456,26 & 90,07 & 15,54 & 428,38 & 510,77 & 1570,23 & 289,23 \\
\hline \multirow{6}{*}{$\begin{array}{c}\text { Otros } \\
\text { insumos } \\
\text { (en miles } \\
\text { de Euros) }\end{array}$} & 2010 & 2,67 & 16,61 & 25,50 & 182,10 & 30,42 & 113,17 & 329,25 & 343,80 & 807,84 & 183,81 \\
\hline & 2011 & 4,31 & 16,29 & 32,36 & 338,22 & 57,38 & 96,49 & 279,36 & 299,77 & 712,54 & 137,89 \\
\hline & 2012 & 3,21 & 15,32 & 29,86 & 315,12 & 49,95 & 79,34 & 255,53 & 289,41 & 753,23 & 149,40 \\
\hline & 2013 & 2,60 & 17,71 & 30,29 & 406,28 & 52,58 & 44,19 & 278,41 & 316,40 & 899,00 & 171,65 \\
\hline & 2014 & 2,97 & 19,17 & 28,01 & 256,82 & 36,74 & 36,44 & 280,13 & 294,08 & 790,37 & 161,38 \\
\hline & 2015 & 2,48 & 19,00 & 31,63 & 292,76 & 43,98 & 39,56 & 240,17 & 262,51 & 810,11 & 149,08 \\
\hline
\end{tabular}


TABLA II

Test para Polonia y Dinamarca

\begin{tabular}{|c|c|c|c|c|c|c|c|}
\hline Objetivo & País & Modelo & DF & LogLik & Df & Chisq & $\operatorname{Pr}(>$ Chisq $)$ \\
\hline \multirow{4}{*}{$\begin{array}{l}\text { Test para determinar } \\
\text { la significancia de } \\
\text { las ineficiencias }\end{array}$} & \multirow{2}{*}{ Polonia } & OLS & 23 & 150,06 & & & \\
\hline & & Error Components Frontier & 24 & 196,58 & 1 & 93,028 & $<2,2 \times 10^{-16 * * *}$ \\
\hline & \multirow{2}{*}{ Dinamarca } & OLS & 23 & 329,19 & & & \\
\hline & & Error Components Frontier & 25 & 388,69 & 2 & 119 & 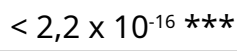 \\
\hline \multirow{4}{*}{$\begin{array}{l}\text { Test de comparación entre } \\
\text { Cobb-Douglas y Translog }\end{array}$} & \multirow{2}{*}{ Polonia } & Cobb-Douglas & 10 & 165,76 & & & \\
\hline & & Translog & 24 & 196,58 & 14 & 61,63 & $6,064 \times 10^{-8} \star \star \star *$ \\
\hline & \multirow{2}{*}{ Dinamarca } & Cobb-Douglas & 9 & 267,27 & & & \\
\hline & & Translog & 25 & 388,69 & 16 & 242,86 & $<2,2 \times 10^{-16 * \star \star}$ \\
\hline \multirow{4}{*}{$\begin{array}{l}\text { Test para medir la } \\
\text { significancia de la } \\
\text { variable tiempo }\end{array}$} & \multirow{2}{*}{ Polonia } & Translog (sin) & 24 & 196,58 & & & \\
\hline & & Translog (con) & 25 & 197,09 & 1 & 1,0125 & 0,3143 \\
\hline & \multirow{2}{*}{ Dinamarca } & Translog (sin) & 24 & 382,41 & & & \\
\hline & & Translog (con) & 25 & 388,69 & 1 & 12,565 & $0.000393 * \star \star$ \\
\hline
\end{tabular}

$\left({ }^{\star}\right),\left({ }^{\star *}\right),\left({ }^{(\star \star}\right)$; indican significancia de $\mathrm{P} \leq 0,10,0,05$ y 0,01 , respectivamente.

capital2 (Incap2), con valores de 0,462 y 0,264, respectivamente. Esto significa que al aumentar $1 \%$ el factor productivo alimento manteniendo los otros factores constantes, la producción porcina aumentará en $0,462 \%$, efecto superior al encontrado en el modelo de Polonia. En cambio, el efecto del capital2 (Incap2) es muy parecido, si aumenta en $1 \%$ este la producción porcina aumentará en $0,264 \%$ ceteris paribus. Les siguen en importancia el trabajo (Inlabor), otros insumos (Inoi) y el capital1 (Incap1), con elasticidades de producción en las medias de 0,145; 0,119 y 0,037 , respectivamente. Se puede observar que, en la muestra de productores de Dinamarca, el factor productivo trabajo tiene mayor efecto que en el modelo polaco.

La sumatoria de las elasticidades de producción $(1,027)$, indicó ligeros rendimientos crecientes de escala. Se aplicó una prueba estadística, cuyos resultados muestraron que el valor de $t(1,677)$, fue menor que el t crítico $(1,966)$, y el $P$-valor $(0,094)$ fue mayor que 0,05 (nivel de significancia), por lo que no se puede rechazar la hipótesis nula y se concluye que los productores de Dinamarca presentaron tecnología con rendimientos constantes de escala (TABLA IV). La tasa anual (constante) de cambio tecnológico de alrededor del $0,6 \%$ no fue significativa lo que expresa que la tecnología de producción (frontera) no cambia en el tiempo. El coeficiente estimado de la variable time fue negativo y significativo al $1 \%$, lo que significa que la eficiencia está decreciendo en el tiempo (TABLA III). En la misma Tabla, la magnitud $(0,876)$ y la significancia estadística al nivel del $1 \%$ del parámetro gamma muestraron que, tanto el término de error aleatorio como la ineficiencia, son importantes para explicar las desviaciones desde la función de producción.

Los resultados obtenidos para ambos SP son coincidentes que otros estudios desarrollados en Europa [23] y África [31]
TABLA III

Estimación frontera de posibilidades de producción Polonia y Dinamarca

\begin{tabular}{|c|c|c|}
\hline Variables & $\begin{array}{c}\text { Translog } \\
\text { (sin variable tiempo) } \\
\text { - Polonia }\end{array}$ & $\begin{array}{l}\text { Translog - } \\
\text { Dinamarca }\end{array}$ \\
\hline Intercept & $\begin{array}{l}0,074 \\
(0,022)^{\star * *}\end{array}$ & $\begin{array}{c}0,103 \\
(0,013)^{\star \star \star}\end{array}$ \\
\hline Infeed & $\begin{array}{l}0,363 \\
(0,029)^{* * *}\end{array}$ & $\begin{array}{c}0,462 \\
(0,023)^{\star * *}\end{array}$ \\
\hline Inoi & $\begin{array}{l}0,155 \\
(0,029)^{\star * *}\end{array}$ & $\begin{array}{c}0,119 \\
(0,033)^{\star * *}\end{array}$ \\
\hline Inlabor & $\begin{array}{c}0,081 \\
(0,034)^{\star \star}\end{array}$ & $\begin{array}{c}0,145 \\
(0,027)^{\star * *}\end{array}$ \\
\hline Incap1 & $\begin{array}{l}0,167 \\
(0,029)^{\star * *}\end{array}$ & $\begin{array}{c}0,037 \\
(0,013)^{\star \star \star}\end{array}$ \\
\hline Incap2 & $\begin{array}{l}0,289 \\
(0,033)^{\star \star *}\end{array}$ & $\begin{array}{c}0,264 \\
(0,042)^{\star \star \star}\end{array}$ \\
\hline mYear & $\begin{array}{c}0,021 \\
(0,005)^{\star \star \star}\end{array}$ & $\begin{array}{c}0,006 \\
(0,005)\end{array}$ \\
\hline $0,5^{*}(\operatorname{lnfeed})^{2}$ & $\begin{array}{l}0,436 \\
(0,081)^{\star * *}\end{array}$ & $\begin{array}{c}0,454 \\
(0,085)^{\star \star *}\end{array}$ \\
\hline $0,5 *(\operatorname{lnoi})^{2}$ & $\begin{array}{c}0,070 \\
(0,067)\end{array}$ & $\begin{array}{l}-0,152 \\
(0,18)\end{array}$ \\
\hline $0,5^{*}(\text { Inlabor })^{2}$ & $\begin{array}{c}0,061 \\
(0,116)\end{array}$ & $\begin{array}{c}0,044 \\
(0,104)\end{array}$ \\
\hline $0,5 *(\text { Incap } 1)^{2}$ & $\begin{array}{c}0,085 \\
(0,067)\end{array}$ & $\begin{array}{c}0,014 \\
(0,006)^{\star *}\end{array}$ \\
\hline
\end{tabular}


TABLA III (cont...)

Estimación frontera de posibilidades de producción Polonia y Dinamarca

\begin{tabular}{|c|c|c|}
\hline $0,5 *(\operatorname{Incap} 2)^{2}$ & $\begin{array}{l}0,236 \\
(0,055)^{\star \star *}\end{array}$ & $\begin{array}{c}0,062 \\
(0,106)\end{array}$ \\
\hline Infeed * Inoi & $\begin{array}{c}-0,072 \\
(0,054)\end{array}$ & $\begin{array}{l}-0,151 \\
(0,083)^{\star}\end{array}$ \\
\hline Inoi * Inlabor & $\begin{array}{l}-0,021 \\
(0,059)\end{array}$ & $\begin{array}{l}-0,011 \\
(0,096)\end{array}$ \\
\hline Infeed * Inlabor & $\begin{array}{l}-0,114 \\
(0,065)^{\star}\end{array}$ & $\begin{array}{l}-0,09 \\
(0,068)\end{array}$ \\
\hline Incap2 * Infeed & $\begin{array}{l}-0,296 \\
(0,058)^{\star * *}\end{array}$ & $\begin{array}{l}-0,338 \\
(0,083)^{\star * *}\end{array}$ \\
\hline Incap2 * Inlabor & $\begin{array}{c}0,093 \\
(0,065)\end{array}$ & $\begin{array}{l}0,109 \\
(0,11)\end{array}$ \\
\hline Incap2 * Inoi & $\begin{array}{c}0,037 \\
(0,049)\end{array}$ & $\begin{array}{c}0,299 \\
(0,16)^{\star}\end{array}$ \\
\hline Incap1 * Incap2 & $\begin{array}{c}0,068 \\
(0,049)\end{array}$ & $\begin{array}{l}-0,054 \\
(0,043)\end{array}$ \\
\hline Incap1 * Infeed & $\begin{array}{c}-0,013 \\
(0,051)\end{array}$ & $\begin{array}{l}-0,003 \\
(0,026)\end{array}$ \\
\hline Incap1 * Inoi & $\begin{array}{c}-0,078 \\
(0,057)\end{array}$ & $\begin{array}{c}0,02 \\
(0,02)\end{array}$ \\
\hline Incap1 * Inlabor & $\begin{array}{c}0,003 \\
(0,059)\end{array}$ & $\begin{array}{l}-0,006 \\
(0,03)\end{array}$ \\
\hline sigmaSq & $\begin{array}{l}0,054 \\
(0,008)^{\star \star *}\end{array}$ & $\begin{array}{c}0,034 \\
(0,007)^{\star * *}\end{array}$ \\
\hline Gamma & $\begin{array}{l}0,715 \\
(0,052)^{\star \star *}\end{array}$ & $\begin{array}{l}0,876 \\
(0,029)^{\star * *}\end{array}$ \\
\hline Time & - & $\begin{array}{l}-0,13 \\
(0,037)^{\star \star \star}\end{array}$ \\
\hline Lambda & $\begin{array}{c}1,585 \\
(0,200)^{\star \star *}\end{array}$ & $\begin{array}{l}2,662 \\
(0,355)^{\star \star *}\end{array}$ \\
\hline GammaVar & 0,477 & - \\
\hline
\end{tabular}

Los errores estándar (EE) de las estimaciones se muestran entre paréntesis. $\left({ }^{*}\right),(* \star),(* \star \star)$; indican significancia de $P \leq 0,10,0,05 y$ 0,01 , respectivamente.

TABLA IV

Test retorno a escala constante Polonia y Dinamarca

\begin{tabular}{|c|c|c|c|c|c|c|}
\hline \multirow{2}{*}{ País } & \multirow{2}{*}{$\begin{array}{l}\text { Sumatoria } \\
\text { coeficientes }\end{array}$} & \multirow{2}{*}{$\begin{array}{c}\text { Valor } \\
\mathbf{t}\end{array}$} & \multirow{2}{*}{$\begin{array}{l}\text { Valor } \\
\text { crítico }\end{array}$} & \multirow{2}{*}{$\begin{array}{c}\text { Valor } \\
\mathbf{p}\end{array}$} & \multicolumn{2}{|c|}{$\begin{array}{c}\text { Intervalo de } \\
\text { confianza (95\%) }\end{array}$} \\
\hline & & & & & $\begin{array}{c}\text { Límite } \\
\text { inferior }\end{array}$ & $\begin{array}{c}\text { Límite } \\
\text { superior }\end{array}$ \\
\hline Polonia & 1,055 & 2,145 & 1,966 & 0,033 & 1,005 & 1,105 \\
\hline Dinamarca & 1,027 & 1,677 & 1,966 & 0,094 & 0,995 & 1,059 \\
\hline
\end{tabular}

que analizaron la contribución de las variables mano de obra y alimentación en la eficiencia de un SP porcino.

La eficiencia técnica promedio para los productores de Polonia (TABLA V) de esta muestra llegó a 0,859 con una mediana de 0,889. La FIG. 1 muestra la distribución de la eficiencia técnica de los productores, donde se observa una distribución asimétrica de la eficiencia con una cola hacia la izquierda, con mayor cantidad de productores en el rango de eficiencias superiores a 0,85.

TABLA V

Resumen eficiencias Polonia

\begin{tabular}{cccc}
\hline Mínimo & Mediana & Media & Máximo \\
\hline 0,644 & 0,889 & 0,859 & 0,971 \\
\hline
\end{tabular}

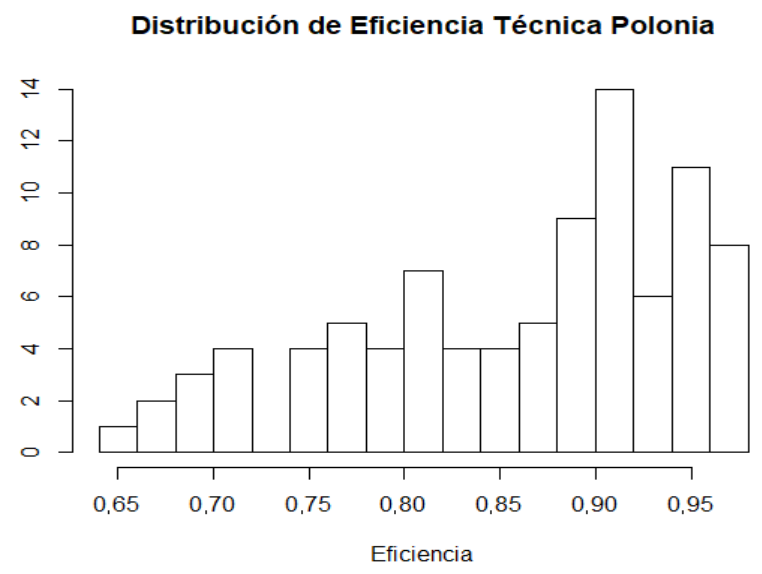

Distribución de Eficiencia Técnica Dinamarca

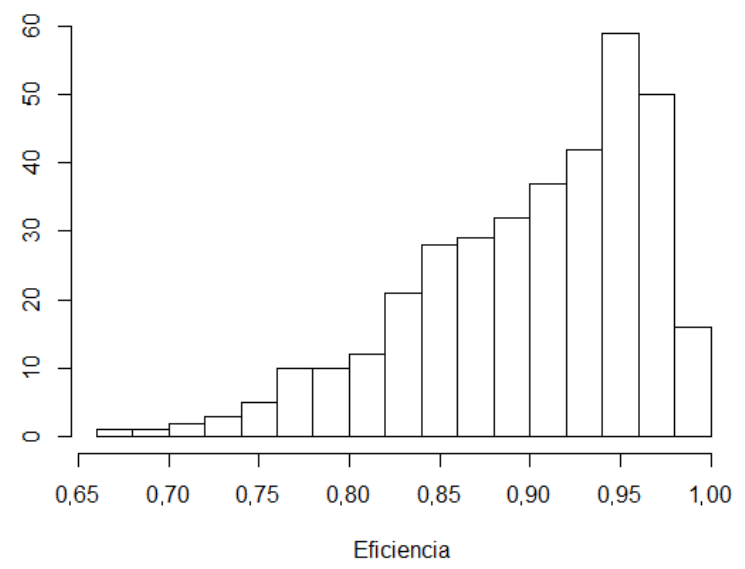

FIGURA 1. Distribución de eficiencia técnica en Polonia y Dinamarca 
La eficiencia técnica promedio de esta muestra de productores porcinos de Dinamarca llegó a 0,899 , lo que es un valor alto y superior al encontrado para los productores de Polonia. Este hecho es coincidente con lo establecido por algunos autores en su análisis sobre el sistema productivo porcino europeo [12, 29]. La distribución de las eficiencias presenta una gran concentración de los productores con eficiencias en los rangos superiores y pocos en la porción inferior del rango, esto genera una distribución con una cola hacia la izquierda, lo cual se puede observar en la FIG. 1.

Además, la TABLA VI muestra un resumen estadístico de las eficiencias por año para la muestra de productores de Dinamarca. Es clara la disminución de la eficiencia media en el periodo de estudio, desde 0,937 el año 2010 hasta 0,899 el año 2015. Esta situación puede ser explicada por la ampliación del rango de valores de la eficiencia, especialmente, debido a la disminución del valor mínimo desde 0,863 hasta 0,667 . Además, lo observado es consistente con el signo y la significancia del coeficiente de la variación de la eficiencia en el tiempo.

TABLA VI

Resumen eficiencias productores Dinamarca por año

\begin{tabular}{ccccc}
\hline Año & Mínimo & Mediana & Media & Máximo \\
\hline 2010 & 0,863 & 0,937 & 0,932 & 0,990 \\
2011 & 0,771 & 0,928 & 0,918 & 0,993 \\
2012 & 0,744 & 0,920 & 0,910 & 0,993 \\
2013 & 0,714 & 0,904 & 0,896 & 0,985 \\
2014 & 0,681 & 0,896 & 0,884 & 0,982 \\
2015 & 0,668 & 0,899 & 0,876 & 0,989 \\
\hline
\end{tabular}

\section{CONCLUSIONES}

El mercado de la $\mathrm{CdC}$ en las últimas décadas está creciendo hasta convertirse en el segundo tipo de carne producido en el mundo. Dentro de este competitivo mercado, Europa es la segunda región en importancia productiva después de Asia. Dos actores relevantes en el mercado europeo son Dinamarca y Polonia. A pesar de que ambos países están realizando cambios de tal forma de adaptarse de manera adecuada a los cambios en el mercado porcino, éstos presentan dispares estados de desarrollo con algunas diferencias estructurales en sus SP de CdC. Dinamarca sobresale como un país líder en tecnología y en sanidad, mientras que Polonia está en procesos de cambios que le permitan mejorar sobre todo en la integración vertical y horizontal de su cadena productiva.

Los resultados de este estudio muestran que, a pesar de las diferencias estructurales que presentan ambos países, la eficiencia técnica relativa media de los productores porcinos en Polonia y Dinamarca es media alta, concretamente de 0,859 y 0,899 , respectivamente, siendo la distribución de eficiencias asimétrica con una cola hacia la izquierda. A pesar de esto, los niveles de eficiencia podrían mejorarse si los productores realizan combinaciones óptimas de los factores productivos que beneficien la producción porcina en el territorio.

El factor productivo que presenta mayor impacto en la producción porcina en ambos países corresponde al alimento, con elasticidades de $0,363 \%$ en Polonia y $0,462 \%$ en Dinamarca. A su vez, el factor trabajo cobra mayor relevancia en Dinamarca que en Polonia, con elasticidades de 0,145 y 0,081, respectivamente, lo que transforma al trabajo en el tercer factor productivo en importancia en Dinamarca. Los factores otros insumos y capital (equipos y edificaciones) son significativos, pero con menores elasticidades de producción para ambos países.

Las muestras de productores de Polonia presentan tecnologías con rendimientos de escala levemente superior a la unidad, lo que indica rendimientos crecientes de escala. Es interesante el hecho que, los productores de Polonia presentan un progreso tecnológico anual constante de 2,1\%, sin cambio de eficiencia en el periodo. Esto puede ser el efecto de cambios estructurales en el SP, que aumentaron la productividad pero no tuvieron efectos significativos en la eficiencia. Mientras tanto, la muestra de productores de Dinamarca no mostró cambios significativos en el progreso tecnológico en el tiempo, pero si una disminución significativa de la eficiencia. Esta situación, junto con factores relacionados al mercado, podría explicar la baja en la producción de $\mathrm{CdC}$ en el periodo de estudio.

Finalmente, este estudio es importante para expandir la literatura en la eficiencia técnica de la producción porcina, sobre todo porque es la primera vez que se mide la eficiencia técnica en dos países relevantes en el mercado europeo. Sin embargo, quedan para posteriores investigaciones determinar los factores que afectan o explican el cambio en la media de la eficiencia técnica, por ejemplo, las causas que subyacen a la caída en la eficiencia en la producción porcina en Dinamarca, la que pasó de 0,937 en 2010 a 0,899 en 2015, y la incorporación del riesgo de producción en el análisis. Esto permitiría enfocar los aspectos de perfeccionamiento en la labor de los productores porcinos, y a su vez, generar y aplicar políticas públicas de apoyo a los productores que contribuyan a mejorar su competitividad y recuperar los niveles de producción y eficiencia de inicio de la década.

\section{AGRADECIMIENTOS}

Los autores agradecen a la European Commission, DirectorateGeneral Agriculture, Unit AGRI.G.3 por proporcionar los datos FADN (Farm Accountancy Data Network) para este análisis.

\section{REFERENCIAS BIBLIOGRAFICAS}

[1] AIGNER, D. C.; LOVELL, A. K.; SCHMIDT, P. Formulation and estimation of stochastic frontier production function models. J. Econometr. 6(1): 21-37. 1977.

[2] ASMILD, M.; HOUGAARD, J. L.; KRONBORG, D.; KVIST, H. K. Measuring inefficiency via potential improvements. J. Product. Analy.19(1): 59-76. 2003.

[3] BATTES.E, G.E.; COELLI, T.J. Frontier production functions, technical efficiency and panel data: With application to paddy farmers in India. J. Product. Analy. 3: 153-169. 1992. 
[4] BATtese, G. E.; COELLI, T. J. A model for technical inefficiency effects in a stochastic frontier production function for panel data. Empiric. Economics. 20: 325-32. 1995.

[5] BOGETOFT, P.; OTTO, L. Stochastic Frontier Analysis SFA. Benchmarking with Dea, Sfa, and R. Springer Science \& Business Media. Pp. 197-232. 2010.

[6] BRAVO-URETA, B.; SOLIS, D.; MOREIRA, V.; MARIPANI, J.; ABDOURAHMANE, T.; RIVAS, T. Technical efficiency in farming: a meta-regression analysis. J. Product. Analy. 27: 57-72. 2007.

[7] CALAFAT, C.; MARTÍ, M.; PUERTAS, R. Eficiencia del sector ganadero valenciano: Aproximación no paramétrica. ITEA Inform. Tecn. Econom. Agra.114(1): 61-77. 2018.

[8] CHAITIP, P.; CHAIBOONSRI, C.; INLUANG, F. The Production of Thailand's Sugarcane: Using Panel Data Envelopment Analysis (Panel DEA) Based Decision on Bootstrapping Method. Procedia Econom. and Finance. 14: 120-127. 2014.

[9] COELLI, T.; HENNINGSEN, A. Frontier: Stochastic Frontier Analysis. R package version 1.1-8. On line: https://bit.ly/3cnP3EC. 2020.

[10] COELLI, T. J.; RAO, D. S. P.; O'DONNELL, C. J.; BATTESE, G. E. Stochastic Frontier Analysis. An introduction to efficiency and productivity analysis. Springer Science \& Business Media Inc. Pp. 241-261. 2005.

[11] DANISH AGRICULTURE AND FOOD COUNCIL (DAFC). Fakta Om Erhvervet 2017: Fødevareklyngen Har Kurs Mod Fremtiden (Facts and figures 2017, the food cluster is heading for the future). Copenhague. 40 pp. 2018.

[12] OFICINA ESTADÍSTICA DE LA UNIÓN EUROPEA (EUROSTAT). Agricultural production - livestock and meat - Statistics Explained. 2020. On-line: https://bit.ly/3yYtQuq. 10.11.2020.

[13] FARRELL, MJ. The measurement of productive efficiency. J. Royal Statist. Soc. 120(A): 253-281. 1957.

[14] ORGANIZACIÓN DE LAS NACIONES UNIDAS PARA LA ALIMENTACIÓN Y LAAGRICULTURA (FAO) Y MINISTERIO DE MEDIO AMBIENTE Y ALIMENTACIÓN DE DINAMARCA - ADMINISTRACIÓN DANESA DE VETERINARIA Y ALIMENTACIÓN. Hacer frente al uso de antimicrobianos y la resistencia a los antimicrobianos en la producción porcina: lecciones aprendidas de Dinamarca. Roma. 52 pp. 2019.

[15] FOOD AND AGRICULTURE ORGANIZATION OF THE UNITED NATION (FAO). Food Outlook - Biannual Report on Global Food Markets: June 2020. Food Outlook. 1. 160 pp. 2020.

[16] GARCÍA, E.; SERRANO, C. Competitividad y eficiencia. Estud. Econom. Aplicad. 21(3): 423-450. 2003.

[17] HENNINGSEN, A. Introduction to Econometric Production Analysis with R. Collection of Lecture Notes. 2nd Draft Version. Department of Food and Resource Economics, University of Copenhagen. 370 pp. 2018.

[18] HENNINGSEN, A.; CZEKAJ, T. G.; FORKMAN, B.; LUND, M; NIELSEN, A. S. The relationship between animal welfare and economic performance at farm level: A quantitative study of Danish pig producers. J. Agric. Econom. 69(1): 142-162. 2018.
[19] HOMAN, M. Structural changes in the Polish pig sector. 2018. Embassy of the Kingdom of the Netherlands. On-line: https:// www.agroberichtenbuitenland.nl. 10.01.2021.

[20] JAIME, M.; SALAZAR, C. Participation in Organizations, Technical Efficiency and Territorial Differences: A Study of Small Wheat Farmers in Chile. Chilean J. Agric. Res. 71(1): 104-113. 2011.

[21] KUMBHAKAR, S.; LOVELL, C. The Estimation of Technical Efficiency. Stochastic Frontier Analysis. Cambridge: Cambridge University Press. Pp. 63-130. 2000.

[22] KUMBHAKAR, S.; WANG, H.; HORNCASTLE, A. Estimation of Technical Efficiency in Single Equation Panel Models. A Practitioner's Guide to Stochastic Frontier Analysis Using Stata. Cambridge: Cambridge University Press. Pp.241-278. 2015.

[23] LABAJOVA, K.; HANSSON, H.; ASMILD, M.; GÖRANSSON, L.; LAGERKVIST, C. J.; NEIL, M. Multidirectional analysis of technical efficiency for pig production systems: The case of Sweden. Livest. Sci. 187: 168-180. 2016.

[24] MEEUSEN, W.; VAN DEN BROECK, J. Efficiency Estimation from Cobb-Douglas Production Functions with Composed Error. Intern. Econom. Rev. 18(2): 435-444. 1977.

[25] MINISTERIO DE AGRICULTURA, PESCA Y ALIMENTACIÓN, GOBIERNO DE ESPAÑA. El sector de la Carne de Cerdo en cifras: Principales Indicadores Económicos. Subdirección General de Producciones Ganaderas y Cinegéticas, Dirección General de Producciones y Mercados Agrarios. 63 pp. 2020.

[26] MROCZEK, R. Red meat sector after accession of Poland to the EU. Econom. Sociol. 2(2): 69-76. 2009.

[27] ORTEGA, L.; WARD, R.; ANDREW, C. Technical Efficiency of the Dual-Purpose Cattle System in Venezuela. J. Agric. Appl. Econom. 39(3):719-733. 2007.

[28] R CORE TEAM. R: A language and environment for statistical computing. R Foundation for Statistical Computing, Vienna, Austria. On Line: https://www.R-project.org/. 2020.

[29] ROGUET, C.; GAIGNÉ, C.; CARIOU, S.; CARLIER, M.; CHATELLIER, V.; CHENUT, R.; DANIEL, K.; PERROT, C. Spécialisation territoriale et concentration des productions animales européennes: état des lieux et facteurs explicatifs. INRA Prod. Anim. 28(1): 5-22. 2015.

[30] TIAN, X.; SUN, F.; ZHOU, Y. Technical efficiency and its determinants in China's hog production. J. Integrat. Agric. 14(6): 1057-1068. 2015.

[31] UMEH, J. C.; OGBANJE, C.; ADEJO, M. A. Technical efficiency analysis of pig production: A sustainable animal protein augmentation for Nigerians. J. Advanc. Agric. Technol. 2(1): 19-24. 2015

[32] WAGAN, S.A.; MEMON, Q.U.A.; QIAN, L.; JINGDONG, $\mathrm{L}$. Measuring the efficiency of Pakistani rice production via stochastic frontier and data envelopment analyses. Custos e @gronegócio on line. 15(2): 63-86. 2019. 


\section{INSTRUCCIONES A LOS AUTORES}

La REVISTA CIENTÍFICA de la Facultad de Ciencias Veterinarias de la Universidad del Zulia es una revista internacional que recibe trabajos para publicación en las formas de artículos científicos originales no publicados, notas técnicas, cartas al editor y revisiones bibliográficas requeridas por el Comité Editorial. Como excepción a la condición de no publicado, podrán considerarse artículos que en forma completa o parcial hayan sido publicados en memorias de reuniones científicas de limitada circulación. Cualquier otra circunstancia debe ser explicada a la Oficina Editorial al momento del envío. Las cartas al editor deben contener comentarios útiles acerca de material publicado en la REVISTA CIENTÍFICA. La meta de publicar estas cartas es contribuir al intercambio constructivo de ideas y puntos de vista, con beneficios para la comunidad científica y para la REVISTA CIENTÍFICA. La aceptación de cartas al editor dependerá de la decisión del Comité Editorial. Para publicaciones como artículos científicos, notas técnicas y cartas al editor se aceptan como lenguajes tanto el español como el inglés.

Las revisiones bibliográficas serán escritas en el idioma inglés y no se aceptan más de dos autores, los cuales deben tener experiencia científica comprobada en el tópico propuesto. Sin embargo, trabajos extensos de edición para corregir lenguaje no se ofrece. Por tanto, los autores deben hacer revisar sus artículos por expertos con sólidos conocimientos de gramática, sintaxis y estilo de la escritura científica.

El uso inapropiado del lenguaje puede conllevar al rechazo temporal de un artículo. Todos los artículos recibidos serán revisados en su forma y contenido por 3 expertos reconocidos usando el método del doble ciego.

Los artículos deben abordar aspectos relacionados a las áreas de la medicina veterinaria, producción animal, economía agropecuaria, salud pública vinculada a las ciencias veterinarias (zoonosis), reproducción animal, tecnología de alimentos y vida silvestre. La aceptación de artículos que aborden cualquier otro tipo de tópicos relacionados será discutida por el Comité Editor. Aunque no de manera restringida, REVISTA CIENTÍFICA enfatiza en la publicación de información científica generada en zonas tropicales y subtropicales, o de aplicabilidad tropical.

El contenido de los artículos debe representar una contribución significativa al cuerpo del conocimiento científico y debe reunir además los requerimientos siguientes:

\section{Originales.}

Los artículos deben ser enviados con una carta de acuerdo entre los autores. En esta carta, el autor responsable y los co-autores deben declarar que el artículo enviado no ha sido publicado previamente, así como su aprobación con respecto a la forma y contenido. La firma de todos los autores debe ser incluida. Los manuscritos deben ser escritos en letra Arial, tamaño 12 ptos, a doble espacio y no más de 20 páginas, colocando en la primera página la información referente al titulo del trabajo (español, inglés), autores y la afiliación institucional, comenzando la segunda página con el resumen y abstract. Los cuatro márgenes serán de $2 \mathrm{~cm}$. Todas las páginas deben estar numeradas consecutivamente y los números de línea deben ser impresos en cada página (empezando con 1 en cada página) para mayor facilidad de referencia para los revisores. Se recomienda enviar el artículo al correo electrónico revistafcv@gmail.com en formato Word. Recomendamos usar “. Doc" en lugar de “. Docx”, por posibles problemas de incompatibilidad. Las tablas, figuras y anexos deben incluirse dentro de documento, justamente después de ser citados en el texto. Los artículos deben ser inéditos y no haber sido enviados a otra revista.

Todos los trabajos aceptados pasan a ser propiedad de la REVISTA CIENTíFICA.

Los artículos deben contener: Título y resumen (español e inglés), introducción, materiales y métodos, resultados y discusión, conclusiones e implicaciones, agradecimiento y referencias bibliográficas.

2. Título.

El título debe describir la esencia del artículo de manera clara y concisa, debiendo aparecer en español e inglés. Debe incluirse un título corto para ser usado como tope de página.

\section{Autores.}

Todos los autores deben ser listados por su nombre completo en el orden respectivo (nombres y apellidos) dejando un espacio debajo del título. Si trae dos apellidos deben separase por un guion. El número de autores es ilimitado. Excepciones deben ser requeridas por escrito al Editor-Jefe por medio de una carta explicativa, especialmente cuando los autores pertenezcan a instituciones diferentes. La afiliación institucional de los autores debe ser señalada mediante numerales superíndices, y con un asterisco superíndice al autor para correspondencia. Seguido al asterisco superíndice, deberá indicarse teléfono, fax y/o dirección electrónica del autor para correspondencia. Así mismo, deben indicar la identificación ORCID de cada uno de los autores.

\section{Resumen.}

En español e inglés con un máximo de 300 palabras y comenzando en la segunda página del manuscrito. Para un apropiado uso del lenguaje y estilo, se recomienda consultar con un experto.

5. Palabras clave.

Estas son necesarias para la ubicación del trabajo en índices internacionales y bases de datos. Incluir un máximo de 5 , en español e inglés en el resumen y abstract, respectivamente. Deben estar separadas con punto y coma.

6. Tablas.

Deben citarse apropiadamente en el texto luego de ser nombradas, identificadas y enumeradas consecutivamente con números romanos. El encabezamiento debe ser conciso y descriptivo. Abreviaciones o símbolos deben ser explicadas al pie de la tabla. El encabezamiento debe ir sobre la tabla en mayúsculas, en español o inglés, dependiendo del idioma en que el trabajo fue escrito; no ambos simultáneamente. No se aceptan fotocopias. Las tablas deben ser tan simples como sea posible y auto explicativas con el encabezamiento y notas al pie, permitiendo su comprensión sin necesidad de recurrir o referir el texto, no se aceptan referencias bibliográficas en las tablas.

\section{Figuras.}

Se puede incluir tanto fotografías como gráficos. Las figuras deben citarse apropiadamente en el texto inmediato a su señalamiento, identificadas y enumeradas consecutivamente usando números arábigos. El encabezamiento debe ser conciso y descriptivo, debiendo colocarse debajo de la figura en mayúsculas, en español o inglés, dependiendo del idioma en que el trabajo fue escrito; no en ambos idiomas. No se aceptan fotocopias. Las fotografías deben ser identificadas en el reverso con un número y una flecha indicando la orientación correcta. En los casos de microfotografías, debe indicarse la magnificación usada.

\section{Conclusiones:}

Las mismas deben ser claras y precisas en ellas no se aceptan llamados a Referencias Biográficas.

\section{Agradecimiento:}

Sólo serán aceptadas agradecimientos institucionales.

\section{Referencias Bibliográficas.}

Deben presentarse en una lista numerada y en estricto orden alfabético. Deben ser citadas en el texto (en orden cronológico) usando números arábigos entre corchetes. Estos números deben parearse con los de la lista de referencias bibliográficas. No se aceptan como referencias trabajos no publicados, artículos de periódicos o revistas populares ni comunicaciones personales. Evite el uso excesivo de literatura no arbitrada (e.g., libros, manuales, referencias electrónicas en exceso, etc.). No deben citarse resúmenes, a menos que sean la única referencia en relación a un aspecto importante. Los autores son responsables del uso correcto presentación de las referencias.

No se permiten citas bibliográficas en el Resumen, abstract ni en Conclusiones, en Tablas y Figuras.

Los siguientes son ejemplos recomendados de como citar la bibliografía:

Revistas:

[1] MARQUEZ, E.J.; BARBOZA DE M., Y.; IZQUIERDO, P. Studies on the incorporation of bovine plasma in emulsion type of meat products. J. Food Sci. Tech. 34:337-339. 1997.

[2] ALVAREZ, R.; VACCARO, L.; VACCARO, R.; VERDE, O.; RIOS, L.; MEJIAS, H. Estimation of weights of dual purpose calves from body measurements. Rev. Cientif. FCV-LUZ. IX (6): 502-507. 1999.

Libros:

Deben señalarse, después de los autores, el título del tema consultado en el texto (no capítulo), seguido de En: o In: (dependiendo del idioma) y título del libro (en renegrido). Luego, los nombres de los editores, si los hay, finalizando con (Ed. o Eds.).

[1] LEELAND, W.W. Steady state kinetics. In: The Enzymes. Boyer, P. (Ed.). 2nd Ed. Academic Press, New York. 66 pp. 1970.

[2] LOOSE-MITCHELL, D.S.; STANCEL, G.M. Estrogens and progestagens. In: The Pharmacological Basis of Therapeutics. Hardman, J.G., Limbird, L.E.; Goodman-Gilman, A. (Eds.). 10th Ed. McGraw Hill, New York, Pp 1613-1651. 2002.

Memorias:

Debe señalarse después del nombre del evento (en renegrido), el lugar, fecha de realización del mismo. Las páginas deben señalarse seguidas de pp.

[1] EDDI, C. Distomatosis, epidemiological and economic aspects of this zoonosis. Proc. Symposium on the Epidemiology of Foodborne Parasitic Zoonoses. P:A:H:O:/W:HO Latin American Congress of Parasitology. I Uruguayan Congress of Parasitology. Montevideo. 03/25-29. Uruguay: Pp 50-59 pp 1997.

[2] FARIA, M.H.; TONHATI, H.; NADER-FILHO, A.; DUARTE, J.M.C. Milk production and some constituents in two buffalo herds in São Paulo State, Brazil. Proceeding 5th World Buffalo Congress. Caserta, 10/13-16. Pp 30-38. 1997.

\section{Referencias electrónicas:}

No se aceptan referencias electrónicas a menos que sean trabajos arbitrados, boletines o comunicaciones respaldadas por instituciones científicas. Evite el uso excesivo de este tipo de referencias. En tales casos, estas referencias deben incluir: autor(es), título del trabajo, y el año del trabajo. Institución(es) que la respaldan. Luego se coloca: En Línea: On Line: (dependiendo del idioma), seguido de la página web consultada, y finalmente, la fecha de consulta. Ejemplo:

[1] FERNÁNDEZ, M.A. Manejo de la calidad de la dieta. 2005. La Mañana (Suplemento) instituto Nacional de Tecnología Agropecuaria (INTA). Argentina. En Línea: http://www. lamañana.com.ar/html. 01/12/05

MUY IMPORTANTE: Cuando un trabajo sea devuelto a la Revista previamente corregido por los autores, no podrá ser sometido a corrección posterior a su publicación. 


\section{GUIDE FOR AUTHORS}

The REVISTA CIENTÍFICA from the Faculty of Veterinary Medicine, Universidad del Zulia is an international journal that receives submissions for publication in the form of original and unpublished manuscripts, technical notes, letters to the editor, and those review articles requested by the Editorial Board. Exceptions to the unpublished condition include the complete or partial publication in scientific meeting proceedings with limited circulation. Any othe circumstance should be explained to the Editorial office at the moment of submission. The letters to the editor must contain useful comments on material published in the journal. It is the goal that publication of such letters may contribute to a constructive exchange of views with benefits to both the scientific community and the journal. Acceptance of submitted letters will depend upon decision of the Editorial.

For publications such as scientific papers, technical notes and letters to the editor are accepted as both languages Spanish and English. Literature reviews will be written in English and no more than two authors are accepted, whose must have scientific expertise in the proposed topic. Extensive editing to correct language is not available. Hence, authors should have their manuscripts reviewed by experts with solid knowledge on spelling, grammar, syntax and scientific writing style. Misused and inappropriate language may lead to temporal rejection of a manuscript. All submissions will be reviewed in their form and content by 3 recognized experts using the method of double blind.

Manuscripts must deal with aspects related to the fields of veterinary clinical sciences, animal production, agricultural economic, public health related to veterinary sciences, animal reproduction, food technology related to animal products and wild life. Acceptance of manuscripts dealing with any other type of related topics will be discussed by the Editorial Board. Although not restricted to, REVISTA CIENTIFICA emphasizes on publishing scientific information generated from tropical and subtropical zones or with tropical applicability. The content of manuscripts should add significant contribution to the body of scientific knowledge and must meet the following requirements:

\section{Originals.}

Manuscripts should be submitted together with an author agreement letter. In such letter, the responsible author and co-authors should declare the unpublished condition of the material and their agreement on the form and content of the manuscript. Signatures of all, the responsible author and co-authors should be included. Manuscripts should be written in Arial, 12-point font, with 2.0 spaced and not more than 20 pages, It should be sent by email to revistafcv@gmail. com, placing on the first page the information about the title of the work (Spanish, English), authors and institutional affiliation, starting second page with abstract. The four margins will be $2.0 \mathrm{~cm}$. All pages should be numbered consecutively, and line numbers should be printed on each page (starting with 1 on each page) to facilitate ease of reference for the reviewers. In Word format as a unique file; we encourage to use .doc files. Tables, figures and appendice should be included into the same Word document,. Manuscripts should be in edit and not sent to any other journal.

\section{All accepted manuscripts become property of REVISTA CIENTIFICA.}

Manuscripts must contain: Title, abstract (English-Spanish), introduction, materials and methods, results and discussion, conclusions and implications, acknowledgement, and bibliographic references.

\section{Title.}

The title should describe the essence of the manuscript in a very clear and concise manner. It should appear in both, English and Spanish. A short title to be used as a head page running title should be also included.

\section{Authors.}

eaving a space below the title, all authors must be listed with full names in the respective order (first names and last names). List of authors is unlimited. Use superscript numbers to match institutional affiliation of authors and a superscript asterisk to identify the corresponding author. Matching the superscript numbers, the institutional affiliation and current address of all authors should be provided. Likewise, matching the asterisk symbol, telephone and fax numbers and e-mail address of the corresponding author should be included. ORCID ID is necesary for all authors.

4. Abstract.

In Spanish and English with a maximum of 300 words and starting on the second page of the manuscript. For an appropriate use of language and style, it is recommended to consult with an expert. Bibliographic references are not accepted.

5. Key words.

These are necessary for placement in international indexes and databases. Maximum of 5 , in English and Spanish accordingly with abstracts, separated with dot and semicolon.

\section{Tables.}

These should be appropriately cited in the text and must be identified and consecutively numbered using Roman numerals. A concise and descriptive heading is requested. Abbreviations or symbols should be explained in a caption below the table. Title must be above the table in capital letters. Title should be presented in both, in Spanish or English, depending of the language in which the work was written, no simultaneously. Xerox copies will not be accepted Keep tables as simple as possible. Tables are self-contained with the title and footnotes providing all information to understand the table without referring the text separated with semicolon. Tables should be included in the text immediately after mentioning them.

\section{Figures.}

These include both photographs and graphs. Figures should be appropriately cited in the text and identified and consecutively numbered using Arabic numerals. A concise and descriptive heading is requested. Title must be below the figure in capital letters. Title should be presented in both, in Spanish or English, depending of the language in which the work was written, no simultaneously. Xerox copies will not be accepted. Photographs should be identified on the back by number and an arrow indicating the correct orientation. When a microphotograph is used, the magnification used should be indicated. Photographs and Figures should be included in the text immediately after mentioned.

\section{Acknowledgment:}

Only institutional acknowledgments are allowed.

9. Conclusions:

Clear and precise. Bibliographic references are not acepted.

\section{Bibliographic references:}

These must be presented in a numbered list organized in a strict alphabetical order. References should be cited in the text in chronological order, using Arabic numbers between brackets. These numbers should be matched with the ones on the bibliographical references list. Unpublished works, newspaper or popular magazines articles, and personal communications are not accepted as references. Avoid the excessive use of non-peer reviewed material (e.g., books, handbooks). Abstract should not be cited unless it is the only available reference to an important concept. Authors are responsible for the correct use and presentation of Bibliographic cites, are not permitted in Abstract, Conclusions, Tables and Figures.

The following are recommended examples:

Journals:

[1] MARQUEZ, E.J.; BARBOZA DE M., Y.; IZQUIERDO, P. Studies on the incorporation of bovine plasma in emulsion type of meat products. J. Food Sci. Tech. 34:337-339. 1997

[2] ALVAREZ, R.; VACCARO, L.; VACCARO, R.; VERDE, O.; RIOS, L.; MEJIAS, H. Estimation of weights of dual purpose calves from body measurements. Rev. Cientif. FCV-LUZ. IX (6): 502-507. 1999.

Books:

After the authors should be included title of the consulted topic or theme in the book (no chapter) followed by In: and title of the book (in black letters). After that, the names of the Editors, if there are, followed by (Ed. or Eds.).

[1] LEELAND, W.W. Steady state kinetics. In: The Enzymes. Boyer, P. (Ed.). 2nd Ed. Academic Press, New York. 66 pp. 1970.

[2] LOOSE-MITCHELL, D.S.; STANCEL, G.M. Estrogens and progestagens. In: The Pharmacological Basis of Therapeutics. Hardman, J.G., Limbird, L.E.; Goodman-Gilman, A. (Eds.). 10th Ed. McGraw Hill, New York, Pp 1613-1651. 2002.

\section{Proceedings:}

After the event name (in black letters) should be included the place, date and country of the event. The pages should be finalized with "pp for total pages or Pp for consulted pages.

[1] EDDI, C. Distomatosis, epidemiological and economic aspects of this zoonosis. Proc. Symposium on the Epidemiology of Foodborne Parasitic Zoonoses. P:A:H:O:/W:HO Latin American Congress of Parasitology. I Uruguayan Congress of Parasitology. Montevideo. 03/25-29. Uruguay: Pp 50-59. 1997.

[2] FARIA, M.H.; TONHATI, H.; NADER-FILHO, A.; DUARTE, J.M.C. Milk production and some constituents in two buffalo herds in São Paulo State, Brazil. Proceeding 5th World Buffalo Congress. Caserta, 10/13-16. Italy. 140 pp 1997.

\section{Electronic references:}

Electronic references are not accepted unless these are peer reviewed manuscripts, bulletins or communications supported by scientific institutions. Avoid the excessive use of this type of references. For such cases, the on-line references must include: authors, title of the work, year of the work, institution that support the work. Later On Line: not under line followed by the consulted web and the complete consult date.

[1] FERNÁNDEZ, M. A. Manejo de la calidad de la dieta. 2005. La Mañana (Suplemento) Instituto Nacional de Tecnología Agropecuaria (INTA). Argentina. En Línea: http://www. lamañana.com.ar/html. 01/12/05

VERY IMPORTANT: When a manuscrit is returned to the Journal, previously corrected by the authors, it won't beable to be subjected to later corrections after publishing 


\section{UNIVERSIDAD DEL ZULIA \\ REVISTA CIENTIFICA \\ FACULTAD DE CIENCIAS VETERINARIAS DIVISIÓN DE INVESTIGACIÓN}

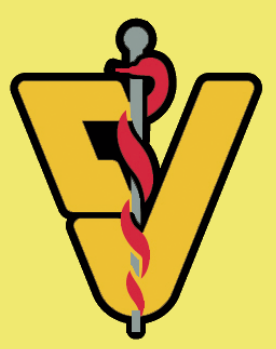

Estimado colega,

La Revista Científica (RCV) está aceptando artículos científicos para su publicación. La RCV publica artículos solicitados y no solicitados de alta calidad, en español e inglés, en todas las áreas de las Ciencias Veterinarias. Todos los artículos publicados en RCV serán revisados por árbitros cualificados.

Nuestro objetivo es informar a los autores de la decisión sobre su manuscrito en unplazo de ocho semanas desde su entrega. Tras la aceptación de su artículo, el mismo será publicado en el número inmediatamente disponible.

Una de las herramientas claves para los investigadores a nivel mundial, es poder disponer de libre acceso a las publicaciones. Y dado que la Revista Científica de Veterinaria está plenamente comprometida con este objetivo, la misma posee el libre acceso a todos los artículos tan pronto como se publiquen y en su base de datos se encuentra desde el primer número editado en 1991.

Es así que en nombre del comité editor, le solicito su apoyo para que esta iniciativa continúe, mediante la publicación de sus documentos en esta revista.

Las instrucciones para autores yo tras informaciones adicionales pueden ser consultadas en nuestra página https://produccioncientificaluz. org/index.php/cientifica/instrucciones.

Aquellos autores interesados en publicar deberán enviar su manuscrito(s) al correo electrónico: revistafcv@gmail.com o revista@fcv. luz.edu.ve.

Saludos cordiales,

\section{Dr. Mario Pérez Barrientos}

Editor Jefe

Revista Científica de Veterinaria 


\section{UNIVERSIDAD DEL ZULIA \\ REVISTA CIENTIFICA \\ FACULTAD DE CIENCIAS VETERINARIAS DIVISIÓN DE INVESTIGACIÓN}

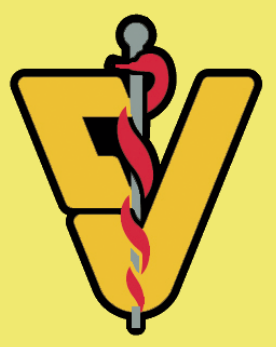

Dear Colleague,

The Revista Cientifica (RCV) is currently accepting manuscripts for publication. RCV publishes high-quality solicited and unsolicited articles, in Spanish and English, in all areas of Veterinary Science. All articles published in RCV will be peer-reviewed.

Our objective is to inform authors of the decision on their manuscript within eigth weeks of submission. Following acceptance, a paper will normally be published in the next avaliable issue.

One key request of researchers across the world is open access to research publications. Revista Científica Veterinaria is fully committed to providing free access to all articles as soon as they are published. We ask you to support this initiative by publishing your papers in the journal.

Instruction for authors and other details are avaliable on our website https://produccioncientificaluz.org/index.php/cientifica/instrucciones.

Prospective authors should send their manuscript(s) revistafcv@gmail.com or revista@fcv.luz.edu.ve

Best regards,

\section{Dr. Mario Pérez Barrientos}

Chif Editor

Revista Científica de Veterinaria 

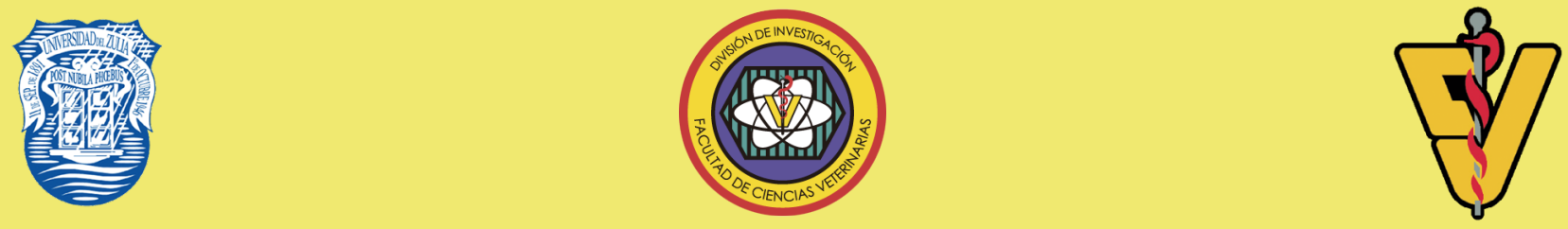

\section{UNIVERSIDAD DEL ZULIA \\ REVISTA CIENTÍFICA}

\section{FACULTAD DE CIENCIAS VETERINARIAS \\ DIVISIÓN DE INVESTIGACIÓN \\ Vol. XXXI (1) 2021}

ÍNDICE

Pag.

EDITORIAL

Salud Pública Veterinaria

Modelo de distribución espacial de Panstrongylus geniculatus Latreille 1811 (Hemiptera: Reduviidae: Triatominae) vector del agente de la Enfermedad de Chagas en Venezuela

\section{Vida Silvestre}

Biometría y longitud de migración de Penaeus stylirostris (Crustacea: Penaeidae) en tres zonas de captura en la costa de Sinaloa, México

\section{Medicina Veterinaria}

Indicadores fisiológicos de respuesta al estrés térmico en ovejas de pelo durante el verano subtropical

Producción Animal

Eficiencia en la producción porcina en países de Europa. Casos de Dinamarca y Polonia

INDEX

EDITORIAL

Veterinary Public Health

Spatial distribution model of Panstrongylus geniculatus Latreille 1811 (Hemiptera: Reduviidae: Triatominae) vector of Chagas Disease agent in Venezuela

Wild Life

Biometric and at migration of Penaeus stylirostris (Crustacea: Penaeidae) in three catch zones on the coast of Sinaloa, Mexico

Veterinary Medicine

Physiological response to thermal stress in hair-sheep ewes during subtropical summer

Animal Production

Efficiency in swine production in European countries. Cases of Denmark and Poland 